Efeitos da Terapia Laser de Baixa Potência na estabilidade e no deslocamento de mini-implantes ortodônticos submetidos a carga

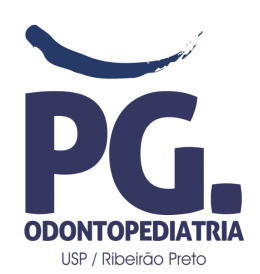

Ribeirão Preto

2018 


\title{
EFEITOS DA TERAPIA LASER DE BAIXA POTÊNCIA NA ESTABILIDADE E DESLOCAMENTO DE MINI-IMPLANTES ORTODÔNTICOS SUBMETIDOS A CARGA
}

\author{
Dissertação apresentada à Faculdade de \\ Odontologia de Ribeirão Preto da Universidade \\ de São Paulo, para a obtenção do Título de \\ Mestre em Ciências. \\ Programa: Odontopediatria \\ Área de Concentração: Odontopediatria \\ Orientador: Prof. Dr. Fábio Lourenço Romano
}

\section{Ribeirão Preto}


AUTORIZO A REPRODUÇÃO E DIVULGAÇÃO TOTAL OU PARCIAL DESTE

TRABALHO, POR QUALQUER MEIO CONVENCIONAL OU ELETRÔNICO, PARA FINS DE ESTUDO E PESQUISA, DESDE QUE CITADA A FONTE.

\section{FICHA CATALOGRÁFICA}

Marañón-Vásquez, Guido Artemio

Efeitos da terapia laser de baixa potência na estabilidade e deslocamento de mini-implantes ortodônticos submetidos a carga.

Marañón-Vásquez, Guido Artemio, Ribeirão Preto, 2018.

131 p.: il. ; $30 \mathrm{~cm}$

Dissertação de Mestrado apresentada à Faculdade de Odontologia de Ribeirão Preto da Universidade de São Paulo. Área de concentração: Odontopediatria.

Orientador: Romano, Fábio Lourenço

1. Parafusos ósseos. 2. Terapia com luz de baixa intensidade. 3. Tomografia computadorizada de feixe cônico. 4. Ortodontia. 
FolHa DE APRovaÇão

MARAÑÓN-VÁSQUEZ, GA. Efeitos da terapia laser de baixa potência na estabilidade e deslocamento de mini-implantes ortodônticos submetidos a carga.

Dissertação apresentada à Faculdade de Odontologia de Ribeirão Preto da Universidade de São Paulo, para a obtenção do Título de Mestre em Ciências. Área de Concentração: Odontopediatria

Aprovado em:

\section{BANCA EXAMINADORA}

Prof. Dr.

Instituição:

Julgamento: Assinatura:

Prof. Dr.

Instituição:

Julgamento: Assinatura:

Prof. Dr.

Instituição:

Julgamento: Assinatura: 



\section{Guido ARTEMio MARAÑón-VÁSQUEZ}

Nascimento 17 de dezembro de 1987, Lima, Peru.

Filiação Victor Augusto Marañón Bendezú

Ana Patricia Vásquez Puntriano

2006-2010 Graduação em Odontologia

Faculdade de odontologia da Universidade de San Martín de Porres, Lima, Peru.

2012-2014 Especialização em Ortodontia e Ortopedia maxilar

Faculdade de Odontologia da Universidade Nacional Mayor de San Marcos, Lima, Peru.

2015-2018 Mestrado em Ciências

Área de Concentração: Odontopediatria

Faculdade de Odontologia de Ribeirão Preto da Universidade de São Paulo - FORP/USP, SP, Brasil. 

“...Ainda estava em dúvida quanto á sua decisão, mas percebia uma coisa importante: as decisões eram apenas o começo de alguma coisa. Quando alguém tomava uma decisão, na verdade estava mergulhando numa correnteza poderosa, que levava a pessoa para um lugar que jamais havia sonhado na hora de decidir."

"Quem deseja ver o arco-iris, precisa aprender a gostar da chuva"

"O que funcionava, sabia ele, era o teste da persistência e da coragem de quem busca sua lenda pessoal. Por isso ele não podia ficar impaciente. Se agisse assim, ia terminar sem ver os sinais que Deus havia posto no seu caminho." 



\section{DEDicatónia}

Para minha família...

... minha mãe Ana, meu pai Willy e minha irmã Maria Pia Vocês são meu exemplo, suporte e motivação...

Dedico este trabalho especialmente ao meu pai Victor Marañón "Willy", que lamentavelmente partiu antes do esperado, no transcorrer dessa minha aventura... Você sempre foi e será meu exemplo de luta, perseverança e fortaleça. O seu esforço e dedicação me permitiram continuar trás dos meus sonhos, ainda em situações de adversidade. Onde seja que você estiver agora, sei que está acompanhando meus passos cada dia.

Sinto muito sua falta! Essa conquista é para você! 

À Faculdade de Odontologia de Ribeirão Preto da Universidade de São Paulo, na pessoa da atual Diretora Prof ${ }^{a}$. Dr ${ }^{a}$. Léa Assed Bezerra da Silva e do Vice-diretor Prof. Dr. Arthur Belém Novaes Júnior e à Coordenação do Curso de Pós-Graduação em Odontopediatria da Faculdade de Odontologia de Ribeirão Preto da Universidade de São Paulo, na pessoa da coordenadora, Prof ${ }^{\mathrm{a}}$. $D^{\mathrm{a}}$. Alexandra Mussolino de Queiroz.

Ao meu orientador Prof. Dr. Fábio Lourenço Romano, pela paciência, pela confiança depositada em mim desde o primeiro dia, e pela disponibilidade e ajuda oferecida durante a execução deste trabalho. Muito obrigado por todo o aprendizado e valiosos ensinamentos, que não somente somaram na minha formação acadêmica, senão que serão, com certeza, de utilidade na minha vida pessoal.

Aos professores do Departamento de Clínica Infantil da Faculdade de Odontologia de Ribeirão Preto da Universidade de São Paulo pelos valiosos ensinamentos e pela oportunidade de conviver com vocês. Uma menção especial para a Prof ${ }^{\mathrm{a}}$. Dr ${ }^{\mathrm{a}}$. Mírian Aiko Nakane Matsumoto, que durante algum tempo, agiu como minha orientadora. Muito obrigado pela disponibilidade, paciência e valiosos ensinamentos.

Aos professores que fizeram parte do delineamento e execução do presente trabalho: Prof $f^{a}$. Dra . Maria da Conceição Pereira Saraiva, Prof ${ }^{a}$. Dr ${ }^{a}$. Maria Cristina Borsato, Prof. Dr. Sérgio Luís Scombatti de Souza, Prof. Dr. Cristiano de Oliveira Santos, Prof. Dr. Manuel Lagravère Vich. Muito obrigado pela colaboração e tempo dado ao desenvolvimento dessa pesquisa. Um agradecimento especial à Profa. Conceição, pelo acompanhamento durante o transcorrer do trabalho e pelos ensinamentos, que com certeza, somaram na minha formação científica. Foi muito bom ter tido a oportunidade de aprender da senhora.

A todo o pessoal técnico envolvido no desenvolvimento do presente trabalho: técnicos da Oficina de precisão da Universidade de São Paulo - Campus Ribeirão Preto; e, pessoal técnico da área de radiologia da Faculdade de Odontologia de Ribeirão Preto, USP. Menção especial para Nilza, que embora não tenha participado da presente pesquisa, sua ajuda e disponibilidade comigo merecem meu reconhecimento.

Um agradecimento especial à turma de especialização em ortodontia da FUNORP (período 2015 - 2017), pela disponibilidade, paciência e colaboração na presente investigação. 
Agradeço também a seus pacientes pela disponibilidade de participar na pesquisa e pelo cumprimento responsável dos protocolos de acompanhamento estabelecidos. Sem eles, não tivesse sido possível a conclusão do presente trabalho. Uma menção especial para Rose, secretária do curso de especialização em ortodontia da FUNORP pelas facilidades dadas, sempre com total disposição de ajudar.

Aos pós-graduandos em Odontopediatria da Faculdade de Odontologia de Ribeirão Preto da Universidade de São Paulo, principalmente à minha turma de mestrado e amigos ortodontistas, pela convivência, trocas de experiências, por todo apoio e amizade.

A todos os funcionários da Faculdade de Odontologia de Ribeirão Preto da Universidade de São Paulo, especialmente aos funcionários do Departamento de Clínica Infantil, pela atenção e por toda ajuda durante esse período.

À Coordenação de Aperfeiçoamento de Pessoal de Nível Superior (CAPES) pela bolsa concedida.

Um agradecimento especial, para a Prof $^{\mathrm{a}}$. Dr ${ }^{\mathrm{a}}$. Erika Calvano Küchler, pela ajuda desinteressada oferecida quando eu mais necessitava-a. Muito obrigado pela oportunidade e valiosos ensinamentos. Sempre estarei agradecido.

Agradeço a todos que de maneira direta ou indireta contribuíram para a concretização deste trabalho e, também, a todos que passaram de alguma forma por minha vida durante esse período. Uma agradecimento especial para Karla Carpio e Silvia Yacarini que tornaram-se minhas melhores amigas durante esse período; muito obrigado por todo seu apoio e por me suportar durante essa caminhada. Agradeço também a Stephanie Diaz, Milagros Sueiro, Jenny Aldana, Dona Eva Carvalho, que junto às primeiras mencionadas e mais outros amigos, converteram-se na minha família durante a minha estadia neste país. Muito obrigado!!!

Aos professores da banca e suplentes, por terem aceito o convite e pela atenção dispensada na leitura da dissertação. 
"Quando você quer alguma coisa, todo o universo conspira para que você realize o seu desejo”

"É justamente a possibilidade de realizar um sonho que torna a vida interessante"

"Uma busca começa sempre com a sorte de principiante. E termina sempre com a prova do conquistador." 

MARAÑÓN-VÁSQUEZ, GA. Efeitos da terapia laser de baixa potência na estabilidade e deslocamento de mini-implantes ortodônticos submetidos a carga. Ribeirão Preto, 2018. 131p. Dissertação (Mestrado)- Faculdade de Odontologia de Ribeirão Preto, Universidade de São Paulo.

\begin{abstract}
RESUMO
O presente estudo teve o objetivo de avaliar o efeito da Terapia Laser de Baixa Potência (TLBP) na estabilidade e no deslocamento de mini-implantes (MIs) submetidos a carga. A hipótese nula testada foi que a irradiação laser e o tipo de carga aplicada (imediata ou mediata) não influenciam na estabilidade e no deslocamento de MIs. Foram avaliados 48 dispositivos para a estabilidade e 35 para o deslocamento, os quais foram implantados em pacientes da clínica de pós graduação em Ortodontia da Faculdade de Odontologia de Ribeirão Preto da Universidade de São Paulo. Os MIs foram divididos em 4 grupos segundo a intervenção recebida: 1- TLBP + CI (carga imediata), 2TLBP + CM (carga mediata / após 4 semanas da implantação), 3- CI (sem TLBP) e 4- CM (após 4 semanas da implantação / sem TLBP). Carga de $150 \mathrm{gF}$ foi aplicada por período de 3 meses para todos os dispositivos. A TLBP foi aplicada usando emissão laser vermelha com comprimento de onda de $660 \mathrm{~nm}$ e potência de $100 \mathrm{~mW}$, imediatamente após implantação (densidade de energia: $4 \mathrm{~J} / \mathrm{cm}^{2}$ ). Nos dias posteriores foram aplicadas emissões laser infravermelhas com comprimento de onda de $808 \mathrm{~nm}$ a cada 48 horas durante duas semanas após colocação dos dispositivos (densidade de energia: $8 \mathrm{~J} / \mathrm{cm}^{2}$ para cada aplicação). A estabilidade dos dispositivos foi avaliada pela Análise de Freqüência de Ressonância (AFR) em três momentos: T0 no dia da implantação; T1 antes da aplicação da carga, somente nos grupos 2 e 4; e T2 após três meses de aplicação de carga. Para a avaliação do deslocamento dos dispositivos foram utilizadas imagens de Tomografias Computadorizadas de Feixe Cônico (TCFC). Planos tridimensionais foram criados a partir de pontos de referência identificados na maxila e mandibula para medir e comparar as diferenças entre as distâncias inicial (TC0) e final (TC1) da cabeça do MI ao plano tridimensional. Os resultados demonstraram que o grupo 2 apresentou a menor perda de estabilidade de todos os grupos ( $\mathrm{p}=0.0161$ ). Os dispositivos que receberam TLBP (Grupos 1 e 2) apresentaram menor perda de estabilidade quando comparados aos grupos que não receberam irradiação laser ( $\mathrm{p}=0.0372)$. Os MIs que receberam CI (Grupos 1 e 3 ) apresentaram maior perda de estabilidade quando foi avaliado o tempo efetivo de aplicação da carga $(p<0.0001)$. Todos os dispositivos apresentaram deslocamento sem diferenças estatisticamente significantes entre os grupos. A hipótese nula foi parcialmente rejeitada. Os MIs que receberam TLBP e CM tiveram menor perda de estabilidade. O deslocamento não foi influenciado pela irradiação laser e pelo protocolo de aplicação da carga.
\end{abstract}

Palavras-chave: Parafusos ósseos, Terapia com luz de baixa intensidade, Tomografia computadorizada de feixe cônico, Ortodontia. 

MARAÑÓN-VÁSQUEZ, GA. Effect of low-level laser therapy on stability and displacement of orthodontic mini-implants submitted to loading. Ribeirão Preto, 2018. 131p. Master's Degree - School of Dentistry of Ribeirão Preto, University of São Paulo.

\begin{abstract}
The present study aimed to evaluate the effect of Low-level Laser Therapy (LLLT) on stability and displacement of mini-implants (MIs) submitted to loading. The null hypothesis tested was that laser irradiation and the applied loading protocol (immediate or mediate) do not influence the stability and displacement of MIs. Forty-eight devices were assessed for stability and 35 for displacement. They were implanted in patients from the graduate clinic of Orthodontics of the School of Dentistry of Ribeirão Preto, University of São Paulo. MIs were divided in four groups according to received intervention: 1- LLLT + IL (immediate loading), 2- LLLT + ML (mediate loading / 4 weeks after implantation), 3- IL (without LLLT) and 4- ML (4 weeks after implantation / without LLLT). Loading of $150 \mathrm{gF}$ was applied during 3 months for all devices. LLLT was implemented using red laser emission with wavelength of $660 \mathrm{~nm}$ and potency of 100 $\mathrm{mW}$, immediately after implantation (energy density: $4 \mathrm{~J} / \mathrm{cm} 2$ ). In the later days they were applied infrared laser emissions with wavelength of $808 \mathrm{~nm}$ every 48 hours during two weeks after placement of devices (energy density: $8 \mathrm{~J} / \mathrm{cm} 2$ for each application). MIs' stability assessment was performed by Resonance Frequency Analysis (RFA) at three moments: T0 on the day of implantation; T1 before loading, for groups 2 and 4; and, T2 after three months of loading application. For displacement analysis, images from Cone-beam Computed Tomography (CBCT) scans were used. Three-dimensional planes were created based on landmarks identified on maxilla and mandible to measure and compare differences of initial (TC0) and final (TC1) distances from the MI's head to the plane. Results demonstrated that group 2 presented the lowest loss of stability of all groups ( $p=0.0161$ ). Devices that received LLLT (Groups 1 and 2) showed lower loss of stability when they were compared with the groups that did not receive LLLT ( $p=$ 0.0372). MIs that received IL (Groups 1 and 3) presented greater loss of stability when the effective time of loading application was assessed $(p<0.0001)$. All groups showed displacement of the devices without significant differences between them. The null hypothesis was partially rejected. MIs that received LLLT and ML had lower loss of stability. Displacement was not influenced by laser irradiation or loading protocol.
\end{abstract}

Keys-word: Bone screws, Low-level light therapy, Cone-beam computed tomography, Orthodontics. 



\section{LISTA DE FIGURAS}

Figura 1. A - Kit Ortoimplante Conexão; B - dimensões do MI; C - MI colocado no osso alveolar interadicular, em gengiva inserida, perto da junção com a gengiva livre

Figura 2. Diâmetro da área irradiada e distância padronizada da fonte de luz laser ao tecido (representação esquemática)

Figura 3. Irradiação laser utilizando dispositivo para padronizar a distância fonte tecido

Figura 4. Equipamento laser de baixa potência Therapy XT

Figura 5. A - Aplicação de carga de $150 \mathrm{gF}$ por meio de cadeias elastoméricas, B Tensiômetro de precisão

Figura 6. Desenho de pesquisa e protocolos de intervenção 47

Figura 7. Equipamento Osstell ISQ RFA 48

Figura 8. A - Transdutor Smartpeg unido ao MI original, B - funcionamento do equipamento para AFR

Figura 9. Desenho de adaptador desenvolvido para mensuração da estabilidade (AFR).

Figura 10. Blocos de osso artificial selecionados para a presente pesquisa. Da esquerda para direita: osso esponjoso (20 PCF), osso esponjoso (20 PCF) com cortical de $1 \mathrm{~mm}$ (40 PCF), osso esponjoso (20 PCF) com cortical de $2 \mathrm{~mm}$ (40 PCF)

Figura 11. Corpos de prova de osso artificial

Figura 12. $\mathrm{A}-$ desenho da cobertura dos corpos de prova, $\mathrm{B}$ - corpo de prova com a região de implantação exposta (seta), $\mathrm{C}$ - total de corpos de prova cobertos e codificados

Figura 13. A - Perfuração prévia utilizando guia de resina acrílica, B - representação da inserção dos MIs, C - MI colocado no corpo de prova, D - amostra total de MIs implantados nos corpos de prova

Figura 14. Sistema MI - adaptador - transdutor

Figura 15. A - Adaptador inserido na cabeça do MI, B - Transdutor parafusado no adaptador e travado com o pino (Sistema MI - adaptador - transdutor)

Figura 16. $\mathrm{A}-$ Visualização $3 \mathrm{D}$ da imagem usando a função Isosurface, $\mathrm{B}$ - marcador esférico no ponto $\mathrm{C}$ (cabeça do $\mathrm{MI}$ ) em uma visualização axial, C confirmação da posição do marcador no plano axial usando a função OrthoSlice, D - marcador esférico no ponto C em uma visualização frontal, E - confirmação da posição do marcador no plano coronal usando a função 
OrthoSlice

Figura 17. Representação esquemática da orientação dos planos na avaliação do deslocamento. A - plano coronal como referência, B - plano axial como referência

Figura 18 Correlação intraclasse entre os valores do torque máximo de inserção e os valores de estabilidade ISQ nas duas avaliações

Figura 19 Diagrama de fluxo dos participantes

Figura 20 Correlação entre estabilidade e deslocamento dos mini-implantes por meio de regressão linear .

Figura 21 Correlação intraclasse entre os valores de estabilidade ISQ da $1^{\circ}$ e $2^{\circ}$ análise (intervalo de duas semanas)

Figura 22 "The ISQ scale" 


\section{LISTA DE TABELAS}

Tabela 1. Grupos do estudo e momentos das avaliações

Tabela 2. Dosimetria. Fatores clínicos e físicos do protocolo de aplicação da TLBP para o presente estudo

Tabela 3. Distribuição da quantidade dos MIs segundo comprimento do dispositivo e espessura do osso cortical

Tabela 4. Pontos de referência utilizados 55

Tabela 5. Caracterização descritiva dos participantes do estudo ..................................... $\quad \mathbf{6 6}$

Tabela 6. Características da distribuição dos mini-implantes por grupo …........................ 67

Tabela 7. Estabilidade e mobilidade dos mini-implantes ................................................ $\quad 67$

Tabela 8. Perda de estabilidade e deslocamento nos mini-implantes segundo grupo de estudo

Tabela 9. Perda de estabilidade e deslocamento nos mini-implantes segundo aplicação da TLBP ou protocolo de aplicação da carga

Tabela 10. Características metodológicas e protocolos laser (ou LED) dos estudos reportados para melhora da estabilidade e / ou osseointegração de MIs 



\section{SUMÁRIO}

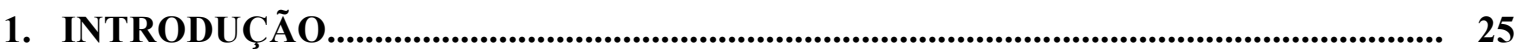

2. PROPOSIÇÃO

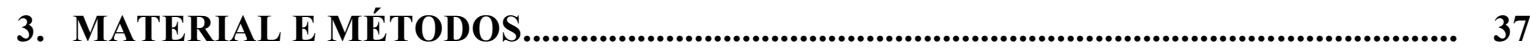

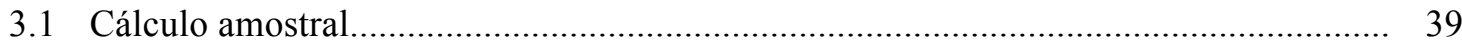

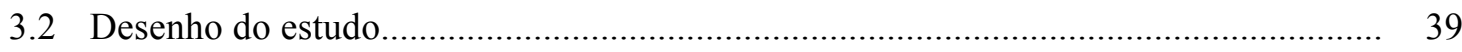

3.3 Participantes, critérios de seleção e elegibilidade.......................................................... 40

3.4 Randomização................................................................................................. 41

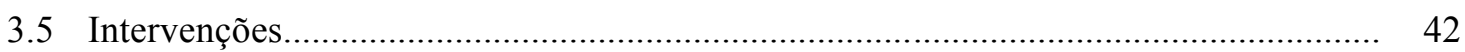

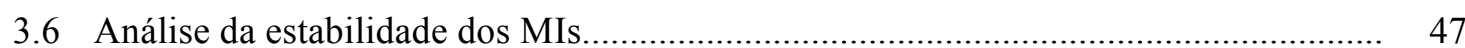

3.6.1 Validação do adaptador personalizado para AFR usando modelos de osso

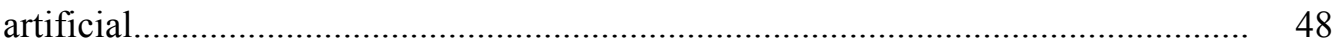

3.6.2 Análise da estabilidade propriamente dito (mensuração clínica)............................. 53

3.7 Análise do deslocamento dos MIs................................................................................ 54

3.8 Blindagem das análises..................................................................................... 59

$3.9 \quad$ Análise estatística............................................................................................. 59

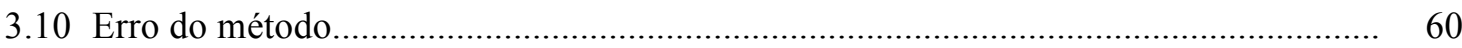

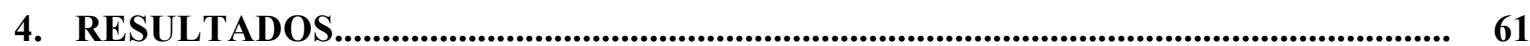

4.1 Validação do método para análise da estabilidade (adaptador personalizado + AFR). 63

4.2 Fluxo dos participantes (Diagrama de fluxo, parada antecipada e períodos de tempo.

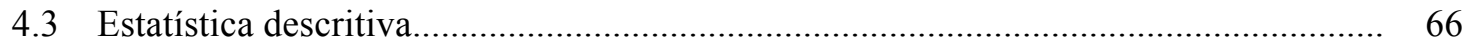

4.4 Avaliação dos desfechos......................................................................................... 68

4.5 Erro do método............................................................................................... 71

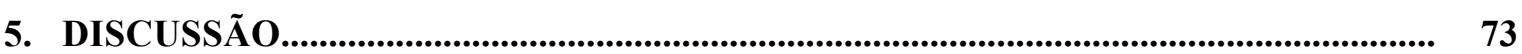

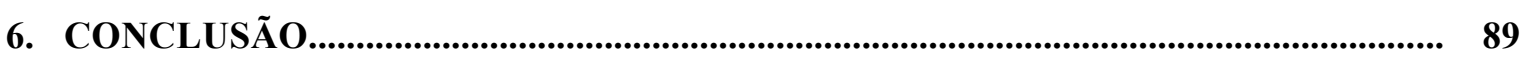

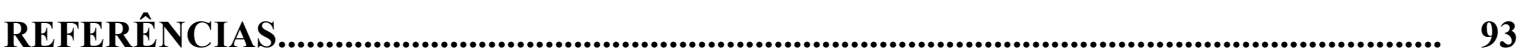

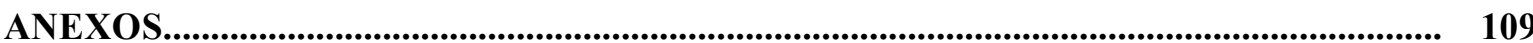






\section{INTRODUÇÃO}

A introdução dos mini-implantes (MI) significou um dos grandes avanços da Ortodontia contemporânea, ${ }^{1}$ sendo considerados auxiliares importantes na prática ortodôntica. $^{2-5}$ Embora o uso desses dispositivos tenha sido amplamente difundido nos últimos anos, nenhum sistema de MIs consegue alcançar taxas de sucesso do $100 \%$. $^{5-10}$ Quando comparados a outros dispositivos de ancoragem temporária, como as miniplacas ou implantes dentários, a taxa de falha ou perda dos MIs é ainda maior. ${ }^{5,11}$ Tem sido demonstrado que a taxa de falhas desses dispositivos é em média de $13,5 \%,{ }^{12}$ podendo variar de $10-30 \%$ de acordo com diferentes pesquisas. ${ }^{5}$

Os benefícios e as vantagens dos MIs são aproveitados se eles forem mantidos estacionários no local de implantação, permitindo cumprir os objetivos ortodônticos estabelecidos, tornando o tratamento mais previsível e menos dependente da colaboração do paciente. Sendo assim, os objetivos dos MIs são propiciar ancoragem sem causar efeitos adversos ou complicações durante a mecânica ortodôntica ${ }^{13}$ e permanecer com estabilidade e na mesma posição (ausência de deslocamento). Estes dois últimos objetivos são os parâmetros principais para considerar os MIs como bem sucedidos. ${ }^{4}$

Poucos anos atrás, pensava-se que dispositivos de ancoragem intraósseos permaneciam absolutamente estacionários quando carga era aplicada, ${ }^{14,15}$ porém, atualmente sabe-se que esta afirmação está equivocada. ${ }^{13}$ Os MIs podem perder estabilidade inclusive antes da aplicação da carga ${ }^{16}$ e podem deslocar quando esta é aplicada. ${ }^{17}$ Ambos os termos (estabilidade e deslocamento) estão relacionados, mas são diferentes. Enquanto estabilidade refere-se à retenção mecânica ou grau de mobilidade do $\mathrm{MI},{ }^{18,19}$ deslocamento refere-se à mudança de posição ou migração do dispositivo. ${ }^{17} \mathrm{O}$ grau de estabilidade primária (inicial) ou secundária (após processo de reparo ósseo) dependerão do desenho do MI, características do osso no local de implantação e da resposta biológica do paciente. ${ }^{18-22}$ No entanto, o deslocamento, que também pode ser primário (imediato) ou secundário (mediato), dependerá das características plásticas e elásticas das estruturas de suporte e da remodelação óssea após certo tempo de uso do dispositivo, respectivamente. ${ }^{17}$

Tradicionalmente, a estabilidade primária tem sido indicada como fator determinante para o sucesso dos MIs. ${ }^{20}$ Sendo assim, grande parte das pesquisas sobre MIs foram orientadas, por muitos anos, para determinar os fatores relacionados com esta estabilidade inicial e para estabelecer estratégias para melhorá-la, seja avaliando as condições ósseas pré- 
operatórias, ${ }^{23-25}$ selecionando adequados protocolos de implantação ou técnicas cirúrgicas, ${ }^{26-29}$ ou determinando o melhor desenho do MI. ${ }^{18,30}$

A estabilidade primária está diretamente relacionada à arquitetura óssea onde os dispositivos são implantados. ${ }^{31,32}$ Adequada qualidade e quantidade de ambos, osso cortical e trabecular, assegurarão a estabilidade primária dos MIs. ${ }^{33-38}$ Inicialmente, esta estabilidade dependerá principalmente do travamento do MI no osso $^{39}$ e posteriormente, durante a aplicação da carga, da existência de osseointegração parcial. ${ }^{20,40-42}$ Pelo fato do osso ser um tecido dinâmico em constante processo de remodelação, a estabilidade não pode ser garantida após implantação e/ou aplicação de carga. Sendo assim, adequada estabilidade primária não assegura necessariamente estabilidade secundária ou ausência de deslocamento dos MIs.

Revisão sistemática da literatura demonstrou que a quantidade de deslocamento secundário varia de 0 a 2,7 mm. ${ }^{17}$ Conhecer essa quantidade de deslocamento é relevante para a clínica ortodôntica. Existe risco de danos severos aos tecidos quando o MI contacta com a raiz dentária, podendo causar reabsorção radicular ou anquilose. ${ }^{43} \mathrm{O}$ dano irá depender da quantidade do contacto, muitas vezes não causando lesão permanente. ${ }^{44,45}$ Em algumas ocasiões, somente a íntima proximidade do MI às estruturas periodontais pode afetar severamente a estabilidade dos dispositivos ${ }^{46,47}$ devido a entrada e saída do dente do alvéolo. Dessa maneira, embora o objetivo primário seja manter estacionário o MI durante a mecânica ortodôntica, o objetivo secundário deverá ser não causar nenhum tipo de dano biológico, dor ou desconforto para o paciente. ${ }^{4}$

Até o presente momento, a quantidade de informação e pesquisas sobre as mudanças ósseas que acontecem após colocação dos MI que contribuem com a perda de estabilidade e deslocamento, assim como dos métodos para mantê-los estacionários no médio e longo prazo, são modestas. A natureza e o mecanismo de como acontece o deslocamento dos MIs no osso alveolar ainda não é bem conhecido, porém, alguns pressupostos tem sido discutidos na literatura. Afirmou-se que o deslocamento secundário de um MI relativamente estável não pode ser explicado pelo conceito tradicional de compressão-tensão periodontal. ${ }^{48} \mathrm{~A}$ explicação poderia ser dada pela Teoria do Mecanostato de Frost, ${ }^{49-52}$ baseada em que o estresse de carga dinâmico máximo controla os processos de remodelação. O mecanismo exato dessa teoria aplicada ao deslocamento dos MIs ainda permanece duvidoso. Frost, em 1989, descreveu o fenômeno de aceleração regional, ${ }^{53-56}$ que também poderia explicar em parte por que acontece esse deslocamento. $\mathrm{O}$ autor afirma que qualquer injuria cirúrgica no tecido ósseo trará, como consequência, eventos de reparo fisiológico tais como remodelação óssea, migração de mediadores químicos e aceleração da atividade osteoclástica, favorecendo 
a diminuição transitória da densidade óssea. Considerando que este osso de características osteoporóticas ao redor dos MIs aumentaria sua densidade somente após 3 meses da implantação, ${ }^{57}$ é fácil pensar que o deslocamento e perda de estabilidade acontecerão. Ainda mais, tendo sido confirmada a presença de quantidades elevadas de RANK-L no fluido crevicular ao redor do MIs que receberam carga, sugerindo atividade osteoclástica. ${ }^{58}$

Nesse contexto, parece ser importante e necessário conhecer quanto tempo leva para que o osso recupere as suas condições favoráveis antes de aplicar carga. Embora os protocolos de aplicação de carga imediata são amplamente recomendados na prática clínica, ${ }^{2-5,11,59}$ a literatura sobre esse assunto ainda não é clara. Alguns estudos são a favor da aplicação de carga imediata, sugerindo que ocorre osseointegração. ${ }^{41,60,61}$ No entanto, alguns deles acreditam que as condições ósseas são melhores quando aguarda-se um período de tempo antes da aplicação de carga. Zhang et al., ${ }^{62}$ baseados em avaliações histomorfológicas e histomorfométricas, concluíram que a carga imediata pode fornecer ancoragem ortodôntica estável, porém, para obter ancoragem estacionária melhorada, é recomendado um tempo de reparo de 4 semanas antes da aplicação da carga. Por outro lado, os autores que sugerem o uso de protocolos de carga mediata, afirmam que a carga precoce pode prejudicar a adequada consolidação óssea ou osseointegração dos MIs. ${ }^{40,42} \mathrm{Um}$ tempo de reparo maior tem sido recomendado quando as condições ósseas não forem as melhores. ${ }^{63}$ Estudos que usaram o Análise de Frequência de Ressonância (AFR), demonstraram que a estabilidade dos MIs está sujeita a mudanças durante o processo de reparo e que após diminuição inicial, os valores de estabilidade permanecem estáveis a partir da quarta semana, ${ }^{16,64,65}$ inclusive podendo aumentar durante a quinta semana. ${ }^{66}$ Um estudo clínico que avaliou a estabilidade dos MIs pelo torque de inserção, confirmou que os MIs apresentam significante perda de torque na primeira semana quando não recebem carga, porém esse estudo não acompanhou a evolução do processo de reparo nas semanas seguintes. ${ }^{67}$ Uma revisão sistemática da literatura na área da Periodontia, sugere que a carga imediata pode ser aplicada em implantes quando há um alto grau de estabilidade primária. ${ }^{68}$ Isto tem provavelmente aplicação limitada ou nula para MIs, pois um dispositivo com baixo grau de estabilidade primária é considerado como fracasso e removido logo após a implantação. Considerando a heterogeneidade metodológica das pesquisas nesse tema, investigações adicionais são necessárias para esclarecer essas dúvidas.

A perda de estabilidade e deslocamento dos MIs pode ser prevenida?, Aguardar o tempo de reparo ósseo usando protocolos de aplicação de carga mediata é a unica estratégia para controlar esses efeitos indesejados? Nesse ponto, é importante mencionar que 
estabilidade adequada e osseointegração dos MIs, inclusive seguindo protocolos de carga mediata, não garantem ausência de deslocamento secundário. Revisão sistemática da literatura mostrou que, embora tenham sido relatados diferentes períodos de reparo, os estudos confirmaram alguma quantidade de deslocamento dos dispositivos. ${ }^{17}$

Alguns métodos têm sido propostos com resultados favoráveis para o aumento da estabilidade e/ou diminuição do deslocamento de MIs. ${ }^{69-76}$ A TLBP é um deles ${ }^{77-80}$ e tem sido utilizada em Odontologia por muitos anos para diferentes aplicações, seja nos tecidos moles como nos tecidos duros. ${ }^{81,82} \mathrm{O}$ princípio básico é que os efeitos bioestimuladores gerados pela luz laser de baixa potência, nos comprimentos de onda vermelho e infravermelho, estimulem moléculas e átomos das células (fotorreceptores) sem efeitos de aquecimento significativos. ${ }^{81,83-85}$ Enquanto a TLBP produz efeitos estimuladores nas células, a irradiação de alta energia produz efeitos inibitórios.

O uso da TLBP para diferentes aplicações na área da Ortodontia tem sido testado. ${ }^{86-88}$ A literatura sugere que esta terapia reduz a dor pós ajuste de aparelhos ou o desconforto causado pelo uso de elásticos separadores, ${ }^{89-92}$ estimula regeneração óssea na sutura palatina mediana após expansão rápida da maxila ${ }^{93,94}$ ou distração osteogênica, ${ }^{95}$ e acelera a movimentação dentária ortodôntica. ${ }^{89,96-102}$

Têm sido descritos grande número de eventos celulares e moleculares quando a irradiação laser de baixa energia é aplicada. A TLBP induz diferenciação e ativação celular, além da expressão de mediadores envolvidos no processo de remodelação óssea. ${ }^{83,86,103-107}$ Sendo assim, essa terapia tem sido sugerida como método efetivo para estimular a cicatrização de feridas e acelerar o reparo ósseo. ${ }^{104-106}$

$\mathrm{Na}$ área de Periodontia, revisão sistemática da literatura relatou que, principalmente em estudos em animais, a TLBP tem efeito positivo na osseointegração de implantes dentários de titânio. ${ }^{108}$ De forma similar, na Ortodontia, estudos têm demonstrado o efeito positivo da TLBP na neoformação óssea ao redor de MIs, ${ }^{78-80}$ aumentando sua estabilidade ${ }^{79,109}$ e retenção mecânica no tecido ósseo. ${ }^{77}$

De acordo com o presente levantamento bibliográfico, atualmente existem alguns poucos estudos em animais ${ }^{77-80}$ e um estudo clínico randomizado ${ }^{109}$ descrevendo o efeito da TLBP na estabilidade de MIs. Embora as metodologias utilizadas sejam diferentes, os resultados parecem ser promissórios, sugerindo esta intervenção como coadjuvante clínico para melhorar o sucesso dos dispositivos. Até o presente momento, não foram encontrados estudos avaliando o efeito da TLBP na quantidade do deslocamento ou migração dos MIs. 
Pesquisas adicionais são necessárias usando modelos in vitro ou em animais e estudos clínicos adequadamente controlados para determinar o efeito real dessa terapia sobre os MIs.

Diferentemente dos estudos clínicos anteriormente publicados, o presente trabalho teve o objetivo de determinar o efeito da TLBP na estabilidade e no deslocamento de MIs colocados na maxila e mandíbula, considerando o protocolo de carga como possível fator influenciador no sucesso ou fracasso da terapia. 

2. Proposição 



\section{PROPOSIÇÃO}

O objetivo do estudo foi avaliar o efeito da TLBP na estabilidade e no deslocamento de MIs após aplicação de carga.

As hipóteses nulas testadas foram:

1. A TLBP não influencia na estabilidade e deslocamento dos MIs;

2. A estabilidade e o deslocamento dos MIs não são influenciados pelo protocolo de aplicação de carga utilizado;

3. Não existe correlação positiva entre a estabilidade e a quantidade de deslocamento dos MIs. 

3. Material e Mét'odos 



\section{MATERIAL E MÉTODOS}

\subsection{Cálculo amostral}

O cálculo do tamanho amostral foi baseado em estudos que avaliaram desfechos semelhantes aos da presente pesquisa e que tinham usado unidades de medida similares, valores ISQ para a estabilidade e quantidade de deslocamento em milímetros. Considerando os dados de Nienkemper et al., ${ }^{16}$ que mostraram redução da estabilidade de MIs de 1,7 ISQ $(\mathrm{DP}=3,9)$ após 4 semanas de tempo de reparo, uma fórmula de tamanho amostral foi realizada com significância de dois lados $\alpha=0,05$, poder estatístico de $\beta=0.8$ e com hipótese nula de efeitos iguais após uso da TLBP, usando o teste t no programa SAS 9.2 (SAS Institute Inc., Cary, NC, USA). O resultado desta estimativa mostrou que no mínimo precisava-se de 22 MIs por grupo (TLBP vs. sem TLBP). Da mesma forma, e considerando os dados reportados por Alves et al., ${ }^{11}$ (deslocamento de $0,78 \mathrm{~mm}, \mathrm{DP}=0,43$ ), uma fórmula foi utilizada para uma estimativa de redução do deslocamento de aproximadamente $50 \%(0,38$ $\mathrm{mm}$ ) quando a TLBP fosse utilizada. O resultado desta estimativa mostrou que seria necessário a mesma quantidade de MIs por grupo (22 MIs). Em relação ao protocolo de aplicação de carga, dados reportados por Kim et al., ${ }^{71}$ foram utilizados para o cálculo do tamanho amostral. Fazendo uma estimativa de redução do deslocamento para $0,14 \mathrm{~mm}(\mathrm{DP}=$ $0,12)$ para um tempo de reparo de 4 semanas, somente 6 MIs seriam necessários. Não entanto, para ser mais flexível, usando diferença média de aproximadamente $50 \%(0,40 \mathrm{~mm})$ e $\mathrm{DP}=$ 0,30, um mínimo de 17 MIs por grupo foram requeridos.

Considerando o maior número de tamanho amostral calculado (44 MIs) e levando em conta a taxa de perda aproximada do $10 \%$, um mínimo de 48 MIs foram considerados para o presente estudo. Devido à inocuidade da intervenção proposta nessa pesquisa e à probabilidade de perda de pacientes durante o período de acompanhamento, foram incluídos no estudo todos aqueles pacientes (73 MIs) avaliados para elegibilidade e que tinham aceitado fazer parte do estudo

\subsection{Desenho do estudo}

Este estudo foi aprovado pelo Comitê de Ética em pesquisa da Faculdade de Odontologia de Ribeirão Preto, Universidade de São Paulo (número CAAE: 56108316.0.0000.5419) (Anexo A).

Inicialmente foi desenhado um estudo clínico controlado randomizado (randomized controlled trial - RCT) paralelo de 4 braços. Foi registrado e publicado no site 
www.clinicaltrials.gov (NCT02891499) (Anexos B e C). Modificações dos dados do estudo inicialmente registrados foram atualizadas no site (Anexo D).

Devido a dificuldades metodológicas ocorridas durante o desenvolvimento da pesquisa, alguns participantes (ou MIs) não receberam a intervenção para a qual foram alocados. Sendo assim, o desenho do estudo mudou para um desenho quase-experimental, ${ }^{110}$ onde foi aplicada, em parte da amostra, intervenção sem respeitar a alocação dos grupos, sendo por conveniência e não aleatória. Foram incluídos todos aqueles participantes que receberam intervenção sendo ou não a inicialmente alocada.

\subsection{Participantes, critérios de seleção e elegibilidade}

Pacientes em tratamento ortodôntico corretivo com planejamento de mecânicas ortodônticas envolvendo uso de MIs foram avaliados para elegibilidade na clínica de pósgraduação em Ortodontia da Faculdade de Odontologia de Ribeirão Preto da Universidade de São Paulo (29 pacientes, 83 MIs no total). Os critérios para a seleção dos participantes foram os seguintes:

\section{Critérios de inclusão}

- Pacientes com dentição permanente;

- Com planejamento de uso de MIs nas regiões vestibulares posteriores superiores ou inferiores (MIs interadiculares), os quais iriam receber carga (elástico em cadeia);

- Higiene oral satisfatória.

Critérios de exclusão

- Presença de doença sistêmica;

- Uso de medicação crônica que interfira no metabolismo ósseo;

- Consumo de álcool ou tabaco de forma crônica.

Oito MIs foram excluídos pois a região planejada para implantação não era a indicada para o estudo (MIs palatinos) e/ou porque o paciente tinha planejamento de tratamento ortopédico (expansão rápida da maxila) durante o período de acompanhamento, o qual poderia causar alterações na análise do deslocamento (as estruturas anatômicas de referência no osso maxilar mudariam de posição alterando a análise). Além disso, a presença do aparelho disjuntor poderia dificultar a execução da análise de estabilidade.

Vinte e nove pacientes (73 MIs) cumpriram os critérios de seleção. Os participantes e/ou pessoas responsáveis foram convidadas a fazer parte do estudo e assinaram o Termo de 
consentimento livre e esclarecido (TCLE, Anexo E) e/ou Termo de assentimento (TA, Anexo F).

\subsection{Randomização}

Os MIs foram randomizados com o objetivo de obter distribuição balanceada dos dispositivos e igualdade dos grupos. Os grupos do estudo estão apresentados na Tabela 1.

Tabela 1 - Grupos do estudo e momentos das avaliações

\begin{tabular}{|c|c|c|c|c|}
\hline \multirow[b]{2}{*}{ GRUPOS } & \multirow[b]{2}{*}{$\begin{array}{l}\text { TERAPIA LASER DE } \\
\text { BAIXA POTENCIA } \\
\text { (TLBP) }\end{array}$} & \multirow[b]{2}{*}{$\begin{array}{l}\text { PROTOCOLO DE } \\
\text { APLICAÇÃO DA } \\
\text { FORÇA }\end{array}$} & \multicolumn{2}{|c|}{ AVALIAÇÕES } \\
\hline & & & $\begin{array}{c}\text { ESTABILIDADE } \\
\text { Análise de Freqüência } \\
\text { de Ressonância (AFR) }\end{array}$ & $\begin{array}{l}\text { DESLOCAMENTO } \\
\text { Tomografia } \\
\text { Computadorizada de } \\
\text { feixe cônico (TCFC) }\end{array}$ \\
\hline \multirow[t]{2}{*}{1} & & FORÇA IMEDIATA & TO e T2 & TCO e TC1 \\
\hline & COM TLBP & & & \\
\hline 2 & & FORÇA MEDIATA & T0, T1 e T2 & TCO e TC1 \\
\hline \multirow[t]{2}{*}{3} & & FORÇA IMEDIATA & TO e T2 & TCO e TC1 \\
\hline & SEM TLBP & & & \\
\hline 4 & & FORÇA MEDIATA & T0, T1 e T2 & TCO e TC1 \\
\hline
\end{tabular}

T0 e TC0 - Primeira avaliação (inicial); T1 - segunda avaliação (somente para análise da estabilidade); e T2 e TC1 - Avaliação final.

Fonte: Própria.

Foram consideradas duas situações no momento da randomização: (1) não foi seguido desenho de estudo de boca dividida (split-mouth), por isto todos os MIs colocados no mesmo paciente deviam receber a mesma intervenção laser, e (2) os dispositivos podiam ser independentemente alocados em diferentes grupos de acordo ao protocolo de aplicação de carga utilizada.

A randomização foi realizada no programa SAS 9.2. Uma vez que os pacientes precisavam de números diferentes de MIs, estes foram alocados seguindo um método estratificado (aleatorização em blocos) considerando a idade e sexo do participante no qual cada MI seria colocado e também o local de implantação (maxila ou mandibula).

A randomização não conseguiu relação de alocação equilibrada em número (17:22:18:16). O pesquisador responsável pela implementação do procedimento de randomização e encobrimento da alocação (MCPS) não esteve envolvido na aplicação das intervenções, acompanhamento dos participantes ou obtenção dos resultados. Todos os procedimentos de randomização foram realizados independentemente sem a presença dos operadores clínicos, após recrutamento. 
Como já mencionado, a aleatorização somente foi cumprida parcialmente, sendo que alguns pacientes receberam intervenção não aleatória. Os principais motivos para este acontecimento foram: (1) dificuldade para seguir o protocolo de aplicação laser completo; (2) o participante não concordou com a designação ao grupo alocado e desistiu de participar ou solicitou o uso de outra intervenção; e (3) mudança repentina no planejamento ortodôntico, em relação ao protocolo de aplicação de carga.

\subsection{Intervenções}

Todos os MIs elegíveis foram alocados em 4 grupos: 1- TLBP + CI (carga imediata), 2- TLBP + CM (carga mediata), 3- CI (sem TLBP) e 4- CM (sem TLBP). Informações pessoais e sobre o tratamento dos pacientes foram coletadas antes da implantação dos dispositivos.

MIs autoperfurantes (1.5 x 8 x $1 \mathrm{~mm})$ (Conexão, Arujá, São Paulo, Brazil) foram implantados nas regiões posteriores interadiculares através da gengiva inserida (Figura 1). O local de implantação cirúrgica foi definido por meio de avaliação clinica e análise de radiografia periapical. Após aplicação de anestésico tópico e subsequente anestesia infiltrativa local, foi realizada lancetagem da cortical vestibular e os MIs foram implantados com chave manual no mesmo local da lancetagem. Um mesmo operador colocou todos os MIs (FLR).

Figura 1 - A - Kit Ortoimplante Conexão; B - dimensões do MI; C - MI colocado no osso alveolar interadicular, em gengiva inserida, perto da junção com a gengiva livre.
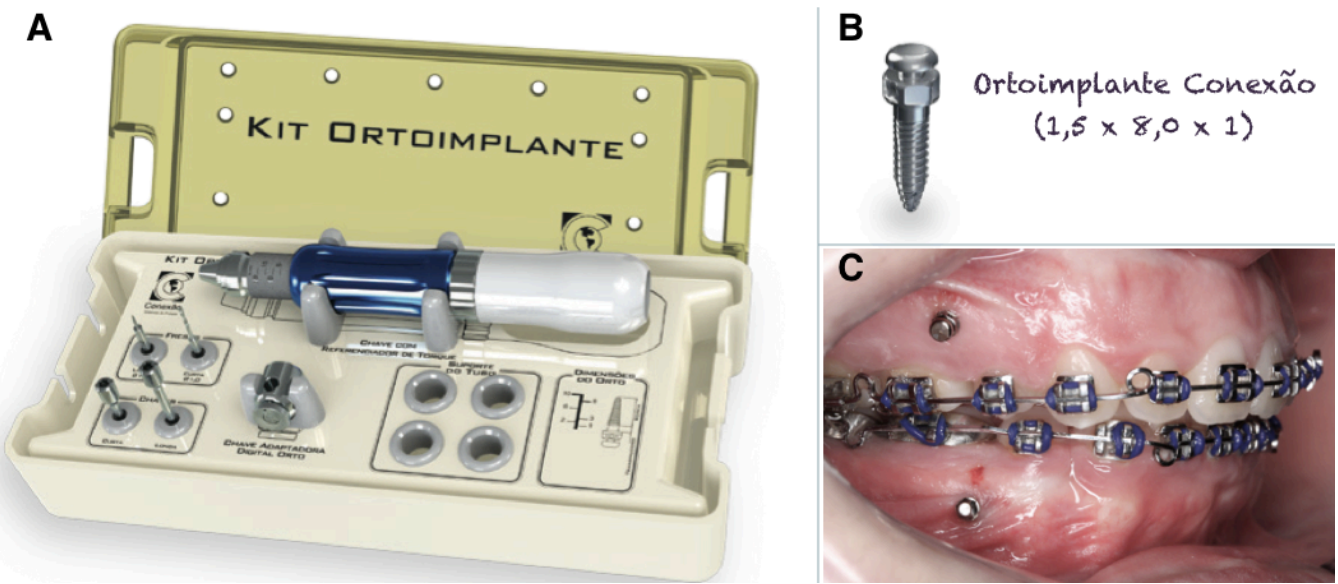

Fonte: A, http://www.conexao.com.br/catalogo/Catalogo_Final2017.pdf; B e C, própria. 
Após instalação dos dispositivos, a ausência de mobilidade foi verificada com pinça clínica apoiada na cabeça do MI. Aqueles MIs que apresentavam mobilidade clinicamente detectável nesse momento foram descartados do estudo.

Após implantação, a TLBP foi aplicada nos grupos designados tendo como objetivo alcançar o osso alveolar ao redor dos MIs. O diâmetro da área irradiada $(8 \mathrm{~mm})$ foi baseado na quantidade máxima possível de deslocamento que o MI pode sofrer relatado pela literatura (aproximadamente $3 \mathrm{~mm})^{17}$ e no diâmetro do MI (Figura 2).

Figura 2 - Diâmetro da área irradiada e distância padronizada da fonte de luz laser ao tecido (representação esquemática).

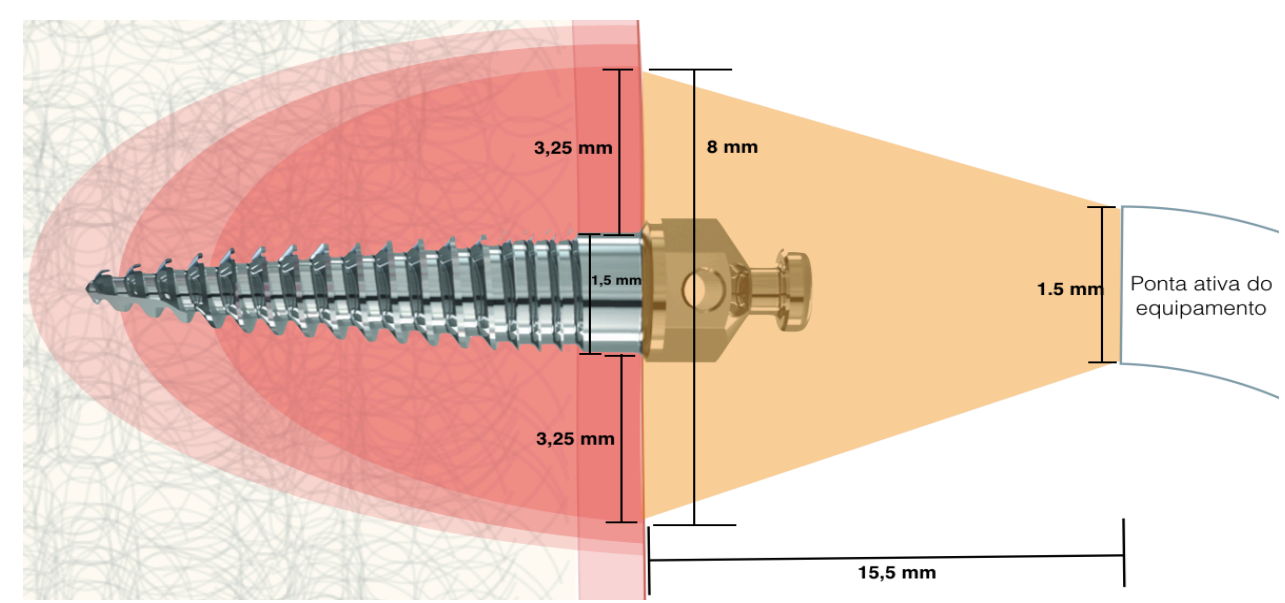

Fonte: Própria.

O cálculo da superfície da área irradiada foi realizado segundo a seguinte fórmula:

Diâmetro da área irradiada: $8 \mathrm{~mm}$

Raio da área irradiada: $4 \mathrm{~mm}=0,4 \mathrm{~cm}$

Área irradiada: $\pi * r^{2}$

$$
3,1416 * 0,4^{2}=\mathbf{0 , 5} \mathbf{c m}^{2}
$$

A TLBP foi aplicada cobrindo a área de implantação $\left(0,5 \mathrm{~cm}^{2}\right)$ sobre a cabeça dos MIs e sem contato entre a fonte de luz do equipamento laser e o dispositivo e os tecidos ao redor (aproximadamente $15.5 \mathrm{~mm}$ afastada do tecido) com uma energia de $2 \mathrm{~J}$ na primeira aplicação e $4 \mathrm{~J}$ nas aplicações seguintes. Um dispositivo foi desenhado e constituído com fío de aço 0,9 mm para padronizar e manter constante a distância entre a fonte de luz e o tecido irradiado e consequentemente o tamanho da área irradiada. Este dispositivo metálico foi adaptado e fixado com fita isolante na ponta ativa do aparelho laser (Figura 3). 
Figura 3 - Irradiação laser utilizando dispositivo para padronizar a distância fonte - tecido.

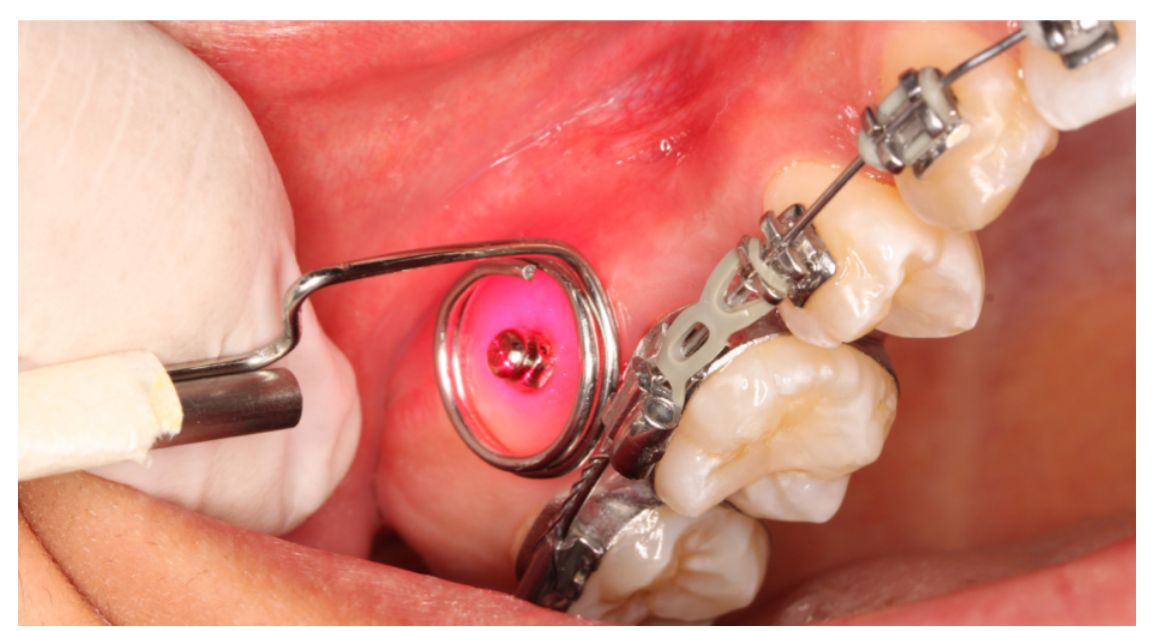

Fonte: Própria.

O protocolo de irradiação teve duração de duas semanas. No dia da colocação do MI (dia 1), o equipamento laser (Therapy XT, DCM, Kearny, NJ, USA) (Figura 4) foi utilizado com emissão de luz vermelha com comprimento de onda de $660 \mathrm{~nm}( \pm 10)$, potência de 100 $\mathrm{mW}( \pm 20)$ e onda contínua, para melhorar o pós-operatório imediato, reduzir a dor e acelerar o processo de reparo inicial. Posteriormente, usando o mesmo equipamento laser, mas com emissão de luz infravermelha, a irradiação laser foi aplicada a cada 48 horas (dia 3, 5, 8, 10, 12 e 15) com comprimento de onda de $808 \mathrm{~nm}$ ( \pm 10$)$ com o objetivo de alcançar o tecido ósseo mais profundo. A potência do equipamento foi mensurada antes do seu uso usando um potenciômetro (Powermaster/Field meter, Coherent, Auburn, CA, USA) e deveria atingir 100 $\mathrm{mW}$.

Figura 4 - Equipamento laser de baixa potência Therapy XT
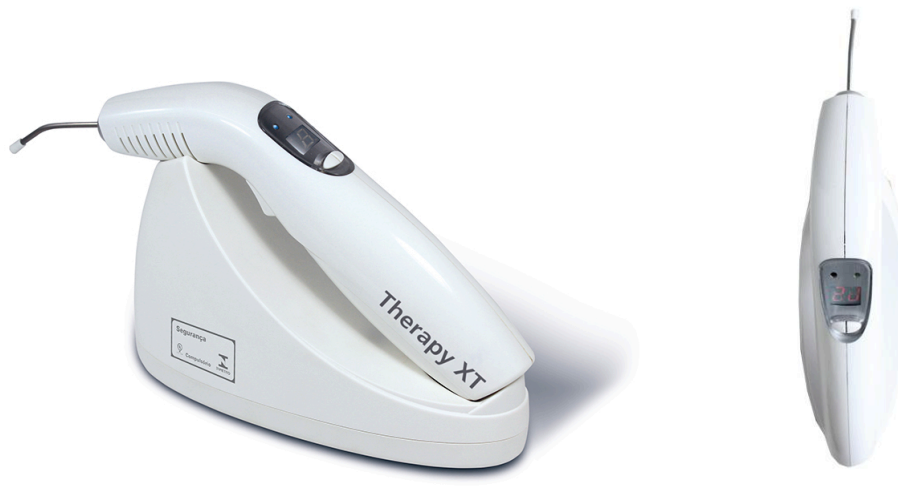

Fonte: http://www.dmcgroup.com.br/br/detalheproduto/odontologica/equipamentos/laserterapia/therapy-xt/117. 
O cálculo do tempo de irradiação para alcançar as energias desejadas de 2 e $4 \mathrm{~J}$, para o pós-operatório imediato e mediato, respectivamente, foi realizado segundo a seguinte fórmula:

Energia $(\mathrm{J})$ = Potência óptica do equipamento $(\mathrm{W}) *$ Tempo de irradiação $(\mathrm{s})$

- Pós-operatório imediato: $2 \mathrm{~J}=0,1 \mathrm{~W} *$ tempo de irradiação

Tempo de irradiação $=20 \mathrm{~s}$.

- Pós-operatório mediato: $4 \mathrm{~J}=0,1 \mathrm{~W} *$ tempo de irradiação

Tempo de irradiação $=40 \mathrm{~s}$.

O cálculo da dose ou densidade de energia aplicada ao tecido foi calculada segundo as seguintes fórmulas:

Densidade de potência $\left(\mathrm{W} / \mathrm{cm}^{2}\right)=\underline{\text { Potência óptica do equipamento }(\mathrm{W})}$

Área irradiada $\left(\mathrm{cm}^{2}\right)$

$$
=\underline{0,1 \mathrm{~W}}
$$

Densidade de potência $=0,2 \mathrm{~W} / \mathrm{cm}^{2}$

Densidade de energia /

dose $\left(\mathrm{J} / \mathrm{cm}^{2}\right)=$ Densidade de potência $\left(\mathrm{W} / \mathrm{cm}^{2}\right) *$ Tempo de irradiação (s)

-Pós-operatório imediato

$=0,2 * 20$

Dose $=4 \mathrm{~J} / \mathrm{cm}^{2}$

-Pós-operatório mediato

$$
=0,2 * 40
$$

Dose $=8 \mathrm{~J} / \mathrm{cm}^{2}$

As características da dosimetria e protocolo de aplicação da TLBP estão detalhadas na Tabela 2. 
Tabela 2 - Dosimetria. Fatores clínicos e físicos do protocolo de aplicação da TLBP para o presente estudo.

\begin{tabular}{|c|c|c|}
\hline Fatores Clínicos & Pós-operatório imediato & Pós-operatório mediato \\
\hline Densidade de energía J/cm² & $4 \mathrm{~J} / \mathrm{cm}^{2}$ & $8 \mathrm{~J} / \mathrm{cm}^{2}$ \\
\hline Densidade de potência $\mathrm{mW} / \mathrm{cm}^{2}$ & $0,2 \mathrm{~W} / \mathrm{cm}^{2}$ & $0,2 \mathrm{~W} / \mathrm{cm}^{2}$ \\
\hline Tempo de irradiação s & $20 \mathrm{~s}$ & $40 \mathrm{~s}$ \\
\hline Pontos irradiados & 01 ponto & 01 ponto \\
\hline Método de irradiação & Não contato & Não contato \\
\hline Ritmo de irradiação & Uniforme & Uniforme \\
\hline Número de tratamentos & 01 & 06 \\
\hline \multicolumn{3}{|l|}{ Fatores Físicos } \\
\hline Comprimento de onda $\mathrm{nm}$ & $660 \mathrm{~nm}( \pm 10 \mathrm{~nm})$ & 808 nm ( \pm 10 nm) \\
\hline Emissão & Contínua & Contínua \\
\hline Potência W & $0,1( \pm 20 \%)$ & $0,1( \pm 20 \%)$ \\
\hline Diâmetro da fibra (equipamento) um & 600 um & $600 \mathrm{um}$ \\
\hline Diâmetro de feixe (equipamento) mm & $1,5 \mathrm{~mm}$ & $1,5 \mathrm{~mm}$ \\
\hline Diâmetro de feixe (Tecido) mm & $8 \mathrm{~mm}$ & $8 \mathrm{~mm}$ \\
\hline Área irradiada $\mathrm{cm}^{2}$ & $0,5 \mathrm{~cm}^{2}$ & $0,5 \mathrm{~cm}^{2}$ \\
\hline Distância fonte - tecido & $15,5 \mathrm{~mm}$ & $15,5 \mathrm{~mm}$ \\
\hline
\end{tabular}

Fonte: Própria (adaptada de Garcez et al. ${ }^{126}$ ).

Carga de $150 \mathrm{gF}$ foi aplicada aos MIs usando cadeias elastoméricas (adaptadas à mecânica planejada para cada paciente) por período de 3 meses (Figura 5A). A magnitude da carga foi mensurada por meio de tensiômetro de precisão (Zeusan, Campinas, SP, Brazil) (Figura 5B), revisada e renovada a cada duas semanas para mantê-la sempre uniforme (troca das cadeias elastoméricas).

Figura 5 - $\quad$ A - Aplicação de carga de 150 gF por meio de cadeias elastoméricas; B - Tensiômetro de precisão.
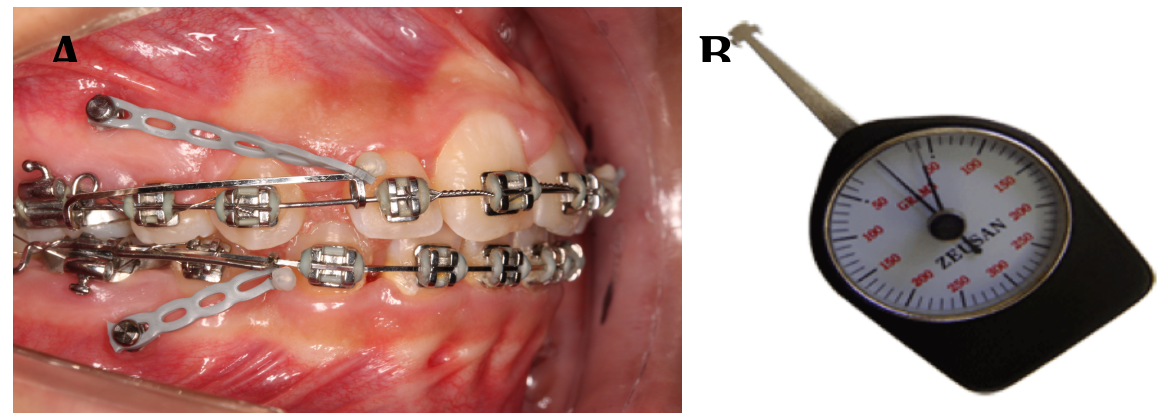

Fonte: Própria.

Nos grupos de aplicação de carga imediata (grupos 1 e 3) a carga foi aplicada no dia da implantação, enquanto que nos grupos de carga mediata (2 e 4) esta foi aplicada 4 semanas após colocação dos MIs. Os protocolos de intervenção estabelecidos nesta pesquisa são indicados na Figura 6. 
Figura 6 - Desenho da pesquisa e protocolos de intervenção.

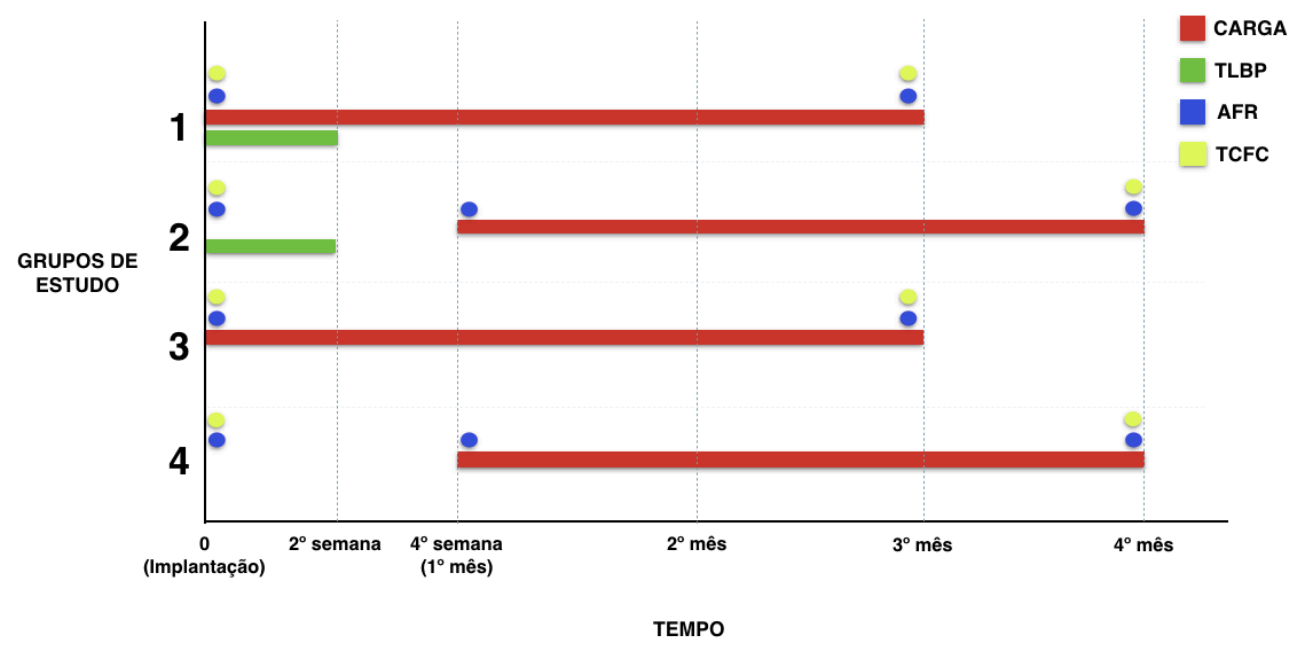

Fonte: Própria.

Nas consultas de controle (a cada 2 semanas), a condição do MI (grau de mobilidade clínica) era avaliada e registrada. Esta avaliação foi categorizada em: (1) ausência de mobilidade clinicamente detectável, (2) presença de mobilidade mas com capacidade para cumprir a sua função de ancoragem, ou (3) mobilidade com perda da função de ancoragem (MI perdido).

Além disso, foi avaliada em cada consulta de controle a ausência de inflamação e higiene bucal do paciente. Os participantes foram adequadamente instruídos e receberam folhetos com orientações para seguir protocolo apropriado de higiene (escovação após cada refeição, uso de escova interproximal para higienizar ao redor do MI, uso de fio dental e uso de solução de Clorhexidina $0.12 \%$ ao redor do MI). Breve profilaxia e revisão das instruções de higiene junto aos participantes foram realizadas em cada consulta de controle.

Informações do paciente como, data de implantação, número e localização dos MIs foram inseridas na Ficha de Coleta de Dados (Anexo G). As intervenções foram implementadas consistentemente sem mudanças após início do estudo.

Como já foi mencionado, aqueles pacientes que não receberam a intervenção alocada, receberam igualmente alguma intervenção das designadas para o presente estudo.

\subsection{Análise da estabilidade dos MIs}

A avaliação da estabilidade foi realizada por meio da AFR usando dispositivo analisador da freqüência (Osstell ISQ, Osstell, Gothenburg, Sweden) (Figura 7). Adaptador personalizado foi desenhado, construído e validado previamente, para permitir união altamente estável e de precisão entre o MI e o transdutor utilizado para esse análise. 


\subsubsection{Validação do adaptador personalizado para AFR usando modelos de osso} artificial

A AFR consiste em impulsos eletromagnéticos emitidos por peça de mão em direção a um transdutor (peça que contém um imã) chamado Smartpeg, previamente parafusado na cabeça do MI, ${ }^{112}$ que gera vibrações que são registradas em valores ISQ (Implant Stability Quotient) (Figura 8). ${ }^{12,113}$

Figura 7 - Equipamento Osstell ISQ RFA

Fonte: https://www.osstell.com/product/osstell-isq/.

Figura 8 - A - Transdutor Smartpeg unido ao MI original, ${ }^{112} \mathrm{~B}$ - funcionamento do equipamento para AFR. ${ }^{16}$
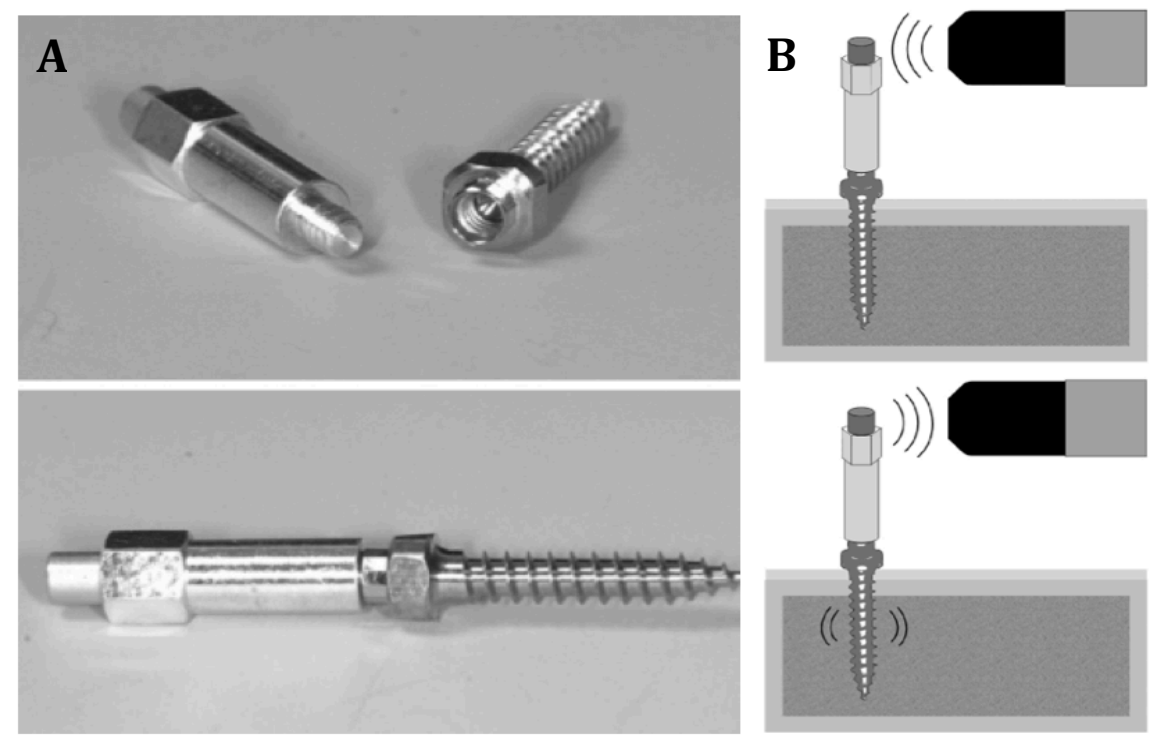

Fonte: A, Nienkemper et al; ${ }^{112}$ B, Nienkemper et al. ${ }^{16}$ 
O desenho de MI utilizado na presente pesquisa não permitia parafusar o transdutor da AFR como ilustrado na Figura 8. Então, um conector perfeitamente adaptado na cabeça do MI foi desenvolvido na Oficina de Precisão da Universidade de São Paulo - Campus de Ribeirão Preto (Figura 9).

Figura 9 - Desenho de adaptador desenvolvido para mensuração da estabilidade (AFR).
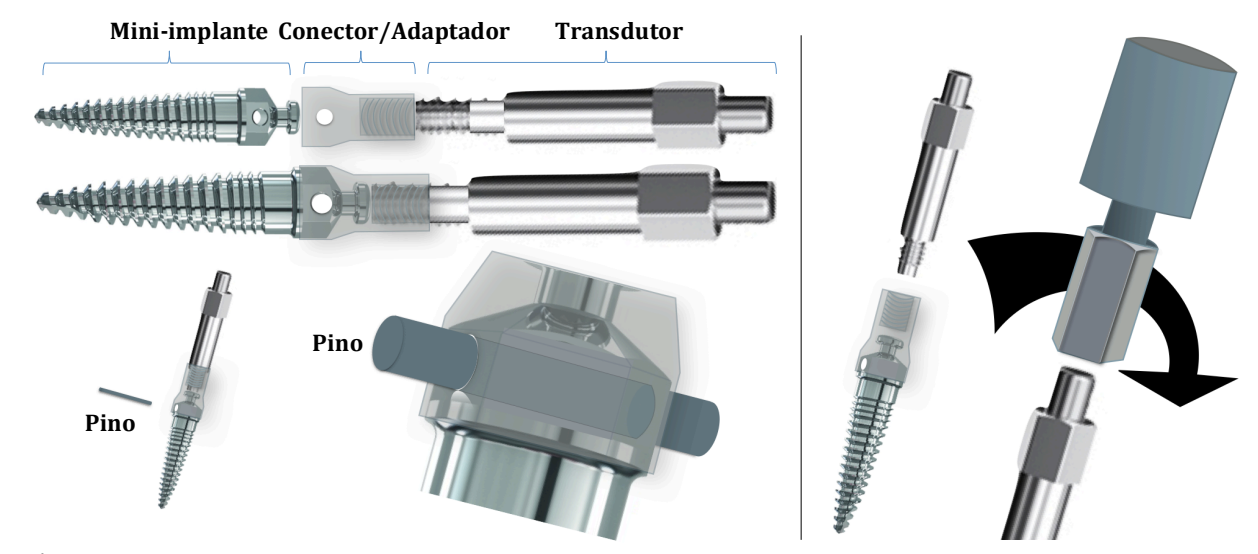

Fonte: Própria.

O adaptador personalizado foi validado para mensuração da estabilidade, correlacionando os valores ISQ com o máximo torque de inserção dos dispositivos. O objetivo da validação foi demonstrar se o método proposto permitia registrar variação nos valores da estabilidade em diferentes situações. Duas variáveis foram selecionadas para este propósito: espessura da cortical óssea e comprimento do MI.

Corpos de prova de osso artificial (20PCF-CP1, 20PCF-CP2, 20PCF-CP; Nacional Ossos, Jaú, SP, Brasil) foram selecionados para a validação do método de mensuração da estabilidade. Modelos de osso sintético constituídos de espuma sólida e rígida de poliuretano de $20 \mathrm{lb} / \mathrm{ft}^{3}\left(0.32 \mathrm{~g} / \mathrm{cm}^{3}\right)$ com diferentes espessuras de espuma rígida de poliuretano laminada de $40 \mathrm{lb} / \mathrm{ft}^{3}\left(0.64 \mathrm{~g} / \mathrm{cm}^{3}\right)$ simulando o osso cortical, foram escolhidos como equivalentes do tecido ósseo (Figura 10).

Figura 10 - Blocos de osso artificial selecionados para a presente pesquisa. Da esquerda para direita: osso esponjoso (20 PCF), osso esponjoso (20 PCF) com cortical de $1 \mathrm{~mm}$ (40 PCF), osso esponjoso (20 PCF) com cortical de $2 \mathrm{~mm}$ (40 PCF).
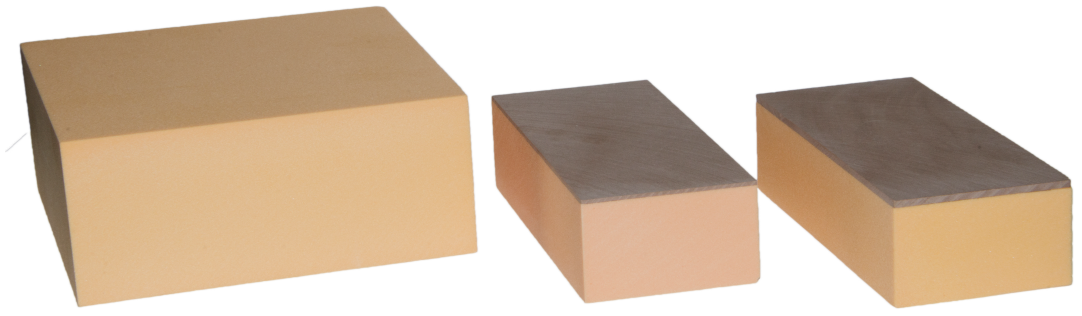

Fonte: Própria. 
Os blocos de osso originais foram classificados de acordo com a presença e/ou espessura do osso cortical em três grupos $(0,1$ e $2 \mathrm{~mm}$ de espessura de osso cortical artificial) (Figura 10). Posteriormente, eles foram cortados simetricamente até se obter 10 corpos de prova por grupo com medidas de $2 \mathrm{~cm}$ de comprimento e largura, e 3, $3.1 \mathrm{ou} 3.2 \mathrm{~cm}$ de altura, dependendo das características do osso cortical de cada grupo (Figura 11).

Figura 11 - Corpos de prova de osso artificial.
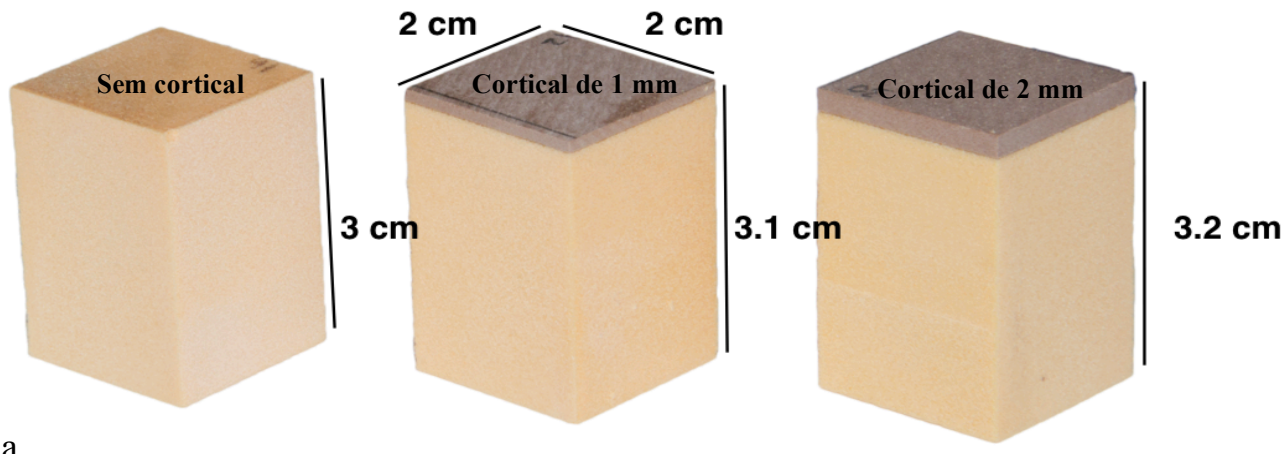

Fonte: Própria.

Para implantação dos MIs de forma blindada, todos os corpos de prova (30 no total) foram codificados, ordenados aleatoriamente (sequência gerada no site http://random.org) e numerados $(1$ - 30). Depois, foram cobertos com cartolina preta e etiquetados com numeração, deixando visível somente a região para implantação dos MIs (Figura 12). Somente um assistente (SEYP) da pesquisa conhecia a codificação dos corpos de prova.

Figura 12 - A - Desenho da cobertura dos corpos de prova, B - corpo de prova com a região de implantação exposta (seta), C - total de corpos de prova cobertos e codificados.

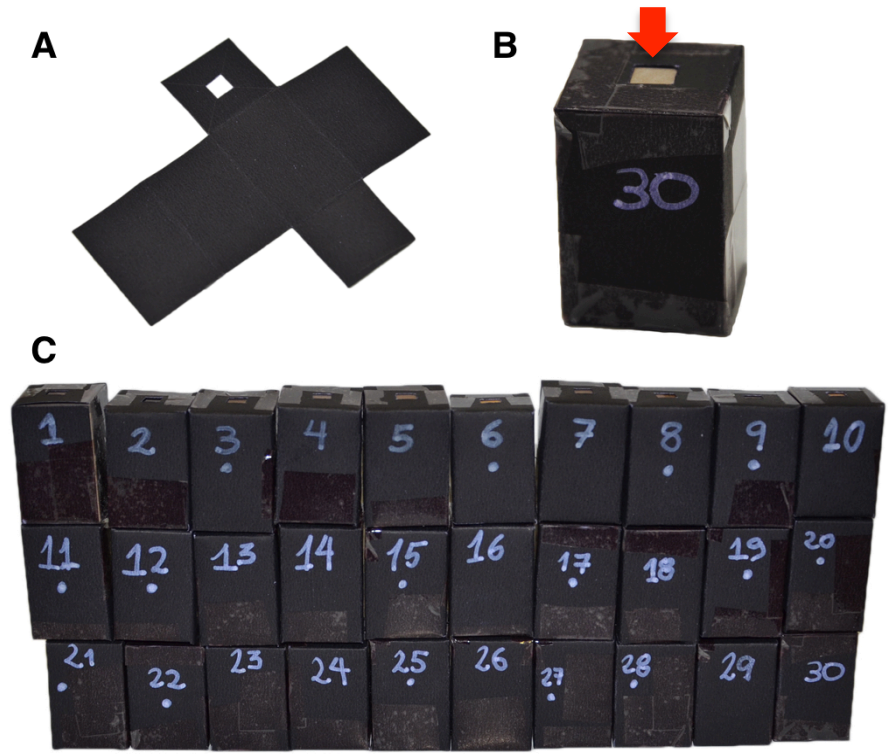

Fonte: Própria. 
Um total de 30 MIs autoperfurantes de $1.5 \mathrm{~mm}$ de diâmetro e perfil transmucoso de 1 $\mathrm{mm}$, foram divididos em dois grupos de 15, cada um de acordo com seu comprimento, 6 e 8 mm (\#98756199, \#95758199; Conexão Sistemas de Prótese, Arujá, SP, Brasil). A distribuição da quantidade dos MIs de acordo com o comprimento dos dispositivos e espessura do osso cortical está apresentada na Tabela 3.

Tabela 3 - Distribuição da quantidade dos MIs segundo comprimento do dispositivo e espessura do osso cortical.

\begin{tabular}{ccc}
\hline COMPRIMENTO DO MI & $\begin{array}{c}\text { ESPESSURA DO OSSO } \\
\text { CORTICAL }\end{array}$ & QUANTIDADE \\
\hline \multirow{3}{*}{$6 \mathrm{~mm}$} & SEM CORTICAL & 5 \\
& CORTICAL DE $1 \mathrm{~mm}$ & 5 \\
& CORTICAL DE $2 \mathrm{~mm}$ & 5 \\
\multirow{2}{*}{$8 \mathrm{~mm}$} & SEM CORTICAL & 5 \\
& CORTICAL DE $1 \mathrm{~mm}$ & 5 \\
& CORTICAL DE $2 \mathrm{~mm}$ & 5 \\
\hline
\end{tabular}

Fonte: Própria.

Os MIs foram implantados nos corpos de prova com ajuda de um guia de resina acrílica para assegurar implantação perpendicular $\left(90^{\circ}\right)$ à superfície do osso e padronizar a inserção dos dispositivos (Figura 13A). Único operador previamente treinado (GAMV), blindado às características do osso artificial utilizado, colocou todos os MIs. Para o procedimento de perfuração e implantação foi utilizado o equipamento iChiropro system (iChiropro, Bien-Air Dental SA, Bienne, Switzerland). Perfurações prévias foram feitas antes da inserção dos MI usando uma broca de 1 mm de diâmetro (\#936101; Conexão Sistemas de Prótese, Arujá, SP, Brasil) à velocidade de $300 \mathrm{rpm}$ até que osso cortical fosse perfurado. Para padronizar este procedimento, todas as perfurações foram realizadas a uma profundidade de 2 mm para todos os corpos de prova (Figura 13B). Os MIs foram implantados automaticamente usando chave adaptadora curta (\#967701; Conexão Sistemas de Prótese, Arujá, SP, Brasil) previamente adaptada em contra-ângulo do equipamento iChiropro system, até a rosca dos MIs ficarem completamente dentro do osso artificial (Figura 13C, 13D). O torque de inserção foi continuamente medido aplicando rotação fixa no sentido horário a $10 \mathrm{rpm}$. Foi estabelecido para o equipamento iChiropro system, registrar os valores de torque a cada 0.1 segundos durante o procedimento de inserção e também o valor máximo em $\mathrm{Ncm}$. 
Figura 13 - $\quad$ A - Perfuração prévia utilizando guia de resina acrílica, B - representação da inserção dos MIs, C - MI colocado no corpo de prova, D - amostra total de MIs implantados nos corpos de prova.
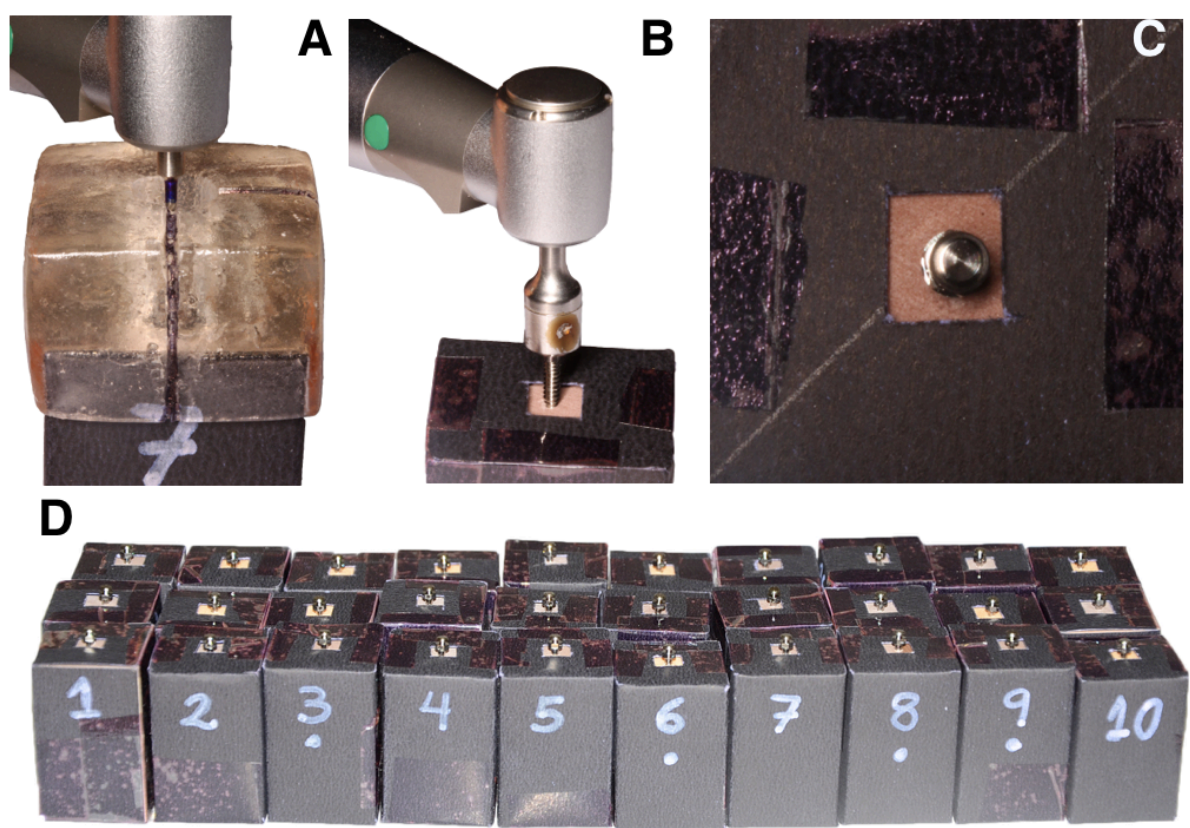

Fonte: Própria.

Após inserção dos dispositivos, a estabilidade primária foi medida por meio do AFR utilizando o analisador de freqüência Osstell ISQ (Osstell, Göteborg, Sweden). O adaptador personalizado foi utilizado para unir de forma precisa o transdutor Smartpeg à cabeça do MI. $\mathrm{O}$ adaptador apresentava rosca interna de $1.1 \mathrm{~mm}$ de diâmetro que permitia acoplar (parafusar) o Smartpeg (Figura 9). Ao ser parafusado exercia pressão, enquanto o adaptador ficava preso na cabeça do MI pela ajuda de um pino de aço inoxidável em sistema de travamento (Figura 9). O sistema permitiu formar um bloco único MI - adaptador transdutor, que possibilitou realizar corretamente o teste de AFR.

$\mathrm{O}$ transdutor foi parafusado à mão no adaptador personalizado previamente conectado à cabeça do MI e ajustado com a pressão do dedo (instruções do fabricante, Figura 14). Com o transdutor Smartpeg paralelo ao eixo longo do MI, a AFR foi realizada colocando a ponta da peça de mão próxima e perpendicular à cabeça do transdutor em 4 direções diferentes, uma para cada lado do corpo de prova. 
Figura 14 - Sistema MI - adaptador - transdutor.

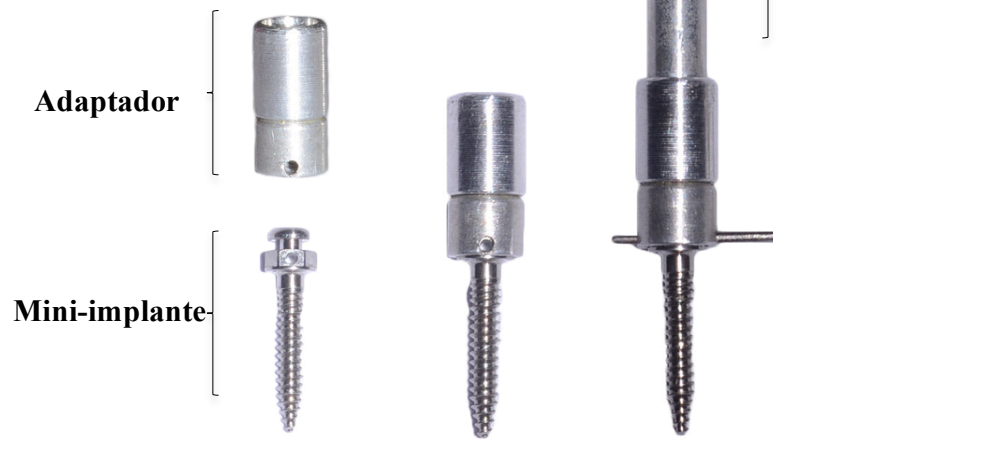

Fonte: Própria

Cada mensuração foi obtida em ISQ e a média dos 4 valores foi calculada para cada MI. Único operador previamente treinado e calibrado realizou todas as análises (GMAV) de forma blindada ao tipo de osso e comprimento dos MIs. A análise de todos os MIs foi realizada duas vezes com um intervalo de duas semanas.

\subsubsection{Análise da estabilidade propriamente dita (mensuração clínica)}

Todos os procedimentos da AFR anteriormente mencionados no experimento in vitro foram igualmente realizados nos MIs implantados nos pacientes (Figura 15A e 15B).

Figura 15 - $\quad$ A - Adaptador inserido na cabeça do MI; B - transdutor parafusado no adaptador e travado com o pino (Sistema MI - adaptador - transdutor).

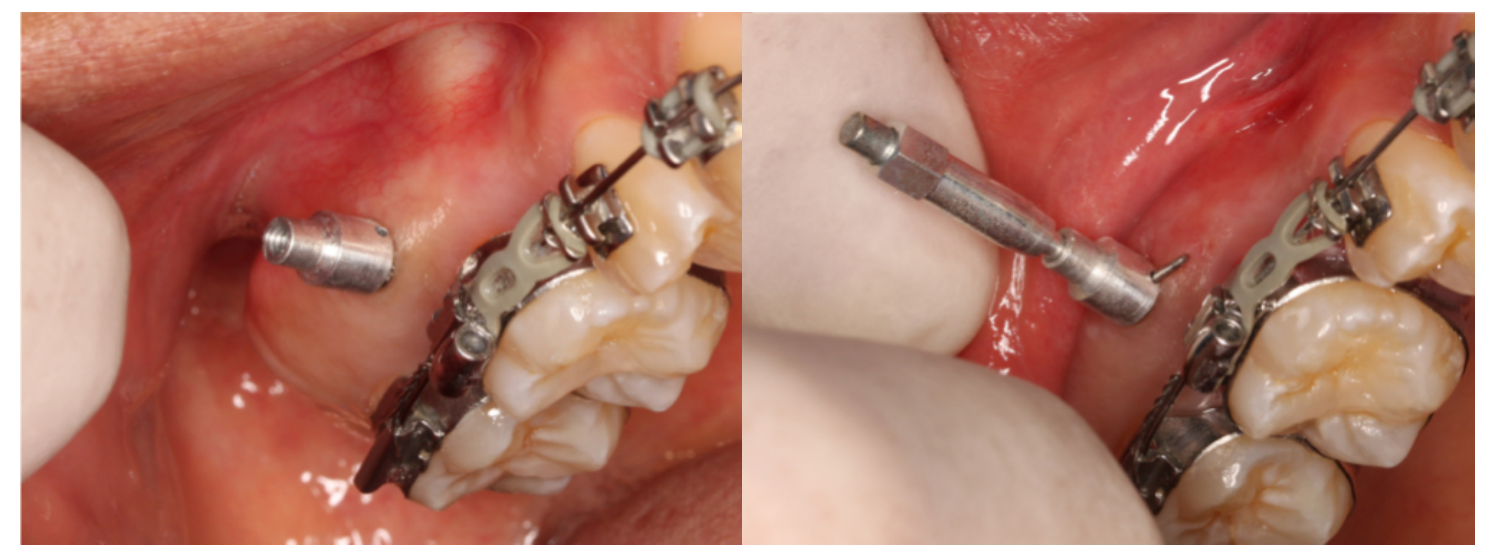

Fonte: Própria. 
O mesmo operador (GAMV), previamente treinado e calibrado, realizou todas as avaliações. As mensurações de estabilidade foram realizadas em duas direções diferentes para cada dispositivo: mesial (sentido mesiodistal) e oclusal (sentido ocluso-gengival). Isto foi executado com o objetivo de minimizar o erro causado por possíveis variações na qualidade óssea ao redor dos MIs. Para reduzir o erro do método foram realizadas três medidas em cada direção e foi calculada a média, e assim, foi gerada uma única medida de estabilidade para cada MI. As mensurações por distal e gingival não foram realizadas devido à dificuldade causada pela mucosa jugal durante a tentativa de realizar a análise. Todas as medidas foram registradas em ISQ.

A avaliação da estabilidade foi realizada em três momentos: T0, imediatamente após inserção dos MIs e antes de aplicar TLBP; T1, 4 semanas após implantação e antes de aplicar carga (somente nos grupos 2 e 4); e T2, após 3 meses de carga (Figura 6). As medidas dos valores ISQ foram registrados na Ficha de Coleta de dados (Anexo G).

\subsection{Análise do deslocamento dos MIs}

Para a análise do deslocamento dos MIs foram obtidas imagens de tomografias computadorizadas de feixe cônico (TCFC) usando o equipamento Orthopantomograph OP300 (Instrumentarium, Nahkelantie, Tuusula, Finland). Imagens regionais da maxila, mandíbula ou de ambos ossos juntos foram feitas com o paciente em pé, com a cabeça posicionada com o plano horizontal de Frankfurt paralelo ao solo e seguindo protocolo para aquisição de imagens de $120 \mathrm{kV}, 5 \mathrm{~mA}$, tamanho de voxel de $0.4 \mathrm{~mm}$ e 40 segundos de escaneamento.. Com o objetivo de reduzir a dose de radiação para os pacientes, um campo de visão (FOV) de $6 \times 8 \mathrm{~cm}$ e resolução baixa - moderada foram selecionados. As imagens foram adquiridas e armazenadas no programa CliniView ${ }^{\mathrm{TM}}$ 10.2.6 (Instrumentarium, Nahkelantie, Tuusula, Finland) e posteriormente, foram convertidas em formato DICOM (Digital Imaging and Communications in Medicine) e analisadas utilizando o programa Avizo 8.1.1 (Visualization Sciences Group, Burlington, Mass, USA).

Os arquivos no formato DICOM foram renderizados em imagens volumétricas, nas quais foram analisadas as visualizações 3D e os cortes gerados pela TCFC, usando as funções Isosurface e OrthoSlice do programa Avizo, respectivamente, com o objetivo de localizar pontos de referência previamente definidos na maxila, mandibula e no MI (Tabela 4, Figura 16). 
Tabela 4 - Pontos de referência utilizados.

\begin{tabular}{|c|c|c|c|c|c|}
\hline & \multirow{2}{*}{ Ponto de referência } & \multirow{2}{*}{ Definição } & \multicolumn{3}{|c|}{ Identificação nos cortes da TCFC } \\
\hline & & & Axial & Coronal & Sagital \\
\hline \multirow{13}{*}{ Maxila } & Espinha nasal posterior (ENP) & Extremo final posterior da crista nasal do palato duro. & Ponto médio posterior & Ponto mais inferior & Ponto mais posterior \\
\hline & Orifício palatino direito (centro) & $\begin{array}{l}\text { Ponto médio do orificio palatino direito (ingresso do canal palatino posterior } \\
\text { direito). }\end{array}$ & Ponto médio & Ponto médio mais inferior & Ponto médio mais inferior \\
\hline & Orifício palatino direito (ponto anterior) & $\begin{array}{l}\text { Ponto mais anterior do orificicio palatino direito, no ingresso do canal palatino } \\
\text { posterior. }\end{array}$ & Ponto mais anterior & Ponto mais inferior & Ponto mais anterior inferior \\
\hline & Orifício palatino esquerdo (centro) & $\begin{array}{l}\text { Ponto médio do orificio palatino esquerdo (ingresso do canal palatino } \\
\text { posterior esquerdo). }\end{array}$ & Ponto médio & Ponto médio mais inferior & Ponto médio mais inferior \\
\hline & $\begin{array}{l}\text { Orifício palatino esquerdo (ponto } \\
\text { anterior) }\end{array}$ & $\begin{array}{l}\text { Ponto mais anterior do orificio palatino esquerdo, no ingresso do canal } \\
\text { palatino posterior. }\end{array}$ & Ponto mais anterior & Ponto mais inferior & Ponto mais anterior inferior \\
\hline & $\begin{array}{l}\text { Junção dos ossos palatinos e maxilares na } \\
\text { sutura palatina mediana }\end{array}$ & $\begin{array}{l}\text { União dos processos palatinos dos ossos maxilares e dos processsos horizontais } \\
\text { dos ossos palatinos ao nivel da linha média (sutura palatina mediana). }\end{array}$ & Ponto médio & Ponto médio mais inferior & Ponto médio mais inferior \\
\hline & $\begin{array}{l}\text { Assa interna do processo pterigoides } \\
\text { direito }\end{array}$ & Ponto médio mais inferior do processo pterigoide medial direito. & Ponto médio mais inferior & Ponto mais inferior & Ponto mais inferior \\
\hline & $\begin{array}{l}\text { Assa interna do processo pterigoides } \\
\text { esquerdo }\end{array}$ & Ponto médio mais inferior do processo pterigoide medial esquerdo. & Ponto médio mais inferior & Ponto mais inferior & Ponto mais inferior \\
\hline & Forame incisivo & Ponto médio mais inferior do orificio oral do canal nasopalatino. & Ponto médio & Ponto médio & Ponto médio mais inferior \\
\hline & Orifício nasal & $\begin{array}{l}\text { Ponto médio mais superior do orificio nasal do canal nasopalatino (ou o ponto } \\
\text { médio dos orificios, quando tiver dois orificios nasais). }\end{array}$ & Ponto médio & Ponto médio mais superior & Ponto médio mais superior \\
\hline & Espinha nasal anterior (ENA) & Projeção óssea mais anterior formada pela união das duas premaxilas. & Ponto médio anterior & Ponto mais anterior & Ponto mais anterior \\
\hline & Junção zigomático - maxilar direita & Ponto mais inferior na sutura entre os ossos zigomático e maxilar direitos. & Ponto médio anterior & Ponto médio inferior & Ponto anterior inferior \\
\hline & Junção zigomático - maxilar esquerda & Ponto mais inferior na sutura entre os ossos zigomático e maxilar esquerdos. & Ponto médio anterior & Ponto médio inferior & Ponto anterior inferior \\
\hline \multirow{11}{*}{ Mandíbula } & Forame mentoniano direito (centro) & Ponto médio mais externo do forame mentoniano direito. & Ponto médio mais externo & Ponto médio mais externo & Ponto médio \\
\hline & Forame mentoniano esquerdo (centro) & Ponto médio mais externo do forame mentoniano esquerdo. & Ponto médio mais externo & Ponto médio mais externo & Ponto médio \\
\hline & $\begin{array}{l}\text { Forame mentoniano direito (ponto } \\
\text { anterior) }\end{array}$ & Ponto mais antero inferior no ingresso ao forame mentoniano direito. & Ponto mais anterior & Ponto mais inferior & Ponto mais anterior inferior \\
\hline & $\begin{array}{l}\text { Forame mentoniano esquerdo (ponto } \\
\text { anterior) }\end{array}$ & Ponto mais antero inferior no ingresso ao forame mentoniano esquerdo. & Ponto mais anterior & Ponto mais inferior & Ponto mais anterior inferior \\
\hline & Forame lingual & Ponto médio mais superior no orificio lingual no ingresso ao canal lingual & Ponto médio mais posterior & Ponto médio & Ponto médio mais posterior \\
\hline & Lingula direita & Ponto mais posterior medial da lingula direita. & Ponto mais posterior medial & Ponto mais medial & Ponto médio mais posterior \\
\hline & Lingula esquerda & Ponto mais posterior medial da lingula esquerda. & Ponto mais posterior medial & Ponto mais medial & Ponto médio mais posterior \\
\hline & Orifício dentário inferior direito & Ponto médio superior do orificio direito no ingresso ao canal dentário inferior. & Ponto médio mais medial & Ponto médio mais medial & Ponto médio \\
\hline & Orifício dentário inferior esquerdo & $\begin{array}{l}\text { Ponto médio superior do orificio esquerdo no ingresso ao canal dentário } \\
\text { inferior. }\end{array}$ & Ponto médio mais medial & Ponto médio mais medial & Ponto médio \\
\hline & Processo geni superior direito & Projeção óssea na superficie lingual da sinfise mandibular. & Ponto mais posterior & Ponto posterior & Ponto mais posterior \\
\hline & Processo geni superior esquerdo & Projeção óssea na superficie lingual da sinfise mandibular. & Ponto mais posterior & Ponto posterior & Ponto mais posterior \\
\hline \multirow{3}{*}{$\begin{array}{c}\text { Mini- } \\
\text { implante }\end{array}$} & Ponto C (Cabeça) & Ponto médio mais externo na cabeça do dispositivo. & Ponto médio mais exterior & Ponto médio mais exterior & Ponto médio \\
\hline & Ponto R (Rosca) & Ponto médio na seşão transversal do dispositivo a $4 \mathrm{~mm}$ do ápice dele. & Ponto médio a 4 mm do ápice & Ponto médio a $4 \mathrm{~mm}$ do ápice & Ponto médio \\
\hline & Ponto A (Ápice) & Ápice do dispositivo. & Ponto médio mais medial & Ponto médio mais medial & Ponto médio \\
\hline
\end{tabular}

Fonte: Própria 
Figura 16 - A - Visualização 3D da imagem usando a função Isosurface (Seta vermelha mostrando ponto de referência/marcador na cabeça do $\mathrm{MI}$ ), B - marcador esférico no ponto $\mathrm{C}$ (cabeça do MI) em uma visualização axial (Seta), C - confirmação da posição do marcador no plano axial usando a função OrthoSlice, D - marcador esférico no ponto C em uma visualização frontal (Seta), E - confirmação da posição do marcador no plano coronal usando a função OrthoSlice.

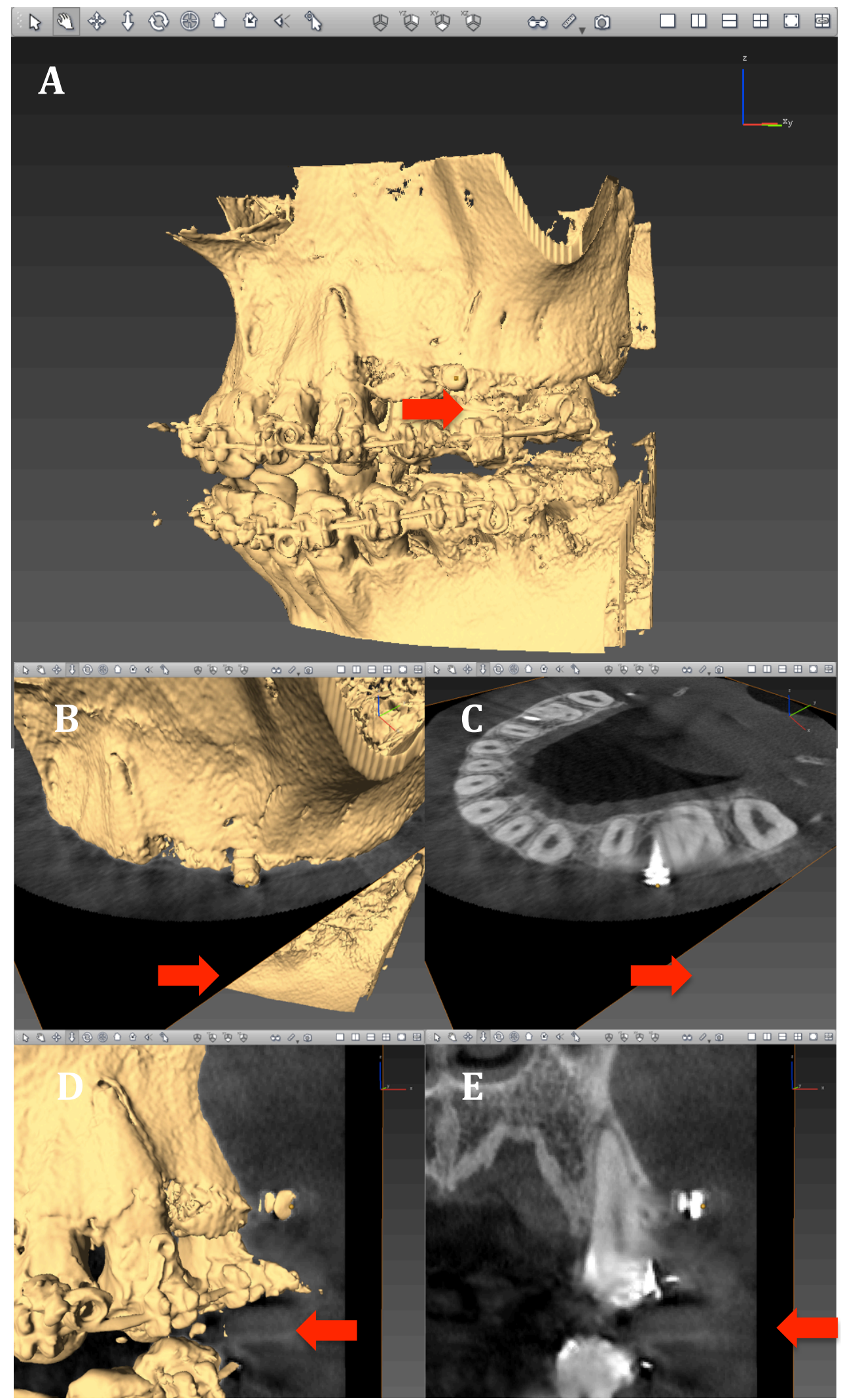

Fonte: Própria. 
Os pontos de referência foram identificados usando marcadores esféricos de 0.25 mm de diâmetro (Figura 16). O centro de cada marcador representou a localização exata do ponto de referência. Eles foram exportados e tabulados no programa Microsoft Excel 2011 (Microsoft, Redmon, Wash, USA) mostrando as coordenadas x, y, e z para a identificação da posição 3D de cada um dos pontos na respectiva imagem inicial e final.

Após tabulação das coordenadas dos pontos de referência no Excel, foram escolhidos ao acaso pontos no MI (pontos que provavelmente sofreriam deslocamento) e pontos nos ossos maxilar ou mandibular (pontos fixos ou estáveis durante o acompanhamento) para calcular a distância entre ambos. Igualmente foi calculada a distância entre dois pontos no MI e dois pontos na estrutura óssea avaliada. Se as distâncias entre os pontos na TCFC inicial e final eram muito discrepantes, a análise foi novamente realizada devido ao erro na identificação dos pontos. A fórmula utilizada para a determinação da distância entre dois pontos 3-dimensionais foi a seguinte:

Distância entre ponto 1 e ponto $2=\mathrm{P}_{1} \mathrm{P}_{2}$

Coordenadas do ponto 1: $\mathrm{X}_{1}, \mathrm{Y}_{1}, \mathrm{Z}_{1}$

Coordenadas do ponto 2: $\mathrm{X}_{2}, \mathrm{Y}_{2}, \mathrm{Z}_{2}$

$\mathbf{P}_{1} \mathbf{P}_{2}=\sqrt{\left(\mathbf{X}_{2}-\mathbf{X}_{1}\right)^{2}+\left(\mathbf{Y}_{2}-Y_{1}\right)^{2}+\left(Z_{2}-Z_{1}\right)^{2}}$

Foram construídos 3 planos matemáticos de referência 3-dimensionais com base nos pontos anatômicos identificados na maxila e mandíbula (J.W. [engenheiro]). Somente alguns pontos foram selecionados dependendo da sua possibilidade de localização nas imagens dos pacientes e do seu grau de confiabilidade segundo o teste previamente realizado. Os planos foram criados com base nos seguintes pontos:

Plano axial maxilar: orifício palatino direito, orifício palatino esquerdo, forame incisivo;

Plano sagital maxilar: ENP, Forame incisivo, ENA;

Plano coronal maxilar: ENP, processo pterigoide direito, processo pterigoide esquerdo;

Plano axial mandibular: orifício dentário inferior direito, orifício dentário inferior esquerdo, forame lingual;

Plano sagital mandibular: ponto médio entre os forames mentonianos (centro) direito e esquerdo, ponto médio entre os forames mentonianos (ponto anterior) direito e esquerdo, forame lingual; 
Plano coronal mandibular: forame mentoniano direito, forame mentoniano esquerdo, forame lingual.

Cada um dos planos serviu para avaliar o deslocamento em diferentes direções: o plano axial, para quantificar o deslocamento no sentido vertical; o plano sagital, no sentido buco lingual; e o plano coronal, o deslocamento no sentido anteroposterior. Como os tipos de mecânica ortodôntica não foram iguais, somente foi padronizada a quantidade da carga e não se trabalhou com o deslocamento nos diferentes sentidos. Somente foi considerada a medida na direção da carga exercida pelo elástico, para assim trabalhar com única medida: deslocamento na direção da carga aplicada (principal vetor da carga). Assim, nos MIs utilizados para mecânicas intrusivas onde vetor principal da carga aplicada sobre eles foi vertical, utilizou-se o plano de referencia axial para avaliação do deslocamento. De forma similar, nos MIS utilizados para mecânicas distalizadoras ou de fechamento de espaços, onde o vetor principal da carga exercida era horizontal, utilizouse o plano coronal para a análise. As distâncias ortogonais do MI ao plano de referência estabelecido foram calculadas (Figura 17). Não incluíram-se MIs cujo vetor principal da carga recebida fosse no sentido vestíbulo lingual.

Figura 17 - Representação esquemática da orientação dos planos na avaliação do deslocamento. A - plano coronal como referência, B - plano axial como referência.
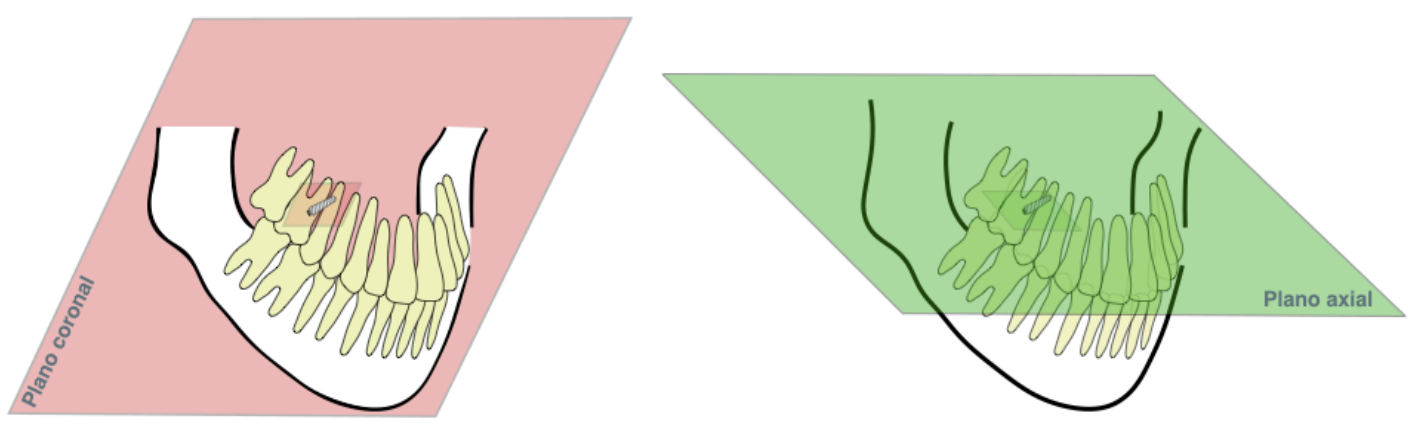

Plano coronal

Plano axial
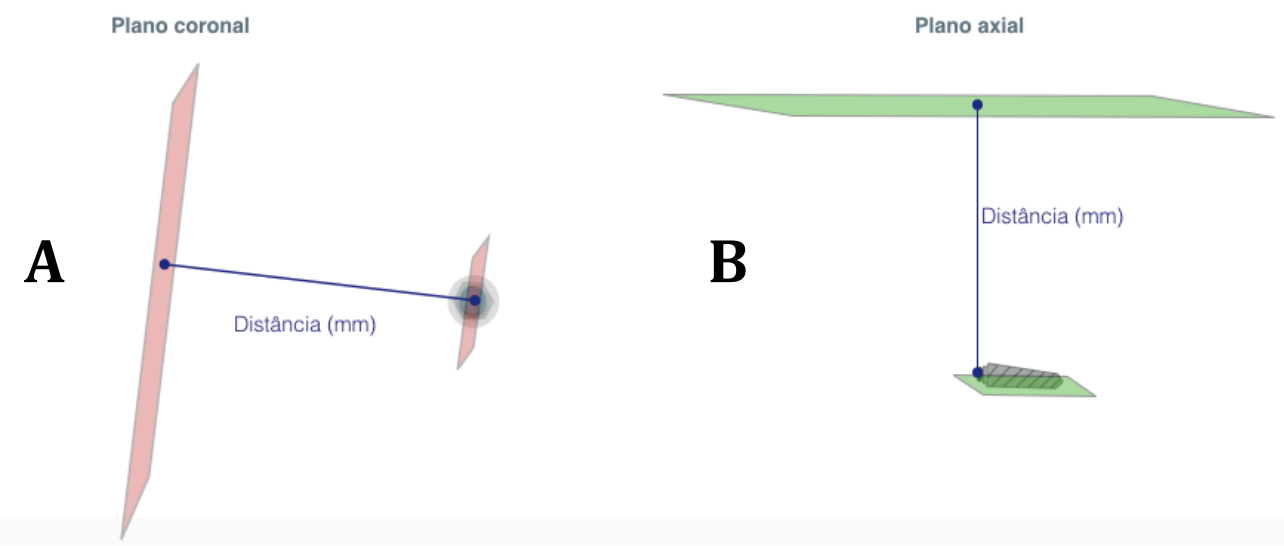

Fonte: Própria. 
As distâncias do MI ao plano de referência escolhido foram obtidas em dois momentos: TC0, imediatamente após implantação dos MIs e antes de aplicar a TLBP; e, TC1, após 3 meses de aplicação de carga (Figura 6). O mesmo operador (GAMV) realizou a identificação de todos os pontos de referência nas imagens, sempre utilizando dois computadores simultaneamente (TCFC inicial e final para cada MI avaliado) para diminuir o erro na identificação dos pontos.

Devido à presença de artefato, baixa qualidade das imagens e a forma afunilada do ápice dos MIs, foi difícil a identificação do ponto A (ápice) e consequentemente do ponto $\mathrm{R}$ (rosca), por isto, somente foi utilizado o ponto $\mathrm{C}$ (cabeça) como referência nos MIs.

O avaliador estava blindado aos grupos de pesquisa. As medidas foram inseridas na Ficha de Coleta de Dados (Anexo G).

As datas dos controles agendados para cada pacientes, e os dados recolhidos durante o acompanhamento dos pacientes foram inseridos nas Fichas de registro da evolução dos pacientes (Anexos H, I, J e K).

\subsection{Blindagem das análises}

Os pacientes estavam cientes do grupo ao qual pertenciam e da intervenção que receberam. O operador que colocou os MIs (FLR) estava blindado à alocação dos grupos.

As avaliações da estabilidade nos diferentes tempos foram registradas em fichas diferentes para minimizar o viés de recordação. Nesse sentido, a blindagem durante a análise dos dados foi também realizada, codificando as amostras para anonimizar os dados.

O pessoal técnico responsável pela aquisição das imagens e posteriormente o pesquisador que realizou as análises das TCFC (identificação dos pontos de referência) (GAMV) estavam blindados à intervenção aplicada. O engenheiro responsável (J.W.) pela criação dos planos 3-dimensionais de referência e mensuração das distâncias do deslocamento estava também blindado à identificação dos grupos.

\subsection{Análise estatística}

Todas as análises foram realizadas com testes bicaudais, assumindo-se alfa de 0.05 e utilizando os programas SAS 9.2 (SAS Institute Inc., Cary, NC, USA) ou SAScallable SUDAAN 11.0.0 (RTI International, Research Triangle Park, Cary, NC, USA) quando necessário. 
Para a validação prévia do método de mensuração da estabilidade (AFR + adaptador personalizado), foi calculado o coeficiente de correlação intraclasse (CCI) entre os valores de estabilidade obtidos com o método proposto versus o torque máximo de inserção dos dispositivos.

A estatística descritiva convencional incluindo médias e desvio padrão, assim como distribuições de freqüência e porcentagens foi utilizada para apresentar as características demográficas de cada grupo de estudo.

Todas as comparações dos desfechos (estabilidade, perda da estabilidade, e deslocamento) ou características demográficas entre os grupos experimentais levaram em consideração a dependência dos dados em um mesmo individuo (conglomerado). As análises incluíram o teste Chi-quadrado para comparação de proporções (dados binários), teste $\mathrm{t}$ ou teste Mann Whitney para comparação de duas médias ou medianas respectivamente, e análise de variância ou teste Kruskal Wallis para comparação de mais de duas médias ou medianas respectivamente (nos dados contínuos), após verificação da normalidade dos dados. Foi realizado um ajuste pela idade, sexo e local de implantação, usando análise de regressão. Quando foi evidenciada diferença estatística entre os grupos, foi aplicado um post teste (false Discovery rate) para comparações múltiplas. A correlação entre estabilidade e deslocamento foi avaliada por meio de regressão linear levando-se em consideração também a presença de conglomerados.

\subsection{Erro do método}

Para avaliar a confiabilidade e reprodutibilidade do método de avaliação da estabilidade foi calculado o coeficiente de correlação intraclasse das medidas repetidas com intervalo de 2 semanas do AFR dos 30 MIs colocados nos modelos de osso artificial.

Da mesma forma, para o método de identificação dos pontos de referência nas TCFC, foram selecionadas 10 tomografias ( 5 da maxila e 5 da mandíbula) as quais foram avaliadas três vezes com intervalos de 1 semana entre cada avaliação. $\mathrm{O}$ coeficiente de correlação intraclasse foi calculado. 
4. RESULTADOS 



\section{RESULTADOS}

4.1. Validação do método para análise da estabilidade (adaptador personalizado + AFR)

O coeficiente de correlação intraclasse demonstrou a validade do método. A correlação entre os valores do torque máximo de inserção e os valores de estabilidade ISQ nas duas mensurações (intervalo de 2 semanas), foram relativamente altas, apresentando $r=0.714$ ( $1^{\mathrm{a}}$ avaliação AFR) e r= 0.719 ( $2^{\mathrm{a}}$ avaliação AFR) (Figura 18).

Figura 18 - Correlação intraclasse entre os valores do torque máximo de inserção e os valores de estabilidade ISQ nas duas avaliações.

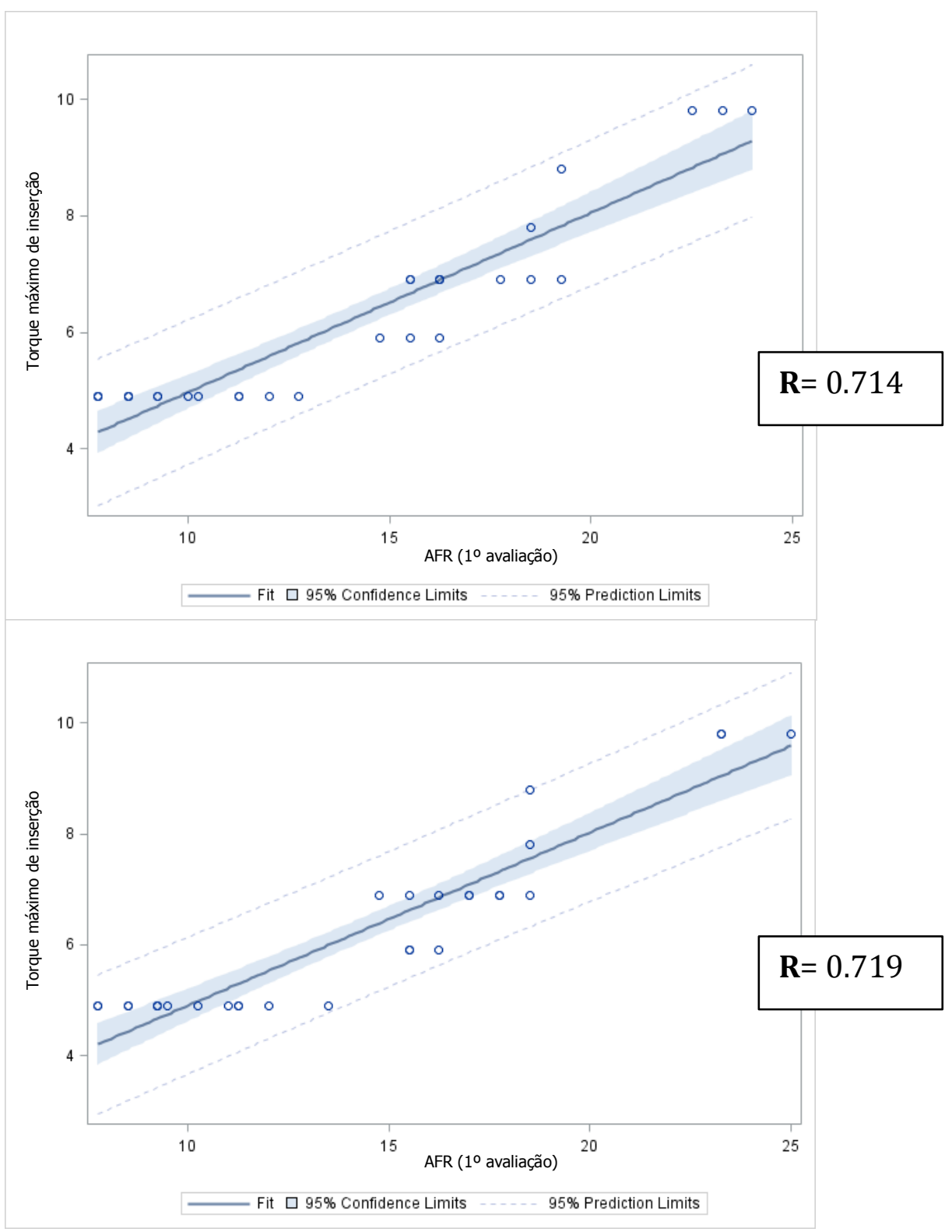

Fonte: Própria (gerada em programa SAS 9.2). 


\subsection{Fluxo dos participantes (diagrama de fluxo, parada antecipada e períodos de tempo)}

Foram recrutados 29 pacientes com planejamento para colocação de MIs (83 MIs no total) os quais aceitaram fazer parte do estudo. É importante lembrar que a nossa unidade amostral no presente estudo foram os MIs. Do total de dispositivos, 10 foram excluídos por não cumprir os critérios de seleção, assim, 73 MIs foram originalmente alocados nos 4 grupos do estudo.

Treze MIs não foram colocados devido a mudança repentina no planejamento ortodôntico dos pacientes ou porque o individuo declinou em participar da pesquisa ou de receber os MIs (após ter aceitado o convite de participação na pesquisa). Além disso, dos 60 MIs colocados, somente 39 receberam a intervenção correspondente ao grupo para o qual foram alocados. Os principais motivos para não ter recebido intervenção aleatória foram: (1) dificuldade para seguir o protocolo de aplicação laser completo; (2) o participante declinou subitamente em participar da pesquisa; (3) o participante não concordou com a designação ao grupo alocado e desistiu de participar ou solicitou o uso de outra intervenção; e, (4) mudança repentina no planejamento ortodôntico, em relação ao protocolo de aplicação de carga. Esses MIs receberam intervenção diferente à designada pela randomização. Ao final, 58 dispositivos receberam intervenção. Desses MIs, 10 não receberam acompanhamento (4 por queda do MI e 6 por falta do paciente à consulta de controle). O grupo 4 foi quem apresentou maior quantidade de dispositivos perdidos (3 quedas). O diagrama de fluxo dos participantes é apresentado na Figura 19.

É importante mencionar que, embora foram 48 os MIs que finalizaram o estudo e contaram com registro dos desfechos (valores ISQ do AFR e TCFC), somente 35 puderam ser avaliados para o deslocamento devido a problemas nas TCFC que serão posteriormente descritas. Isto não aconteceu com o análise da estabilidade pois o registro dos valores ISQ foram obtidos diretamente no paciente. Quarenta e oito MIs foram avaliados para estabilidade e 35 para deslocamento. 
Figura 19 - Diagrama de fluxo dos participantes.

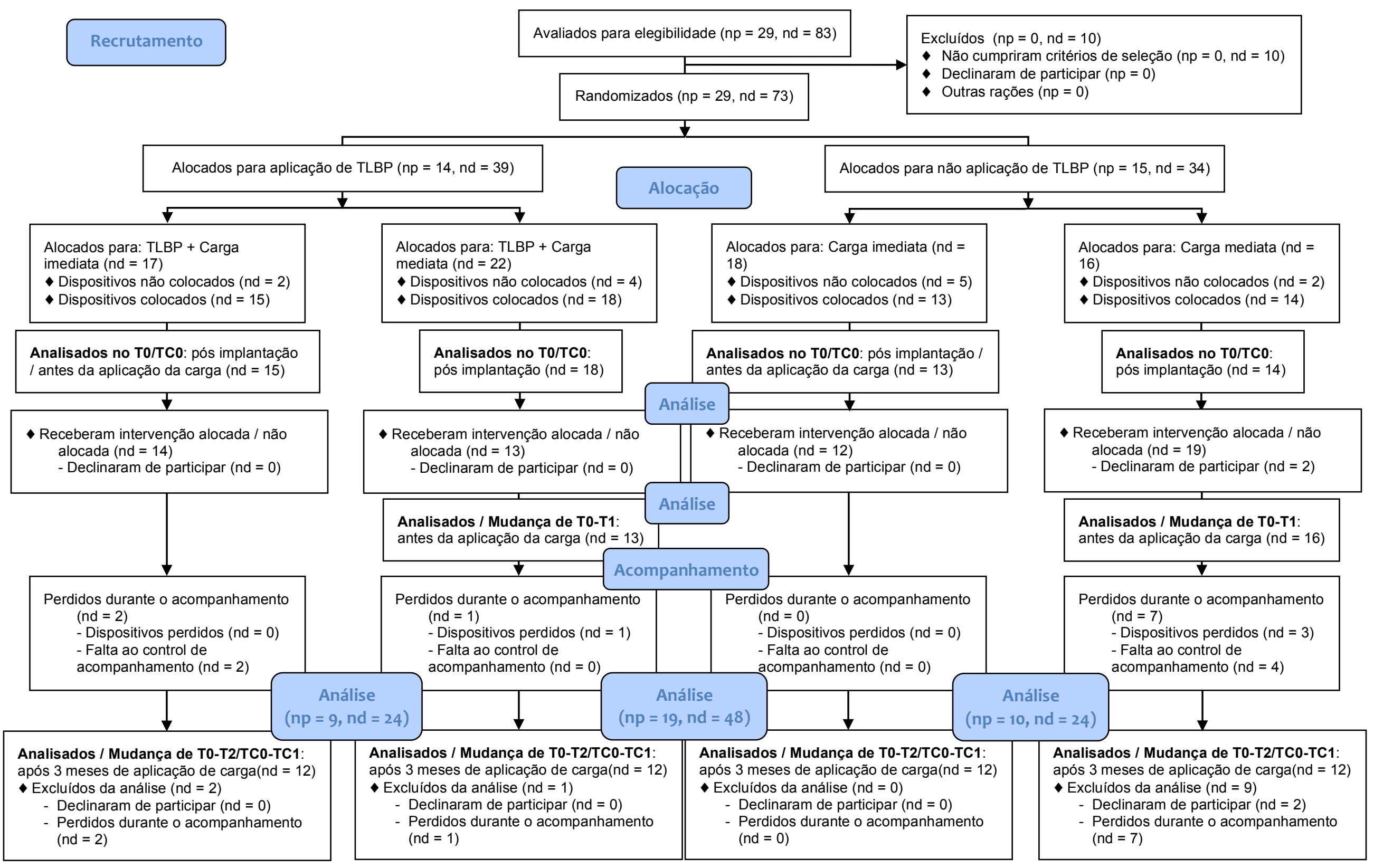

$\mathrm{np}=$ número de pacientes; $\mathrm{nd}$ = número de dispositivos

Fonte: Própria (baseada em CONSORT flow diagram / http://www.consort-statement.org) 


\subsection{Estatística descritiva}

A análise descritiva dos 19 e 16 indivíduos que participaram das avaliações da estabilidade e deslocamento, respectivamente, encontra-se na Tabela 5.

Tabela 5 - Caracterização descritiva dos participantes do estudo.

\begin{tabular}{lcc}
\cline { 2 - 3 } & $\begin{array}{c}\text { Estabilidade } \\
(\mathrm{np}=19, \mathrm{nd}=48)\end{array}$ & $\begin{array}{c}\text { Deslocamento } \\
(\mathrm{np}=16, \mathrm{nd}=35)\end{array}$ \\
\hline Sexo np (\%) & $5(26.3)$ & $3(18.7)$ \\
\hline $\begin{array}{l}\text { Masculino } \\
\text { Feminino }\end{array}$ & $14(73.7)$ & $13(81.3)$ \\
\hline Idade & $18.4(9.7)$ & $17.2(9.4)$ \\
\hline $\begin{array}{l}\text { Média (DP) } \\
\text { Mediana (Q1-Q3) }\end{array}$ & $15(12.5-15)$ & $15(12-15)$ \\
\hline Mini-implantes/pacientes np & $2(10.5)$ & $3(18.7)$ \\
\hline I Mini-implante & $9(47.3)$ & $9(56.3)$ \\
\hline 2 Mini-implantes & $4(21.1)$ & $2(12.5)$ \\
\hline Mini-implantes & $4(21.1)$ & $2(12.5)$ \\
\hline 4 Mini-implantes & & $20(57.1)$ \\
\hline Local de implantação nd (\%) & $24(50)$ & $15(42.9)$ \\
\hline $\begin{array}{l}\text { Maxila } \\
\text { Mandibula }\end{array}$ & $24(50)$ & \\
\hline
\end{tabular}

np: número de pacientes, nd: número de dispositivos

Fonte: Própria.

As características da distribuição dos MIs nos grupos do estudo, segundo sexo, idade e local de implantação estão apresentadas na Tabela 6. Não foram encontradas diferenças estatisticamente significantes entre os grupos para nenhuma das características observadas, tanto para os MIs avaliados para estabilidade como para os avaliados para deslocamento. De forma geral a proporção de MIs colocados em pacientes do sexo feminino foi maior para todos os grupos, enquanto a distribuição segundo local de implantação não seguiu um padrão definido. Não foram encontradas diferenças significantes entre as idades para os grupos avaliados tanto para estabilidade como para deslocamento ( $\mathrm{p}=0.6609$ e $\mathrm{p}=0.2225$, respectivamente), porém, o grupo 3 apresentou idade ligeiramente maior (Tabela 6).

De forma geral e em resumo, pode ser dito que embora não tenha sido possível cumprir a aleatorização programada, os grupos estiveram balanceados segundo as características que inicialmente foram levadas em consideração durante a randomização. 
Tabela 6 - Características da distribuição dos mini-implantes por grupo.

\begin{tabular}{|c|c|c|c|c|c|}
\hline & $\begin{array}{c}\text { Grupo 1 } \\
(\mathrm{TLBP}+\mathrm{CI})\end{array}$ & $\begin{array}{c}\text { Grupo 2 } \\
(\mathrm{TLBP}+\mathrm{CM})\end{array}$ & $\underset{\text { (CI) }}{\text { Grupo } 3}$ & $\begin{array}{c}\text { Grupo } 4 \\
(\mathrm{CM})\end{array}$ & p valor \\
\hline \multicolumn{6}{|c|}{ Analisados para estabilidade } \\
\hline Quantidade de MIs & 12 & 12 & 12 & 12 & \\
\hline \multicolumn{6}{|l|}{ Sexo n (\%) } \\
\hline Masculino & $3(25)$ & $4(33.3)$ & $2(16.7)$ & $3(25)$ & \multirow{2}{*}{0.7910} \\
\hline Feminino & $9(75)$ & $8(66.7)$ & $10(83.3)$ & $9(75)$ & \\
\hline \multicolumn{6}{|l|}{ Idade } \\
\hline Média (DP) & $16.4(6.8)$ & $16.2(4.3)$ & $21.6(13.6)$ & $15.0(3.5)$ & \multirow{2}{*}{0.6609} \\
\hline Mediana $(Q 1-Q 3)$ & $15(12.5-15)$ & $15(13.5-18.5)$ & $18(14-20)$ & $15(12-15)$ & \\
\hline \multicolumn{6}{|c|}{ Local de implantação n (\%) } \\
\hline Maxila & $8(66.7)$ & $5(41.7)$ & $7(58.3)$ & $4(33.3)$ & \multirow{2}{*}{0.3255} \\
\hline Mandíbula & $4(33.3)$ & $7(58.3)$ & $5(41.7)$ & $8(66.7)$ & \\
\hline \multicolumn{6}{|c|}{ Analisados para deslocamento } \\
\hline Quantidade de MIs & 6 & 8 & 12 & 9 & \\
\hline \multicolumn{6}{|l|}{ Sexo n (\%) } \\
\hline Masculino & $1(16.7)$ & $2(25)$ & $2(16.7)$ & 0 & \multirow{2}{*}{0.4132} \\
\hline Feminino & $5(83.3)$ & $6(75)$ & $10(83.3)$ & $9(100)$ & \\
\hline \multicolumn{6}{|l|}{ Idade } \\
\hline Média (DP) & $13.2(1.5)$ & $15.6(4.2)$ & $21.6(13.6)$ & $15.0(4.1)$ & \multirow{2}{*}{0.2225} \\
\hline Mediana (Q1 - Q3) & $12.5(12-15)$ & $15(12-18.5)$ & $18(14-20)$ & $13(12-15)$ & \\
\hline \multicolumn{6}{|c|}{ Local de implantação n (\%) } \\
\hline Maxila & $5(83.3)$ & $5(62.5)$ & $7(58.3)$ & $3(33.3)$ & \multirow{2}{*}{0.2363} \\
\hline Mandíbula & $1(16.7)$ & $3(37.5)$ & $5(41.7)$ & $6(66.7)$ & \\
\hline
\end{tabular}

TLBP: Terapia laser de baixa potência, CI: Carga imediata, CM: Carga mediata.

O teste chi-quadrado e o Teste Kruskal Wallis ou Mann-Whitney foram utilizados para comparação de proporções e medianas, respectivamente.

Fonte: Própria.

A informação relacionada à análise da estabilidade dos dispositivos em T0, T1 e T2 está apresentada na Tabela 7. Embora não foi objetivo do trabalho, as médias de estabilidade (valores ISQ) dos grupos nos diferentes tempos de estudo foram comparadas e não apresentaram-se diferenças estatisticamente significantes entre eles.

Tabela 7 - Estabilidade e mobilidade dos mini-implantes.

\begin{tabular}{cccccc}
\cline { 2 - 5 } & $\begin{array}{c}\text { Grupo 1 } \\
(\mathrm{TLBP}+\mathrm{CI})\end{array}$ & $\begin{array}{c}\text { Grupo 2 } \\
(\mathrm{TLBP}+\mathrm{CM})\end{array}$ & $\begin{array}{c}\text { Grupo 3 } \\
(\mathrm{CI})\end{array}$ & $\begin{array}{c}\text { Grupo 4 } \\
(\mathrm{CM})\end{array}$ & p valor \\
\hline Valores ISQ m (EP) & & & & & \\
$\quad$ Estabilidade T0 & $19.8(0.1)$ & $18.7(1.1)$ & $18.6(1.1)$ & $20.7(0.5)$ & 0.1485 \\
$\quad$ Estabilidade T1 & - & $16.3(1.3)$ & - & $17.5(0.6)$ & 0.4309 \\
Estabilidade T2 & $12.2(1.5)$ & $12.2(1.3)$ & $10.1(1.3)$ & $12.0(0.7)$ & 0.5547 \\
\hline
\end{tabular}

TLBP: Terapia laser de baixa potência, CI: Carga imediata, CM: Carga mediata.

Análise de variância ou teste $t$, foram utilizados para comparação de médias.

Fonte: Própria. 


\subsection{Avaliação dos desfechos}

Os resultados referentes à análise dos desfechos, perda da estabilidade e deslocamento dos MIs, estão apresentados na Tabela 8.

Tabela 8 - Perda de estabilidade e deslocamento nos mini-implantes segundo grupo de estudo.

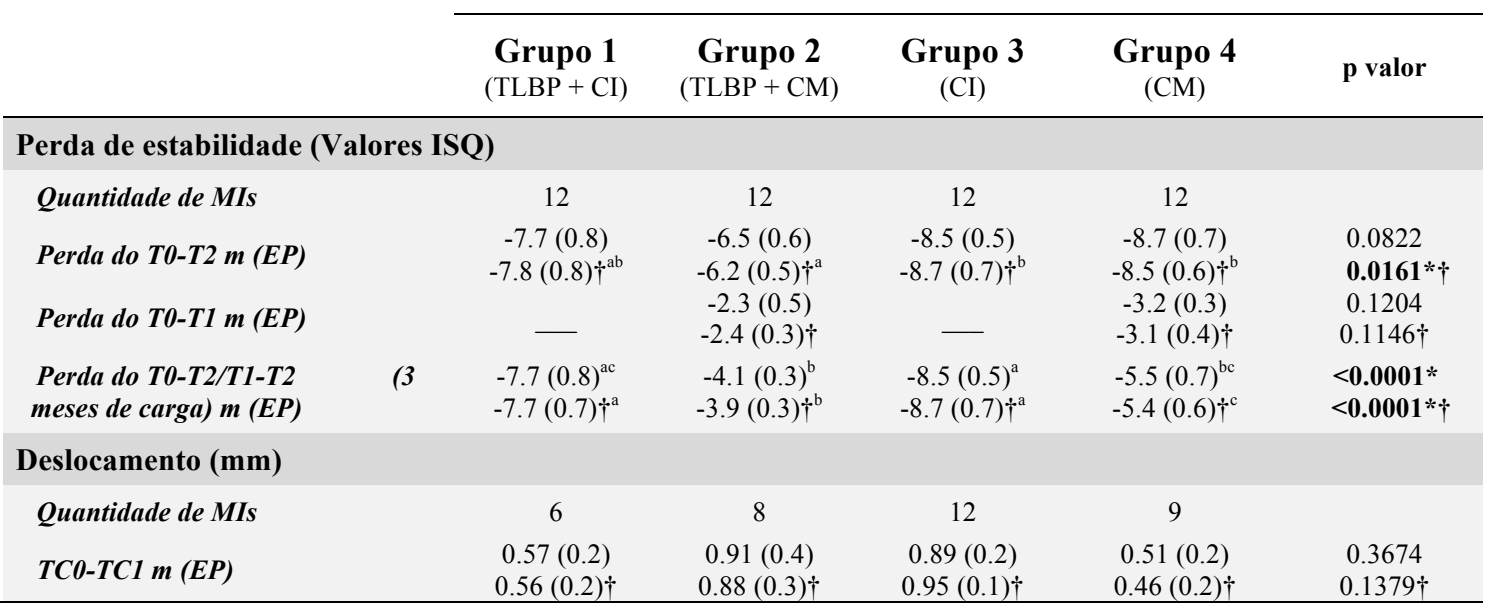

TLBP: Terapia laser de baixa potência, CI: carga imediata, CM: carga mediata.

Análise de variância ou teste $t$, foram utilizados para comparação das médias.

* Diferença estatisticamente significante.

$\uparrow$ Valores e análise ajustado pela idade, sexo e local de implantação.

Letras diferentes indicam diferença estatisticamente significante entre os grupos.

Fonte: Própria.

A análise revelou que houve diferença estatisticamente significante entre os grupos quando comparou-se a perda da estabilidade do T0 para T2. O grupo 2 (TLBP + CM) apresentou a menor perda da estabilidade dos 4 grupos, sendo estatisticamente diferente em relação aos grupos que não receberam TLBP. Não houve diferença estatística significante entre ambos grupos que receberam irradiação laser, porém, o grupo 1 (TLBP + CI) apresentou maior perda quando comparada ao grupo 2 .

Não foram encontradas diferenças estatisticamente significantes entre os grupos 2 e 4 no período de reparo (de T0 para T1). Embora não tenha sido encontrada diferença estatística significante, o grupo 2 (TLBP) apresentou menores valores de perda de estabilidade nesse período (Tabela 8).

Quando foi avaliado somente o período efetivo de aplicação de carga (3 meses para todos os grupos), houve diferença significante entre os grupos, sendo os grupos 2 e 4 (carga mediata) aqueles que apresentaram menor perda de estabilidade. O grupo 2 (TLBP $+\mathrm{CM}$ ) manteve-se como o de menor perda de estabilidade (Tabela 8).

Em relação ao deslocamento, dos 48 MIs que finalizaram o estudo, somente 35 dispositivos foram analisados. As perdas foram devidas aos seguintes motivos: (1) falta 
de qualidade de alguma das imagens tomográficas (inicial ou final), (2) inadequado posicionamento do paciente na tomada das imagens e consequente ausência de pontos de referência, (3) presença de artefatos nas imagens impossibilitando a correta análise e (4) ausência do participante ao controle de acompanhamento marcado para a realização da TCFC. Não foram encontradas diferenças estatísticas significantes entre os grupos do estudo.

Os resultados dos grupos combinados segundo aplicação da TLBP ou protocolo de aplicação de carga estão apresentados na Tabela 9.

Tabela 9 - Perda de estabilidade e deslocamento nos mini-implantes segundo aplicação da TLBP ou protocolo de aplicação de carga.

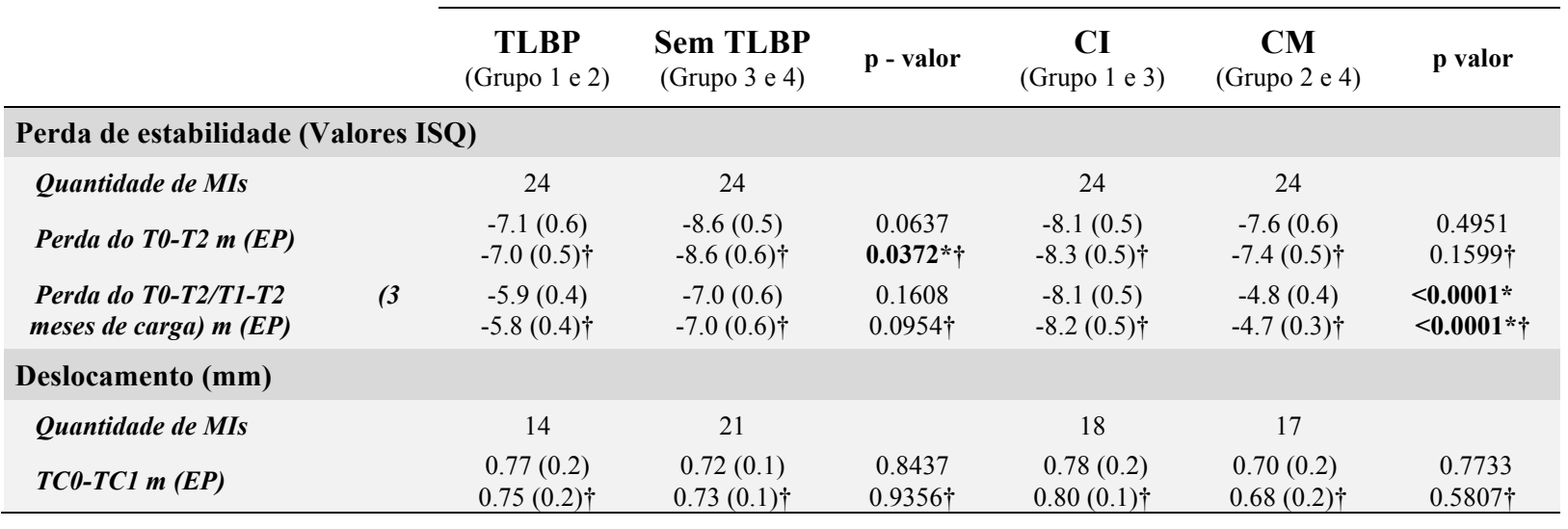

TLBP: Terapia laser de baixa potência, CI: Carga imediata, CM: Carga mediata.

$\mathrm{O}$ teste $\mathrm{t}$ foi utilizado para comparação das médias.

* Diferença estatisticamente significante.

† Valores e análise ajustado pela idade, sexo e local de implantação.

Fonte: Própria.

Quando os dados foram agrupados de acordo à aplicação da TLBP, confirmou-se a diferença existente quando a terapia foi aplicada, em relação à perda da estabilidade de T0 para T2. Os grupos que receberam TLBP (grupos 1 e 2) perderam menos estabilidade do que os grupos que não receberam a terapia (grupos 3 e 4). De igual forma, quando combinaram-se os grupos de acordo ao protocolo de carga, revelou-se diferença estatística significante entre os grupos, sendo que aqueles que receberam carga mediata apresentaram menor perda da estabilidade no período efetivo de aplicação de carga. Em relação ao deslocamento, não foram encontradas diferenças entre os grupos (Tabela 9).

Além do ajuste estatístico realizado, na exploração dos dados foram encontradas interações entre idade e o efeito da TLBP para a perda de estabilidade $(p=0.0008)$ e deslocamento $(p=0.0001)$. Embora, o efeito seja favorável em adolescentes $(p=0.0788)$, o efeito da terapia foi melhor observado em pacientes de maior idade ( $>17$ anos). 
Os dados de estabilidade e deslocamento dos MIs foram correlacionados. Não houve correlação estatística entre a estabilidade inicial dos dispositivos ou a perda de estabilidade durante o estudo com a quantidade do deslocamento dos dispositivos. Os valores de $r$ foram de $0.044(p=0.2485)$ e $0.009(p=0.5035)$, respectivamente.

Figura 20 - Correlação entre estabilidade e deslocamento dos mini-implantes por meio de regressão linear.
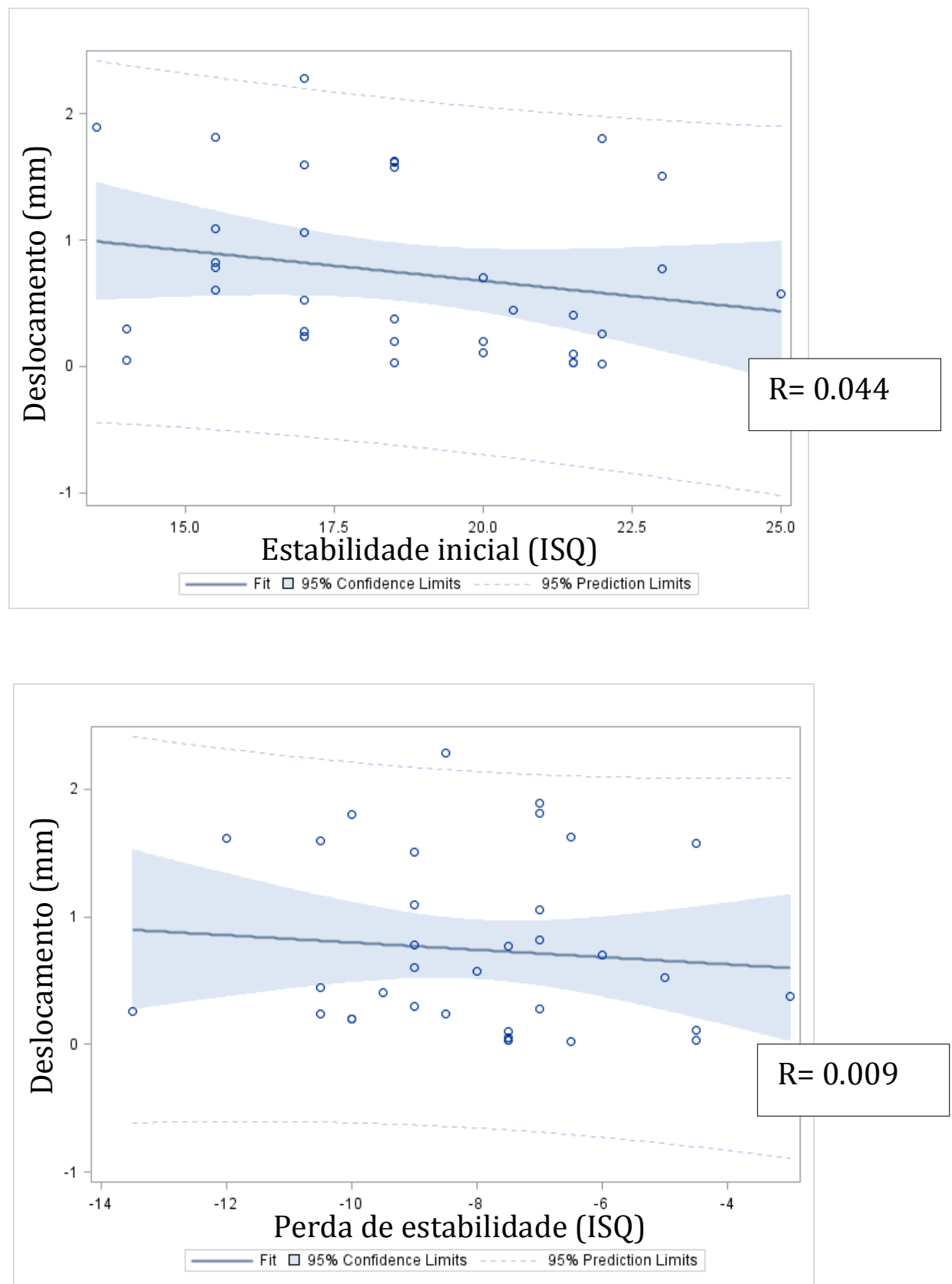

Fonte: Própria (gerada em programa SAS 9.2) 


\subsection{Erro do método}

A correlação intraclasse entre os valores de estabilidade ISQ obtidos nas duas análises (intervalo de 2 semanas) foi quase perfeita $(\mathrm{CCI}=0.997)($ Figura 23).

Figura 21 - Correlação intraclasse entre os valores de estabilidade ISQ da $1^{\circ}$ e $2^{\circ}$ análise (intervalo de duas semanas)

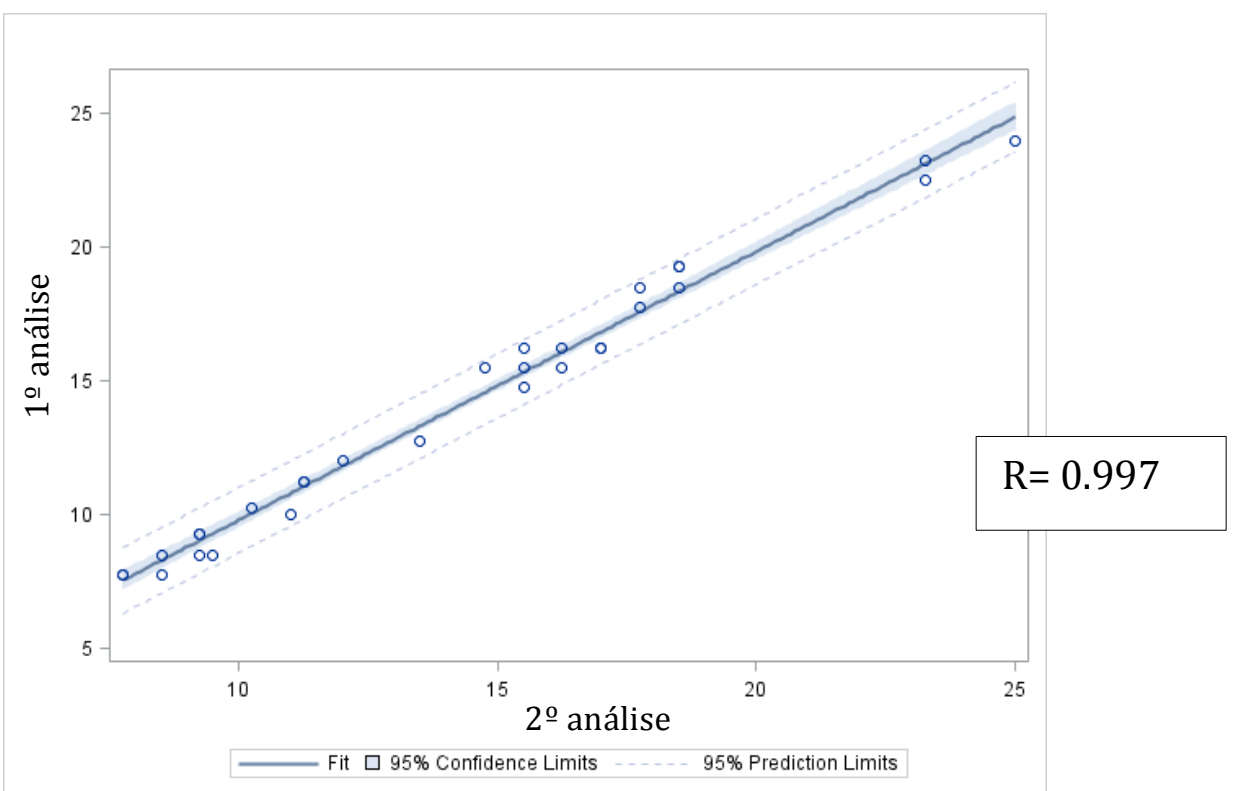

Fonte: Própria (gerada em programa SAS 9.2)

De forma similar, o coeficiente de correlação intraclasse foi muito alto na determinação dos pontos de referência nas imagens tomográficas (3 avaliações com intervalo de 1 semana entre cada uma). Enquanto para os pontos de referência identificados na maxila, os valores do $r$ foram de $0.792-0.997$, de $0.986-1$ e de $0.981-$ 1, para as coordenadas $\mathrm{x}, \mathrm{y}$ e $\mathrm{z}$, respectivamente, para os pontos na mandíbula, os valores do $\mathrm{r}$ foram de $0.987-0.999$, de $0.995-0.999$ e de 0.997 - 1, para as coordenadas $\mathrm{x}$, y e z. Em relação aos pontos identificados nos MIs, os valores do $r$ foram de 0.994 - 1 para todas as coordenadas. 



\section{DisCUSSÃ̃o}





\section{DISCUSSÃO}

Alguns métodos, aparentemente bem sucedidos, têm sido propostos para melhorar a estabilidade dos MIs e/ou reduzir o deslocamento. ${ }^{69-76}$ A TLBP é um desses métodos. ${ }^{77-}$ 80,109 Embora tenha sido demonstrado, principalmente por estudos em animais, o efeito positivo da TLBP na neoformação óssea ao redor dos MIs, ${ }^{78-80}$ aumentando sua estabilidade $^{79}$ e retenção mecânica no tecido ósseo, ${ }^{77}$ ainda são necessários experimentos adequadamente conduzidos e controlados para determinar, não somente seu efeito na estabilidade, mas também no deslocamento em médio e longo prazo.

Originalmente foi idealizado um estudo experimental, mas devido as perdas e dificuldades para seguir com os parâmetros estabelecidos, foi executado um desenho quase-experimental, no qual parte dos MIs não receberam a intervenção designada pela randomização.

Segundo o nosso levantamento bibliográfico, somente um estudo clínico controlado e randomizado foi conduzido com o objetivo de estabelecer o efeito da TLBP na estabilidade dos MIs, ${ }^{109}$ porém ele seguiu metodologia diferente à proposta na presente pesquisa. O estudo citado usou desenho de boca dividida (split-mouth), seguiu outro protocolo de irradiação laser e o método para determinação da estabilidade foi o teste de percussão (Periotest), somente em MIs colocados na maxila. O tempo de acompanhamento estabelecido foi de 60 dias e todos os dispositivos receberam carga duas semanas após implantação. ${ }^{109}$

O presente estudo clínico teve o objetivo de determinar o efeito da TLBP na estabilidade e também no deslocamento de MIs colocados na maxila e mandíbula que receberam carga durante um período de 3 meses, considerando como possível variável o protocolo de aplicação de carga. O desenho metodológico seguido pela presente investigação foi diferente. Embora o desenho de boca dividida é uma metodologia frequentemente utilizada para estudos controlados usando a TLBP, ele pode produzir falsos negativos devido aos efeitos sistêmicos que a terapia produz, i.e., tratar um dos lados da boca pode afetar o lado controle (chamado placebo quando os pacientes são blindados à intervenção). ${ }^{84,114,115}$ Sendo assim, todos os dispositivos implantados no mesmo paciente receberam a mesma intervenção laser na presente pesquisa. A randomização dos MIs levou este fator em consideração e, embora isto não permitiu conseguir alocação balanceada dos grupos segundo quantidade de dispositivos, os grupos ficaram equiparados segundo as características dos pacientes onde cada MI foi colocado. 
Os grupos dos MIs finalmente analisados, mesmo não respeitando totalmente a aleatorização (alocação por conveniência), não apresentaram diferenças estatisticamente significantes (Tabela 6).

$\mathrm{Na}$ tentativa de obter resultados que tenham validade interna, tentou-se controlar algumas variáveis. Alguns estudos têm relatado que a espessura do osso cortical pode ser diferente de acordo com o sexo e idade dos pacientes. ${ }^{116,117}$ Tem sido observado que existe maior perda de MIs em pacientes adolescentes. ${ }^{118}$ A taxa de sucesso dos MIs nesses pacientes é de $60-80 \%$ aproximadamente, ${ }^{119}$ provavelmente devido ao metabolismo ósseo ativo em pacientes ainda em crescimento e ao baixo grau de maturidade óssea. ${ }^{120} \mathrm{O}$ local de implantação (maxila ou mandíbula) apresenta também variação nas características do tecido ósseo. ${ }^{117,121}$ Todas as informações anteriormente mencionadas poderiam consequentemente afetar a estabilidade dos MIs. ${ }^{122}$ Assim, a randomização foi realizada idealmente seguindo um método estratificado por idade e sexo do paciente onde cada dispositivo era colocado, considerando também o local de implantação. De igual forma, tem sido demonstrada a influência que o material ${ }^{123}$ e o desenho do MI, ${ }^{18,30}$ assim como o protocolo cirúrgico utilizado para a colocação dos dispositivos ${ }^{26-28,124}$ podem ter na estabilidade. Na tentativa de controlar isto, o mesmo tipo de MI foi colocado por único operador (FLR) em todos os pacientes, seguindo única técnica de implantação.

Embora o desenho metodológico não tenha respeitado totalmente a aleatorização, os grupos também não apresentaram diferença segundo sexo, idade e local de implantação (Tabela 6). Além disto, a estatística levou em consideração a possível intervenção dessas variáveis e os dados foram ajustados por meio da análise de regressão.

Os dados descritivos revelaram que embora as idades dos participantes tiveram ampla variação (Tabela 5), não foi possível evidenciar diferença estatisticamente significante entre os grupos. Similarmente, não foram evidenciadas diferenças segundo sexo e local de implantação entre os grupos, porém, de forma geral, pode ser dito que os MIs foram colocados majoritariamente no sexo feminino e na maxila.

A retenção dos participantes foi uma dificuldade do presente estudo. Dos 73 MIs (colocados em 29 pacientes) inicialmente aleatorizados, somente 60 chegaram a ser implantados. Desses 60 dispositivos, 58 receberam intervenção (somente 39 receberam a intervenção para a qual foram alocados) e somente 48 concluíram o estudo. A principal perda ocorreu antes de receberem intervenção (início do estudo propriamente dito). Como os pacientes foram selecionados da clínica de pós-graduação em Ortodontia, em 
tratamento, e não exclusivamente para a pesquisa, dificuldades ou imprevistos aconteceram, mesmo que os participantes tenham aceitado colaborar e fazer parte do estudo. Assim, os motivos da dificuldade de retenção dos pacientes (descritos na secção de resultados), não foram possíveis de serem previstas ao início do estudo.

Em relação ao protocolo de irradiação laser escolhido, algumas considerações podem ser discutidas. Apesar de estar comprovado que a TLBP pode estimular osseointegração de biomateriais e pode melhorar o crescimento e recuperação funcional do osso, a literatura é frequentemente controvérsia e carece de precisão na descrição dos protocolos de tratamento. ${ }^{105}$ Torna-se difícil comparar estudos sobre o mecanismo de ação exato da TLBP no tecido ósseo e estabelecer dose correta de irradiação devido aos diferentes modelos experimentais e à diferença na duração das terapias. ${ }^{108,125}$ Experimentos que usaram doses muito baixas ou muito altas de terapia laser têm pouca probabilidade de alcançar os efeitos desejados, pois tem sido comprovado que as respostas biológicas estimuladas pelo laser ocorrem em densidades de energia entre 1.0 e $10 \mathrm{~J} / \mathrm{cm}^{2}{ }^{105}$ Isso ocorre nos estudos na área da Ortodontia utilizando a TLBP. As características dos protocolos de irradiação laser e LED apresentados na literatura para melhorar a estabilidade de MIs estão apresentadas na Tabela 10. Mesmo que esses estudos ${ }^{75-80,109}$ sugiram diferentes protocolos com resultados aparentemente favoráveis, distintos fatores como as metodologias propostas, estudos com animais, variação do local ósseo de implantação, equipamentos diferentes de laser e falta de precisão na descrição exata do protocolo utilizado dificultaram a adequada seleção e replicação de algum protocolo laser para a presente investigação.

Conhecer a energia ou a dose laser (densidade de energia) desejadas e a potência do equipamento, além de definir o tamanho da área a ser irradiada, são fatores determinantes no delineamento do protocolo laser. Os fatores físicos e clínicos da dosimetria utilizada na presente pesquisa (Tabela 2) se basearam na premissa de que melhores resultados de regeneração tecidual são obtidos quando as células estudadas são irradiadas com energia de $1 \mathrm{~J}$ a $4 \mathrm{~J}$, em intervalos de 48 horas e nos estágios iniciais de reparo, iniciando imediatamente após cirurgia. ${ }^{126}$ Revisão da literatura que analisou 137 artigos no total, concluiu segundo a maioria dos trabalhos que, respostas biológicas favoráveis são observadas em densidades de energia (dose laser) entre $1 \mathrm{~J} / \mathrm{cm}^{2}$ e $4 \mathrm{~J} / \mathrm{cm}^{2}$, podendo ser observados resultados positivos com até $10 \mathrm{~J} / \mathrm{cm}^{2}{ }^{105}$ 
Tabela 10 - Características metodológicas e protocolos laser ou LED dos estudos relatados para melhora da estabilidade e/ou osseointegração de MIs.

\begin{tabular}{|c|c|c|c|c|c|c|c|c|}
\hline $\begin{array}{l}\text { Autor/país/ano de } \\
\text { publicação }\end{array}$ & $\begin{array}{l}\text { Tipo de estudo / } \\
\text { Desenho da } \\
\text { pesquisa }\end{array}$ & $\begin{array}{c}\text { Tamanho de } \\
\operatorname{amostra}(\mathbf{M} / \mathrm{F})\end{array}$ & Idade (anos) & Tipo de MI & $\begin{array}{c}\text { Local de } \\
\text { implantação }\end{array}$ & Carga & Desfecho avaliado & $\begin{array}{l}\text { Método de } \\
\text { avaliação }\end{array}$ \\
\hline $\begin{array}{l}\text { Uysal et } \\
\text { al./Turquia/2012 }\end{array}$ & Modelo animal (Coelho) & 15 coelhos / 60 MIs & - & 8 x 1.4 mm; titânio. & Tíbia & 0,150 e $300 \mathrm{cN}$ & Estabilidade & $\begin{array}{l}\text { AFR após inserção, } 21 \\
\text { dias. }\end{array}$ \\
\hline $\begin{array}{l}\text { Omasa et } \\
\text { al./Japão/2012 }\end{array}$ & Modelo animal (Rato) & $\begin{array}{c}30 \text { ratos / } 78 \mathrm{MIs} \\
\text {-14 para análise da } \\
\text { estabilidade (28 MIs). } \\
\text {-16 para análise do RNA } \\
\text { (32 Mis) e avaliação do } \\
\text { osso ao redor dos } \\
\text { dispositivos (18 Mis). }\end{array}$ & - & $\begin{array}{c}28+32 \text { MIs: } 7.3(4 \mathrm{~mm} \\
\text { de roscas) } \times 1.4 \mathrm{~mm} \\
18 \text { Mis: } 3.5(2.5 \mathrm{~mm} \mathrm{de} \\
\text { roscas) } \times 1.5 \mathrm{~mm}\end{array}$ & Tíbia & Não & $\begin{array}{c}\text { Estabilidade } \\
\text { Volume óssea } \\
\text { Expressão gênica de } \\
\text { BMP-2 }\end{array}$ & $\begin{array}{c}\text { Periotest } 7 \text { e } 35 \text { dias } \\
\text { TC microfocal } \\
\text { PCR }\end{array}$ \\
\hline Pinto et al./Brasil $/ 2013^{77}$ & Modelo animal (Coelho) & 16 coelhos / 64 MIs & - & $\begin{array}{l}32 \text { MIs autoperfurantes } \\
\text { e } 32 \text { autoroscantes } \\
\text { cilíndricos: } 9(4 \mathrm{~mm} \text { de } \\
\text { roscas) x } 1.5 \mathrm{~mm} \text {; } \\
\text { alheação de titânio (Ti- } \\
\text { 6Al-4V). }\end{array}$ & Tíbia & $\begin{array}{l}\text { Carga imediata / 200g } \\
\text { durante } 21 \text { dias }\end{array}$ & $\begin{array}{l}\text { Osseointegração } \\
\text { "imbricação" }\end{array}$ & $\begin{array}{l}\text { Teste de tração (Pull- } \\
\text { out). Animais foram } \\
\text { sacrificados aos } 21 \text { dias. } \\
\text { O teste foi aplicado } \\
\text { após mais } 15 \text { dias. }\end{array}$ \\
\hline $\begin{array}{l}\text { Garcez et } \\
\text { al./Brasil/2015 }\end{array}$ & $\begin{array}{l}\text { Modelo animal (Porco) / } \\
\text { Desenho de boca } \\
\text { dividida (Split mouth) }\end{array}$ & 5 porcos / $50 \mathrm{MIs}$ & - & $\begin{array}{l}\text { MIs autoperfurantes; } 6 \text { x } \\
1.6 \text { mm; alheação de } \\
\text { titânia (Ti-6Al-4V). }\end{array}$ & $\begin{array}{c}\text { Região bucal da } \\
\text { mandíbula (20 MIs) } \\
\text { Região palatina no osso } \\
\text { maxilar ( } 30 \mathrm{MIs})\end{array}$ & $\begin{array}{l}\text { Carga imediata / } 250 \mathrm{~g} \\
\text { durante } 3 \text { semanas }\end{array}$ & $\begin{array}{l}\text { Taxa de sucesso } \\
\text { Inflamação e } \\
\text { neoformação óssea }\end{array}$ & $\begin{array}{l}\text { Análise histológico e } \\
\text { microscopia } \\
\text { fluorescente (3 semanas } \\
\text { após implantação) } \\
\text { Inflamação clínica }\end{array}$ \\
\hline $\begin{array}{l}\text { Goymen et } \\
\text { al./Turquia/2015 }\end{array}$ & Modelo animal (Coelho) & 17 coelhos / 68 Mis & - & $\begin{array}{c}\text { Autoperfurantes } \\
\text { cilíndricos; } 8 \text { × } 1.4 \text { mm, } \\
\text { alheação de titânio } \\
\text { (Ti6Al4V) }\end{array}$ & Fíbula & $\begin{array}{l}3 \text { grupos sem aplicação } \\
\text { de carga; e, } 3 \text { grupos } \\
\text { com aplicação de carga } \\
\text { imediata } 150 \mathrm{~g} \text { durante } 4 \\
\text { semanas. }\end{array}$ & $\begin{array}{l}\text { Estabilidade / } \\
\text { Osseointegração }\end{array}$ & $\begin{array}{c}\text { Análise } \\
\text { histomorfomêtrica }\end{array}$ \\
\hline $\begin{array}{c}\text { Ekizer et } \\
\text { al./Turquia/2016 }\end{array}$ & $\begin{array}{c}\text { Estudo clínico } \\
\text { controlado randomizado } \\
\text { / Desenho de boca } \\
\text { dividida (Split-mouth) } \\
\text { duplo cego }\end{array}$ & $\begin{array}{c}20 \text { participantes ( } 7 \mathrm{M}, 13 \\
\text { F) / } 40 \mathrm{MIs}\end{array}$ & $16.77 \pm 1.41$ & $8 \times 1.6 \mathrm{~mm}$ & $\begin{array}{l}\text { Região bucal do osso } \\
\text { alveolar entre o } 2^{\circ} \text { pré- } \\
\text { molar e } 1^{\circ} \text { molar } \\
\text { superior }\end{array}$ & Não especificado & $\begin{array}{l}\text { Taxa de movimentação } \\
\text { ortodôntica } \\
\text { Estabilidade } \\
\text { Expressão de } \\
\text { Interleucina - 1B }\end{array}$ & $\begin{array}{c}\text { Superposição de } \\
\text { modelos 3-dimensionais } \\
\text { RFA } \\
\text { ELISA }\end{array}$ \\
\hline $\begin{array}{c}\text { Osman et } \\
\text { al./Líbano/2017 }\end{array}$ & $\begin{array}{l}\text { Estudo clínico } \\
\text { controlado randomizado } \\
\text { / Desenho de boca } \\
\text { dividida (Split-mouth) }\end{array}$ & $\begin{array}{l}12 \text { participantes ( } 6 \mathrm{M}, 6 \\
\text { F) / } 24 \text { MIs. }\end{array}$ & $14-18$ & - & $\begin{array}{l}\text { Região bucal do osso } \\
\text { alveolar entre o } 2^{\circ} \text { pré- } \\
\text { molar e } 1^{\circ} \text { molar } \\
\text { superior }\end{array}$ & $\begin{array}{l}\text { Carga precoce. } 150 \mathrm{~g} \\
\text { após } 14 \text { dias de } \\
\text { irradiação laser. }\end{array}$ & $\begin{array}{l}\text { Estabilidade e condição } \\
\text { gingival peri-implantar }\end{array}$ & $\begin{array}{c}\text { Periotest após inserção } \\
\text { e após aplicação de } \\
\text { carga ( } 7,14,21,30 \text { e } 60 \\
\text { dias) } \\
\text { Índice gengival }\end{array}$ \\
\hline
\end{tabular}

Fonte: Própria. 
Tabela 10 - Características metodológicas e protocolos laser ou LED dos estudos relatados para melhora da estabilidade e/ou osseointegração de MIs. (Continuação)

\begin{tabular}{|c|c|c|c|c|c|c|c|c|c|c|}
\hline $\begin{array}{l}\text { Autor/país/ } \\
\text { ano de } \\
\text { publicação }\end{array}$ & $\begin{array}{l}\text { Tipo de } \\
\text { Laser }\end{array}$ & $\begin{array}{l}\text { Densidade } \\
\text { de energia } \\
(\mathrm{J} / \mathrm{cm} 2)\end{array}$ & $\underset{(J)}{\text { Energia }}$ & $\begin{array}{c}\text { Potência } \\
(\mathrm{mW})\end{array}$ & $\begin{array}{c}\text { Densidade } \\
\text { de } \\
\text { potencia } \\
(\mathrm{W} / \mathrm{cm} 2) \\
\end{array}$ & $\begin{array}{l}\text { Comprimento } \\
\text { de onda (nm) }\end{array}$ & $\begin{array}{c}\text { Área } \\
\text { irradiada / } \\
\text { tamanho do } \\
\text { ponto } \\
\end{array}$ & $\begin{array}{c}\text { Características da irradiação laser } \\
\text { (contato, tempo de irradiação, } \\
\text { frequiência) }\end{array}$ & Resultados & Conclusão \\
\hline $\begin{array}{l}\text { Uysal et al./ } \\
\text { Turquia / } 2012^{76}\end{array}$ & $\begin{array}{l}\text { LED } \\
\text { (Light- } \\
\text { emitting } \\
\text { diode) }\end{array}$ & - & - & - & 20 & 618 & - & $\begin{array}{l}\text { Irradiação com contato durante } 20 \\
\text { minutos, diariamente por } 10 \text { dias } \\
\text { iniciando imediatamente após cirurgia. }\end{array}$ & $\begin{array}{l}\text { Incremento significativo dos valores ISQ quando luz } \\
\text { LED foi aplicada (valores das medianas): } 0 \mathrm{cN} \\
\text { (+11.63 ISQ), } 150 \mathrm{cN}(+10.50 \text { ISQ), e } 300 \mathrm{cN}(+7.00 \\
\text { ISQ). Foi determinado que os valores ISQ diminuíram } \\
\text { quando a magnitude da carga é acrescentada nos } \\
\text { grupos sem aplicação de luz LED. }\end{array}$ & $\begin{array}{l}\text { LED tem efeitos favoráveis na } \\
\text { retenção de MIs de titânio. }\end{array}$ \\
\hline $\begin{array}{l}\text { Omasa et al./ } \\
\text { Japão / } 2012^{79}\end{array}$ & $\begin{array}{c}\text { Laser } \\
\text { diodo } \\
\text { (GaAlAs) }\end{array}$ & 195 & $\begin{array}{l}54 \text { por } \\
\text { sessão }\end{array}$ & 200 & - & 830 & $\begin{array}{l}4.2 \mathrm{~mm} \\
\text { diâmetro }\end{array}$ & $\begin{array}{c}\text { Irradiação sem contato ( } 1 \mathrm{~mm} \text { afastada } \\
\text { do tecido) com emissão laser continua, } \\
135 \text { segundos em dois pontos nas regiões } \\
\text { mesial e distal do MI, uma vez por dia } \\
\text { durante } 7 \text { dias iniciando imediatamente } \\
\text { após cirurgia. }\end{array}$ & $\begin{array}{l}\text { Os valores PTV foram significativamente menores no } \\
\text { grupo laser. Os valores PTV no dia } 35 \text { foram menores } \\
\text { dos que foram apresentados no dia } 7 \text { para ambos } \\
\text { grupos. O volume ósseo foi maior no grupo laser no } \\
\text { dia } 7 \text {. Similarmente, a expressão de BMP-2 foi maior } \\
\text { no grupo laser tão cedo quanto } 1 \text { dia após TLBP. }\end{array}$ & $\begin{array}{l}\text { A TLBP melhorou a estabilidade } \\
\text { dos MIs e acelerou a formação } \\
\text { óssea por meio da expressão } \\
\text { gênica de BMP-2 pelas células } \\
\text { adjacentes. }\end{array}$ \\
\hline $\begin{array}{l}\text { Pinto et al./ } \\
\text { Brasil / } 2013^{77}\end{array}$ & $\begin{array}{c}\text { Laser } \\
\text { diodo } \\
\text { (GaAlAs) }\end{array}$ & 90 & 2.5 & - & - & 808 & - & $\begin{array}{l}\text { Irradiação em } 2 \text { pontos por } 25 \text { segundos, } \\
\text { externa e internamente na região da tíbia, } \\
\text { por um período de } 21 \text { dias iniciando após } \\
\text { cirurgia e com intervalos de } 48 \text { horas } \\
\text { entre cada aplicação, totalizando } 10 \\
\text { sessões ao final do experimento. }\end{array}$ & $\begin{array}{c}\text { MIs AR } / \text { TLBP }=177.39(24.9) \\
\text { MIs AR } / \text { Sem TLBP }=108.58(17.92) \\
\text { MIs AP TLBP }=137.37(11.78) \\
\text { MIs AP Sem TLBP }=124.63(13.48)\end{array}$ & $\begin{array}{l}\text { TLBP acrescentou a estabilidade } \\
\text { de MIs AR. }\end{array}$ \\
\hline $\begin{array}{l}\text { Garcez et al.// } \\
\text { Brasil / } 2015^{78}\end{array}$ & $\begin{array}{c}\text { Laser } \\
\text { diodo } \\
\text { (InGaAlP) }\end{array}$ & 34 & - & 70 & - & 780 & $\begin{array}{l}0.12 \mathrm{~cm} 2 / \\
0.04 \mathrm{~cm} 2\end{array}$ & $\begin{array}{l}\text { Irradiação sem contato sobre a cabeça do } \\
\text { MI, durante } 1 \text { minuto, após inserção e } \\
\text { semanalmente após reativação da carga. }\end{array}$ & $\begin{array}{l}\text { O grupo laser apresentou menor quantidade de células } \\
\text { inflamatórias e a neoformação óssea foi mais intensa. }\end{array}$ & $\begin{array}{l}\text { Os resultados clínicos mostraram } \\
\text { uma taxa de sucesso do } 60 \% \\
\text { para o grupo controle e do } 80 \% \\
\text { para o grupo tratado com TLBP. }\end{array}$ \\
\hline $\begin{array}{l}\text { Goymen et al./ } \\
\text { Turquia / } 2015^{80}\end{array}$ & $\begin{array}{c}\text { Laser } \\
\text { diodo } \\
(\text { GaAlAs })\end{array}$ & 10 ou 20 & - & 300 & - & 810 & $\Psi^{15.85 \mathrm{~cm} 2}$ & $\begin{array}{l}\text { Emissão laser continua durante } 195 \text { ou } \\
390 \text { segundos por ponto imediatamente } \\
\text { após cirurgia e diariamente por } 10 \text { dias } \\
\text { consecutivos. }\end{array}$ & $\begin{array}{c}\text { BIC/CBT } \\
\text { G1 (sem carga+sem TLBP): } 36.2 / 1.9 \\
\text { G2 (sem carga+TLBP 10J//m2: } 53.9 / 2.0 \\
\text { G3 (Sem carga+TLBP 20J/cm2):64.9/2.2 } \\
\text { G4 (carga+sem TLBP): } 57.2 / 2.0 \\
\text { G5 ( carga+TLBP 10J/cm): } 72.7 / 2.0 \\
\text { G6 (carga+TLBP 20J/cm2): 83.1/2.0 } \\
\text { Não foi detectada correlação substancial entre os } \\
\text { valores do BIC e CBT. }\end{array}$ & $\begin{array}{l}\text { A TLBP melhorou } \\
\text { significativamente os valores do } \\
\text { BIC. A aplicação de carga afetou } \\
\text { positivamente a quantidade do } \\
\text { BIC. A CBT não afetou a } \\
\text { osseointegração dos dispositivos. } \\
\text { Os valores do BIC dos grupos } \\
\text { que receberam TLBP 20J/cm2 } \\
\text { foram maiores do que os outros } \\
\text { grupos. }\end{array}$ \\
\hline $\begin{array}{l}\text { Ekizer et al. / } \\
\text { Turquia / } 2016^{75}\end{array}$ & $\begin{array}{l}\text { LED } \\
\text { (Light- } \\
\text { emitting } \\
\text { diode) }\end{array}$ & - & - & - & 20 & 618 & - & $\begin{array}{c}\text { Emissão transcutanea com a luz LED } \\
\text { posicionada na superfície externa da } \\
\text { bochecha sobre a área do canino e o MI, } \\
20 \text { minutos por dia, durante } 21 \text { dias } \\
\text { consecutivos. }\end{array}$ & $\begin{array}{c}\text { LED/Controle } \\
\text { T0: } 69.05 / 69.21 \\
\text { T1 }\left(1^{\circ} \text { mês): } 69.70 / 68.60\right. \\
\text { T2 }\left(2^{\circ} \text { mês): } 71.75 / 68.35 *\right. \\
\text { T3 ( } 3^{\circ} \text { mês): } 70.85 / 66.55 *\end{array}$ & $\begin{array}{l}\text { LED tem efeito positivo na } \\
\text { estabilidade dos MIs. }\end{array}$ \\
\hline $\begin{array}{l}\text { Osman et al. / } \\
\text { Líbano / } 2017^{109}\end{array}$ & $\begin{array}{l}\text { Laser } \\
\text { diodo }\end{array}$ & - & - & 700 & - & 910 & - & $\begin{array}{l}\text { Irradiação sem contato durante } 60 \\
\text { segundos. } 4 \text { aplicações durante os } \\
\text { primeiros } 14 \text { dias com intervalos de } 72 \\
\text { horas entre cada aplicação. }\end{array}$ & $\begin{array}{l}\text { TLBP/controle } \\
\text { Início: } 1.26 / 2.27 \\
7 \text { dias: } 1.68 / 3.32 \\
14 \text { dias: } 1.19 / 2.97 \\
21 \text { dias: } 2.08 / 3.25 \\
1 \text { mês: } 2.60 / 4.32 \\
2 \text { meses: } 2.02 / 4.29\end{array}$ & $\begin{array}{l}\text { TLBP poderia ser sugerida para } \\
\text { melhorar o sucesso clínico dos } \\
\text { MIs. }\end{array}$ \\
\hline
\end{tabular}

Fonte: Própria. 
Em referência ao tamanho da área irradiada ao redor dos MIs, neste presente estudo ela não foi determinada ao acaso. O comprimento do diâmetro dessa área foi baseado na máxima quantidade possível de deslocamento que os dispositivos podem sofrer de acordo com a literatura (aproximadamente $2.7 \mathrm{~mm}$ ). ${ }^{17}$ Diferentemente da maioria de estudos, a área calculada foi padronizada com o uso de um dispositivo confeccionado e adaptado à ponta ativa do equipamento laser, para manter constante a distância entre a fonte de luz laser e o tecido irradiado (Figura 3).

Cabe mencionar que o sucesso clínico da TLBP também depende do comprimento de onda, duração dos pulsos, tempo de exposição e natureza do tecido irradiado. ${ }^{127}$ Luzes laser com diferentes comprimentos de onda podem penetrar nos tecidos humanos em diferentes profundidades. O laser vermelho penetra em maior profundidade quando comparado com lasers violeta, azul, verde ou amarelo. Luzes infravermelhas e do infravermelho próximo são invisíveis mas tem sido demonstrado que penetram nos tecidos em maior profundidade que a luz vermelha visível. ${ }^{128}$ Tem sido relatado que comprimentos de onda maiores são mais favoráveis para bioestimulação pois são mais resistentes à dispersão e assim penetram mais nos tecidos. ${ }^{129,130}$

Para se obter período pós-operatório mais confortável, ${ }^{131}$ com aceleração do reparo da mucosa recentemente lesada, o tecido pode ser irradiado com emissão laser vermelha $(630-690 \mathrm{~nm})$, energia de $1 \mathrm{~J}$ a $2 \mathrm{~J}$ por ponto e potência do equipamento de 30 - $100 \mathrm{~mW}$, imediatamente após implantação. Durante a primeira semana pós cirúrgica, para melhores resultados de reparo, osseointegração ${ }^{132}$ e biomodulação da inflamação, as irradiações devem ser realizadas com intervalos de dois dias e com emissão laser infravermelha $(780-904 \mathrm{~nm}) .{ }^{126}$ Baseado neste conhecimento, o protocolo deste estudo foi dividido em duas etapas para satisfazer ambos objetivos. Pode observar-se na Tabela 10 que alguns protocolos utilizados em outras pesquisas, foram inadequadamente delineados, explicados e carecem de precisão. Como já foi anteriormente mencionado, torna-se difícil realizar comparações nesse sentido e é quase impossível estabelecer único protocolo para esta indicação. Embora os protocolos apresentados na Tabela 10 sejam diferentes e a maioria deles utilizem doses laser relativamente elevadas, ${ }^{77-80}$ os resultados relatados são favoráveis.

Tradicionalmente, a avaliação da estabilidade dos MIs tem sido equivocadamente reduzida para simples avaliação subjetiva da mobilidade dos dispositivos. Apesar do julgamento clínico ser importante, frequentemente é insuficiente. Alguns métodos tem sido descritos para determinar objetivamente a estabilidade dos MIs, ${ }^{133}$ entre os principais 
estão o torque de inserção ${ }^{134-137}$ e remoção, ${ }^{137-139}$ teste de tração (Pull-out test), ${ }^{77}$ teste de percussão ${ }^{29,36,140}$ e análise de freqüência de ressonância (AFR). ${ }^{16,66,112,113,141}$ Uma vez que a validade do torque para avaliação da estabilidade de implantes e predição do sucesso é ainda controversa ${ }^{136}$ e o teste de percussão é um método de menor precisão, ${ }^{142,143}$ a AFR tem sido sugerida como padrão-ouro para a mensuração da estabilidade clínica. ${ }^{112}$ Além disso, a análise do torque somente pode ser realizada durante os procedimentos de inserção e remoção, não sendo o método mais apropriado para monitorar os MIs durante o uso clínico. Em referência ao teste de percussão (Periotest), embora pareça ter utilidade clínica no registro da estabilidade primária de implantes dentários, ${ }^{144}$ a AFR tem apresentado valores mais confiáveis ${ }^{144}$ e de maior precisão. ${ }^{142}$

Apesar da AFR ter sido inicialmente desenvolvida para mensuração da estabilidade de implantes dentários, este método pode ser utilizado como alternativa viável para aplicação em MIs. ${ }^{112}$ As principais vantagens são: não é invasiva, pode ser aplicada em qualquer momento durante o acompanhamento dos dispositivos, tem habilidade de avaliar o reparo ósseo ao redor dos MIs sem mudar as características mecânicas da interface osso-implante e permite medir quantitativamente in vivo a osseointegração. ${ }^{142-144}$ Embora tenha vantagens, a literatura é ainda controversa referente a previsibilidade do método em relação à osseointegração futura dos dispositivos. ${ }^{145,146}$

Nem todas as marcas comerciais disponíveis de MIs permitem acoplar em sua cabeça o transdutor para aplicar a AFR, sendo assim esse método não tem sido amplamente difundido na prática clínica e na pesquisa científica ortodôntica. Mesmo sendo o método de maior precisão, alguns autores propõem o uso do teste de percussão devido a maior facilidade clínica. ${ }^{142,143,147,148} \mathrm{Na}$ tentativa de utilizar a AFR em MIs, algumas modificações nos dispositivos têm sido desenvolvidas, como: modificações no transdutor Smartpeg, ${ }^{112}$ modificações no desenho de transdutor, ${ }^{149}$ uso de um jig intermediário ou conetor entre o transdutor e o MI ${ }^{141,150}$ ou modificações no desenho do MI. ${ }^{66,151}$ Porém, a maioria dessas tentativas aparentemente não tem sido inseridas na prática clínica, nem replicadas em outras pesquisas.

$\mathrm{Na}$ presente pesquisa foi construído e validado um adaptador personalizado (conector) entre o transdutor e a cabeça do MI. O objetivo da validação foi demonstrar, por meio da comparação da AFR com o torque de inserção, a confiabilidade do método proposto para registrar a estabilidade em diferentes situações, sendo que se o torque de inserção registrava valores maiores de estabilidade, a AFR deveria fazer o mesmo, e viceversa. Tem sido demonstrado que a estabilidade dos MIs varia de acordo à profundidade 
da inserção e comprimento dos dispositivos. ${ }^{27,64,123,135}$ Considerando que a espessura do osso cortical afeta diretamente os valores da estabilidade, ${ }^{34,37,152}$ seja esta registrada pela AFR ou pelo torque de inserção, essas variáveis foram selecionadas como as condições de variação no teste de validação do método. Alta correlação entre os valores de estabilidade de ambas análises foi evidenciada $(\mathrm{r}=0.714$ e $\mathrm{r}=0.719)$. Apesar das limitações do método proposto (valores ISQ baixos em relação aos relatados pela literatura para MI com sistema Smartpeg), ele foi validado para a posterior avaliação clínica.

Os valores ISQ registrados em nossa análise devem ser avaliados com cautela. O equipamento Osstell transforma as frequências de ressonância em stablity quotients de 0 até o 100, sendo que valores maiores indicam maior estabilidade. Os valores ISQ são derivados da rigidez do sistema transdutor/implante/osso e dos parâmetros de calibração do transdutor. Assim, os índices estabelecidos são somente validados para transdutores calibrados para um tipo específico de implante colocados nos maxilares humanos. Tem sido criada uma escala ISQ dos valores recomendados para análise da estabilidade de implantes dentários (Figura 22), ${ }^{153}$ baseada em pesquisas publicadas na área da periodontia, onde valores ISQ menores de 60 são considerados como estabilidade baixa, valores de 60 - 70 como estabilidade intermediária e valores acima de 70 como estabilidade alta. ${ }^{154-158}$ Esses valores não apresentam correlação linear com a micromobilidade do dispositivo, diminuição maior que $50 \%$ na micro mobilidade pode variar para os valores ISQ somente de 60 a $70 .{ }^{159,160}$

Figura 22 - " "The ISQ scale"

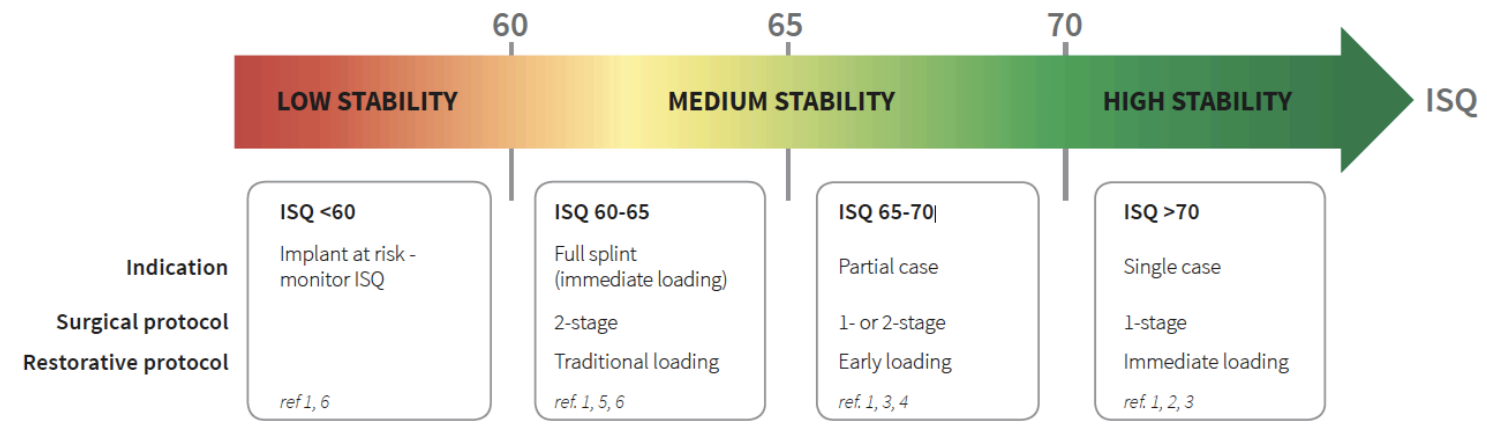

Fonte: https://www.osstell.com/clinical-guidelines/.

Na área da Ortodontia, poucos são os grupos de pesquisa que têm aplicado essa análise para avaliação da estabilidade em MIs. Os valores ISQ encontrados apresentam grande variação e as metodologias para aplicação do mencionado método também são 
diversas. Os valores ISQ encontrados na presente investigação, sejam nos modelos de osso sintético ou nos pacientes, foram baixos $(6.5$ - 25.0) quando comparados com aqueles obtidos por outros estudos. ${ }^{16,64,66,76,112,141,149,161-163}$ Mesmo que a maioria desses estudos apresentaram valores ISQ abaixo de 40, ${ }^{16,64,66,112,161,162}$ alguns mostraram mensurações acima desse valor, ${ }^{76,150,163}$ e inclusive encontraram-se valores ISQ maiores de 70. ${ }^{141,149}$ Como já foi mencionado as metodologias foram diversas. En relação ao modelo ósseo utilizado ou local de implantação, a maioria dos estudos avaliaram a estabilidade de MIs por meio da AFR usando modelos animais, ${ }^{66,76,112,149,150,161}$ alguns usaram osso maxilar e/ou mandibular de cadáveres humanos e MIs colocados em diferentes regiões, ${ }^{141,163}$ outros selecionaram a região medial ou paramedial do palato de pacientes adultos. ${ }^{16,64,162}$ Um deles usou osso artificial (embora tenha relatado valores da AFR em outra unidade de mensuração, $\mathrm{KHz})^{123}$ e outro avaliou MIs implantados na região vestibular do osso alveolar maxilar. ${ }^{75}$ Em referência ao desenho dos MIs, a maioria usou dispositivos de comprimento e diâmetro maior que 8 e $1,5 \mathrm{~mm}$, respectivamente ${ }^{16,64,66,112,161,162}$ enquanto outros utilizaram MIs de tamanho similar ao nosso. ${ }^{76,141,149,150}$ Somente um estudo usou dispositivos de menor comprimento (4 e 6 $\mathrm{mm})$ e diâmetro muito maior $(3.3 \mathrm{~mm}) .{ }^{163}$

Alguns estudos ${ }^{16,64,112,161}$ relataram valores ISQ relativamente constantes com aparente alta reprodutibilidade e que seguiram metodologia definida para aplicação da AFR, local de implantação e tipo de dispositivo utilizado. Isto supõe que os valores obtidos são consideravelmente influenciados pela metodologia utilizada. Porém, isto não impede necessariamente alguma variação nos resultados dos valores ISQ, causada por exemplo, pela mudança no local de implantação. ${ }^{162}$ Atualmente, a metodologia utilizada para realizar a AFR, principalmente para estudos in vitro, é muita cuidadosa e detalhada na tentativa de acrescentar precisão e reprodutibilidade ao método. ${ }^{161}$

É importante mencionar que existe a possibilidade de que o desenho do adaptador desenvolvido para AFR na presente pesquisa possa estar associado com os baixos valores ISQ diferindo de estudos que usaram conector e encontraram valores ISQ altos. ${ }^{141,149} \mathrm{O}$ adaptador proposto pode ter apresentado três principais deficiências: (1) incorporou muitas peças, as quais não favoreceram a formação do sistema transdutor/implante/osso; (2) incrementou o tamanho da porção do mencionado sistema que fica fora do osso durante a análise (conector + cabeça do MI + transdutor propriamente dito) (Figura 9, Figura 14), favorecendo maior freqüência de ressonância devida ao incremento da proporção não balanceada do sistema; e (3) apresentou um ponto de falha nos orifícios 
onde foi inserido o pino de travamento do sistema (Figura 14). Entretanto, devido à falta de transdutores específicos para cada tipo e marca de MI usado na prática clínica e pesquisa, foi utilizado um transdutor originalmente desenvolvido para o uso em implantes e calibrado para dar valores para um dispositivo de outras dimensões (MIs).

Fatores como densidade óssea, tipo de osso (maxila ou mandíbula), comprimento do abutment (pilar, ou transdutor para nossos fins) e comprimento do implante fora do osso (supracristal) parecem influenciar a AFR em implantes dentários. ${ }^{145,164}$ Considerando que uma mudança em qualquer uma das variáveis metodológicas mencionadas acima poderia alterar também os valores ISQ de estabilidade dos MIs, é fácil entender a ampla variação dos valores encontrados e o porque da dificuldade de ainda não se ter desenvolvido escala de valores para MIs.

Os valores ISQ baixos da presente investigação não significam que o método não funcionou, mas sim, que nossos resultados, assim como da maioria dos publicados na literatura, não são comparáveis e devem ser avaliados com cuidado. Cabe ressaltar que o método foi validado, porém, recomenda-se realizar estudos adicionais para padronizar o método de aplicação da AFR em MIs, ou sugere-se a criação de transdutores que permitam aplicar o método a qualquer tipo de MI, de modo que se possa aproveitar nas análises da estabilidade. Existe catálogo da Osstell (marca que tem a patente do equipamento para AFR) com desenhos de transdutores para vários tipos, tamanhos e marcas de implante existentes no mercado. Este método é confiável para ser usado na área da Ortodontia? Realizar a AFR após colocados os MIs apresenta relevância clínica? Outras análises de maior aplicação clínica (teste de percussão) poderiam ser usadas na prática diária e também na pesquisa ortodôntica? Mais pesquisas são necessárias para responder estes questionamentos.

No que se refere ao efeito da TLBP na estabilidade dos MIs, torna-se difícil comparar nossos resultados com outros estudos devido à grande variação nas metodologias que tiveram esse mesmo objetivo (Tabela 10). De forma geral, nossos resultados mostraram que a TLBP tem efeito positivo na estabilidade dos MIs.

Dos estudos mostrados na Tabela 10 que garantiram ter mensurado estabilidade, alguns avaliaram realmente o grau de imbricação óssea, ${ }^{77}$ neoformação óssea ${ }^{78}$ ou a osseointegração por meio de análise histomorfomêtrica da interface osso/dispositivo. ${ }^{80}$ Somente 4 estudos avaliaram a estabilidade dos MIs, ${ }^{75,76,79,109}$ seja por AFR ou teste de percussão. Aqueles dispositivos avaliados por meio do teste de ressonância receberam luz LED e não TLBP. ${ }^{75,76}$ Note-se que estamos considerando para nossa discussão também 
aqueles trabalhos que usaram luz LED, já que tiveram o mesmo objetivo de melhorar a estabilidade dos MIs e também pois o efeito de bioestimulação de ambas terapias é praticamente o mesmo.

Dos estudos que avaliaram a estabilidade dos MIs, aqueles que aplicaram a TLBP tiveram efeito positivo no valores PTV (teste de percussão - Periotest) dos dispositivos tratados em comparação aos controles. ${ }^{79,109}$ Omasa et al. ${ }^{79}$ em estudo animal com ratos encontrou melhora na estabilidade dos MIs, evidenciando-se redução dos valores PTV após 35 dias da implantação dos dispositivos na tíbia dos animais que receberam TLBP, mas sem aplicação de carga. Por outro lado, Osman et al. ${ }^{109}$ em estudo clínico controlado randomizado, usando o mesmo método de avaliação (periotest), embora todos os dispositivos tenham perdido estabilidade durante o acompanhamento (60 dias com aplicação de carga), demonstraram que o grupo tratado com TLBP perdeu menos estabilidade quando comparado ao grupo controle, apesar que esta diferença não foi estatisticamente significante. Nossos resultados corroboram com estes achados. A TLBP não acrescentou estabilidade aos dispositivos em nenhum dos grupos avaliados (todos apresentaram valores da AFR menores do que os iniciais) (Tabela 7), porém quando comparou-se a perda de estabilidade, os grupos que receberam TLBP mostraram menor perda (Tabelas 8 e 9). A diferença encontrada tem relevância clínica devido à tendência dos valores piorem durante o acompanhamento. Considerando que os MIs são, na maioria das vezes, usados por períodos maiores de 3 meses, esta perda de estabilidade deve ser monitorada e controlada.

Dos estudos que avaliaram a estabilidade dos MIs por meio da AFR, Uysal et al. ${ }^{76}$ encontraram ganhos da estabilidade em MIs colocados na tíbia de coelhos (+7.00 +11.63 ISQ) quando luz LED foi aplicada (maior nos grupos sem aplicação de carga). Ocorreu também diminuição da estabilidade nos grupos controle, com maior perda quando a magnitude da carga foi maior durante o período de acompanhamento (21 dias). De forma similar, Ekizer et al. ${ }^{75}$ em estudo clínico controlado e randomizado, relataram ganhos pequenos na estabilidade de MIs durante tempo de acompanhamento de 3 meses com aplicação de carga e de luz LED (de 69.05 para 70.85 ISQ), e perdas leves quando a terapia não foi aplicada (de 69.21 para 66.55 ISQ). Embora as mudanças dos valores ISQ sejam pequenas, a diferença entre ambos os grupos foi estatisticamente significante quando comparados no segundo e terceiro mês de acompanhamento. Esses resultados são contraditórios com os encontrados em nosso estudo, pois embora houveram diferenças leves entre os grupos, sempre existiu perda da estabilidade. 
Dos estudos transversais (sem acompanhamento) o efeito da TLBP (teste de tração, análise histológica ou histomorfomêtrica), os resultados relatados sempre foram positivos, seja na resistência à tração dos dispositivos, ${ }^{77}$ no grau de inflamação e taxa de sucesso $^{78,165}$ ou nas características ósseas ao redor dos dispositivos. ${ }^{80}$ Não foi possível por meio dos métodos utilizados nesses estudos avaliar longitudinalmente a quantidade de perda da estabilidade dos MIs, porém, sempre os grupos que receberam TLBP apresentaram resultados significativamente melhores do que os grupos que não receberam a terapia.

Tem sido demonstrado que a estabilidade dos MIs está sujeita a mudanças durante o processo de reparo e que após diminuição inicial, os valores de estabilidade permanecem estáveis a partir da quarta semana. ${ }^{16,64,65}$ Além disto, tem se recomendado tempo de reparo de 4 semanas antes da aplicação da carga. O nosso desenho de pesquisa incluiu dois protocolos de aplicação de carga diferentes, para determinar qual (carga imediata versus carga mediata) tinha efeitos mais favoráveis quando associado à aplicação da TLBP. Nossos resultados evidenciaram que o grupo laser com aplicação de carga mediata apresentou menor perda de estabilidade, de T0 para T2 (-6.2 ISQ) e também quando foi somente avaliado o tempo efetivo de aplicação da carga (-3.9 ISQ). O grupo sem aplicação laser associado a aplicação de carga imediata apresentou a maior perda de estabilidade para ambos períodos avaliados (-8.7 ISQ). Quando os grupos foram combinados de acordo à aplicação da TLBP, existiu menor perda no grupo laser (-7.0 ISQ) quando comparado ao grupo que não recebeu irradiação laser. Quando avaliou-se somente o tempo efetivo de aplicação da carga, e os grupos foram agrupados de acordo ao protocolo de carga, encontrou-se diferença estatisticamente significante, demonstrando que a carga mediata apresentou menor perda de estabilidade para os dispositivos avaliados (-4.7 ISQ).

É importante mencionar que na análise da perda da estabilidade do T0 para T1 nos grupos de carga mediata ( 2 e 4), mesmo sendo apresentada perda pequena, ambos perderam estabilidade durante o tempo de reparo (4 semanas) antes da aplicação da carga. Porém a perda foi menor no grupo em que foi aplicada a TLBP (-2.4 ISQ) quando comparado ao grupo que não recebeu a TLBP (-3.1 ISQ). Os nossos resultados demonstram que o uso do laser junto à aplicação de carga mediata tem efeitos positivos na estabilidade de MIs.

A maior perda de dispositivos aconteceu no grupo 4 (3 quedas de MIs) (Figura 19). Embora não tenha sido objetivo do presente estudo, pode-se afirmar que até a 
porcentagem de falhas diminui quando a TLBP foi utilizada. Dos 27 MIs que receberam TLBP somente um dispositivo (grupo 2) foi perdido, enquanto que dos 31 MIs que não receberam TLBP, 3 dispositivos (grupo 4) foram perdidos. Isto representou 3,7\% e 9,7\% de falha para cada grupo segundo aplicação da TLBP, respectivamente. De acordo ao relatado na literatura, ${ }^{5}$ a taxa de falha do grupo sem aplicação de laser esteve dentro dos parâmetros estabelecidos (aproximadamente 10\%), enquanto que aplicação laser diminuiu significativamente a porcentagem de perdas.

Em relação à análise do deslocamento dos MIs, não existem estudos prévios que avaliem o efeito da TLBP sobre esta variável. Tem sido confirmado pela literatura que os MIs sofrem deslocamento após aplicação de carga. ${ }^{17} \mathrm{O}$ deslocamento de MIs tem sido avaliado usando diferentes métodos como radiografias cefalométricas, ${ }^{13,33,166-169}$ radiografias oclusais, ${ }^{170}$ tomografias computadorizadas ${ }^{48,171}$ e TCFC. ${ }^{111}$ Embora tenha sido demonstrado que a TCFC seja um método de maior precisão na avaliação do posicionamento de MIs quando comparado com métodos radiográficos, ${ }^{172,173}$ a alta dose de radiação desse exame e o custo são desvantagens que impedem ainda seu uso rotineiro. ${ }^{174}$ Os estudos que avaliaram o posicionamento de MIs por meio de imagens 3dimensionais, usaram escaneamentos da cabeça inteira do paciente ${ }^{48,111,171}$ e doses moderadas de radiação para obter imagens em alta resolução. ${ }^{48,171}$ A presente pesquisa, com um ponto de vista radio-protetor, ${ }^{175}$ usou imagens regionais da maxila, mandíbula ou ambas (FOV reduzido) em baixa resolução. Por isto não foi possível realizar métodos de superposição mais sofisticados ${ }^{48,171,176-178}$ ou realizar sobreposição em estruturas da base do crânio. Foram criados planos 3D baseados em pontos de referência padronizados nos ossos maxilares, para avaliar a distância do MI à cada plano e quantificar a diferença entre a distância inicial e final, de forma similar ao estudo de Alves et al. ${ }^{11}$

Os pontos de referência estáveis selecionados nos ossos maxilar e mandibular foram localizados em estruturas afastadas dos processos alveolares e também estruturas dentárias, partindo do princípio de que o processo de remodelação óssea não seria considerável durante o período de acompanhamento. Devido às dificuldades já mencionadas no capítulo Material e Métodos, somente foi possível trabalhar com o deslocamento do ponto $\mathrm{C}$ dos MIs em direção da carga. Isto não significou grande perda, pois tem sido comprovado que o deslocamento acontece na direção da carga e que os MIs sofrem inclinação ao invés de movimentação de corpo. ${ }^{17}$

Somente foram avaliados 35 dispositivos em relação ao deslocamento e não foram encontradas diferenças estatísticas significantes entre os grupos. O grupo 3, sem 
aplicação da TLBP e com aplicação de carga imediata, apresentou os valores maiores de deslocamento $(0.95 \mathrm{~mm})$. Contrariamente ao esperado, o grupo de aplicação laser e carga mediata, apresentou também grande quantidade de deslocamento $(0.88 \mathrm{~mm})$, embora ele tenha apresentado a menor perda de estabilidade para o presente estudo. Esses valores devem ser avaliados com cuidado pois provavelmente se devem à pouca quantidade de dispositivos analisados.

Os resultados de deslocamento, resultaram em ausência de correlação entre os valores iniciais e a perda de estabilidade, com a quantidade do deslocamento apresentado pelos dispositivos. Embora não tenha sido encontrada correlação entre ambos desfechos, os gráficos (Figura 20) mostraram ligeira associação entre as duas variáveis, quando foram observadas as inclinações das pendentes de correlação. Quanto maior estabilidade inicial, menor a quantidade do deslocamento e quanto maior perda da estabilidade, maior quantidade de deslocamento. Esses resultados demonstram que a nossa hipótese poderia estar certa, e que poderia ter acontecido um erro tipo II (falso positivo) na análise do deslocamento.

Em relação às limitações do presente estudo podem se mencionar as seguintes:

- Deficiências no registro das imagens tomográficas e dificuldades apresentadas durante o acompanhamento do estudo, fizeram que a perda fosse maior para os dispositivos analisados para deslocamento. $\mathrm{O}$ desenho quase-experimental proposto, resolveu essa dificuldade para a análise da estabilidade, acrescentado poder aos testes estatísticos.

- O estudo foi aplicado em pacientes que encontravam-se com tratamento ortodôntico já em andamento; não foram participantes exclusivamente selecionados para a presente pesquisa, por isto esta perda foi difícil de prever.

- Baixa qualidade das imagens tomográficas utilizadas e falta de padronização das TCFC. Sugerem-se testudos posteriores usando TCFC com campos de visão maiores, alta resolução e com sobreposição na base do crânio. 
G.Conchusã̃o 



\section{CONCLUSÃO}

As hipóteses nulas foram parcialmente rejeitadas. A TLBP teve influência na estabilidade mas não no deslocamento dos MIs. O protocolo de irradiação laser proposto diminuiu a perda de estabilidade dos dispositivos.

O protocolo de aplicação de carga teve influência na estabilidade mas não no deslocamento de MIs. A aplicação de carga mediata diminuiu a perda de estabilidade dos dispositivos. A TLBP associada com aplicação de carga mediata apresentou menor perda de estabilidade para os MIs avaliados.

Não foi possível demonstrar correlação entre a estabilidade e a quantidade de deslocamento dos MIs. 

R EFERÊNCIAS 



\section{REFERÊNCIAS}

1.Kanomi R. Mini-implant for orthodontic Anchorage. J Clin Orthod 1997;31(11):763-7.

2.Papadopoulos MA, Tarawneh F. The use of miniscrew implants for temporary skeletal anchorage in orthodontics: A comprehensive review. Oral Surg Oral Med Oral Pathol Oral Radiol Endod 2007;103(5):e6-15.

3.Crismani AG, Bertl MH, Celar AG, Bantleon HP, Burstone CJ. Miniscrews in orthodontic treatment: review and analysis of published clinical trials. Am J Orthod Dentofacial Orthop 2010;137(1):108-13.

4.Reynders R, Ronchi L, Bipatb S. Mini-implants in orthodontics: A systematic review of the literature. Am J Orthod Dentofacial Orthop 2009;135(5):564.e1-19.

5.Schätzle M, Männchen R, Zwahlen M, Lang NP. Survival and failure rates of orthodontic temporary anchorage devices: a systematic review. Clin Oral Implants Res 2009;20(12):1351-9.

6.Antoszewska J, Papadopoulos MA, Park HS, Ludwig B. Five-year experience with orthodontic miniscrew implants: a retrospective investigation of factors influencing success rates. Am J Orthod Dentofacial Orthop 2009;136(2):158.e1-10; discussion 1589.

7.Moon CH, Lee DG, Lee HS, Im JS, Baek SH. Factors associated with the success rate of orthodontic miniscrews placed in the upper and lower posterior buccal region. Angle Orthod 2008;78(1):101-6.

8.Kuroda S, Sugawara Y, Deguchi T, Kyung HM, Takano-Yamamoto T. Clinical use of miniscrew implants as orthodontic anchorage: success rates and postoperative discomfort. Am J Orthod Dentofac Orthop 2007;131(1):9-15.

9.Chen YJ, Chang HH, Huang CY, Hung HC, Lai EH, Yao CC. A retrospective analysis of the failure rate of three different orthodontic skeletal anchorage systems. Clin Oral Implants Res 2007;18(6):768-75.

10. Huja SS. Bone anchors - can you hitch up your wagon? Orthod Craniofac Res 2015;18 Suppl 1:109-16.

11. Ohashi E, Pecho OE, Moron M, Lagravere MO. Implant vs screw loading protocols in orthodontics. Angle Orthod 2006;76(4):721-7.

12. Papageorgiou SN, Zogakis IP, Papadopoulos MA. Failure rates and associated risk factors of orthodontic miniscrew implants: A meta-analysis. Am J Orthod Dentofacial Orthop 2012;142(5):577-95.e7.

13.Liou EJW, Pai BCJ, Lin JCY. Do miniscrews remain stationary under orthodontic forces? Am J Orthod Dentofacial Orthop 2004;126(1):42-7. 
14.Chen J, Esterle M, Roberts WE. Mechanical response to functional loading around the threads of retromolar endosseous implants utilized for orthodontic anchorage: coordinated histomorphometric and finite element analysis. Int $\mathrm{J}$ Oral Maxillofac Implants 1999;14(2):282-9.

15.Saito S, Sugimoto N, Morohashi T, Ozeki M, Kurabayashi H, Shimizu H, et al. Endosseous titanium implants as anchors for mesiodistal tooth movement in the beagle dog. Am J Orthod Dentofacial Orthop 2000;118(6):601-7.

16.Nienkemper N, Wilmes B, Pauls A, Drescher D. Mini-implant stability at the initial healing period. A clinical pilot study. Angle Orthod 2014;84(1):127-33.

17.Nienkemper M, Handschel J, Drescher D. Systematic review of mini-implant displacement under orthodontic loading. Int J Oral Sci 2014;6(1):1-6.

18.Wilmes B, Rademacher C, Olchoff G, Drescher D. Parameters affecting primary stability of orthodontic mini-implants. J Orofac Orthop 2006;67(3):162-74.

19.O'Sullivan D, Sennerby L, Meredith N. Influence of implant taper on the primary and secondary stability of osseointegrated titanium implants. Clin Oral Implants Res 2004;15(4):474-80.

20.Melsen B, Costa A. Immediate loading of implants used for orthodontic anchorage. Clin Orthod Res 2000;3(1):23-8.

21.Martinez H, Davarpanah M, Missika P, Celletti R, Lazzara R. Optimal implant stabilization in low density bone. Clin Oral Implants Res 2001;12(5):423-32.

22.Meredith N. Assessment of implant stability as a prognostic determinant. Int $\mathbf{J}$ Prosthodont 1998;11(5):491-501.

23. Wilmes B, Drescher D. Impact of bone quality, implant type, and implantation site preparation on insertion torques of mini-implants used for orthodontic anchorage. Int $\mathbf{J}$ Oral Maxillofac Surg 2011;40(7):697-703.

24. Kang S, Lee SJ, Ahn SJ, Heo MS, Kim TW. Bone thickness of the palate for orthodontic mini-implant achorage in adults. Am J Orthod Dentofacial Orthop 2007;131(4 Suppl):S74-81.

25. Kim HJ, Yun HS, Park HD, Kim DH, Park YC. Soft-tissue and cortical-bone thickness at orthodontic implant sites. Am J Orthod Dentofacial Orthop 2006;130(2):177182.

26. Romano FL, Consolaro A. Why are mini-implants lost: the value of the implantation technique! Dental Press J Orthod. 2015;20(1):23-9.

27. Wilmes B, Drescher D. Impact of insertion depth and predrilling diameter on primary stability of orthodontic mini-implants. Angle Orthod 2009;79(4):609-14. 
28. Miyawaki S, Koyama I, Inoue M, Mishima K, Sugahara T, Takano-Yamamoto T. Factors associated with the stability of titanium screws placed in the posterior region for orthodontic anchorage. Am J Orthod Dentofacial Orthop 2003;124(4):373-8.

29. Uemura M, Motoyoshi M, Yano S, Sakaguchi M, Igarashi Y, Shimizu N. Orthodontic mini-implant stability and the ratio of pilot hole implant diameter. Eur J Orthod 2012;34(1):52-6.

30. Wilmes B, Ottenstreuer S, Su YY, Drescher D. Impact of implant design on primary stability of orthodontic mini-implants. J Orofac Orthop 2008;69(1):42-50.

31. da Cunha AC, Marquezan M, Lima I, Lopes RT, Nojima LI, Sant'Anna EF. Influence of bone architecture on the primary stability of different mini-implant designs. Am $J$ Orthod Dentofacial Orthop 2015;147(1):45-51.

32. Migliorati M, Drago S, Schiavetti I, Olivero F, Barberis F, Lagazzo A, et al. Orthodontic miniscrews: an experimental campaign on primary stability and bone properties. Eur J Orthod 2015;37(5):531-8.

33. Santiago RC, de Paula FO, Fraga MR, Assis NMSP, Vitral RWF. Correlation between miniscrew stability and bone density in orthodontic patients. Am J Orthod Dentofacial Orthop 2009;136(2):243-50.

34. Vilani GN, Ruellas AC, Mattos CT, Fernandes DJ, Elias CN. Influence of cortical thickness on the stability of mini-implants with microthreads. Braz Oral Res $2015 ; 29(1): 1-7$.

35. Marquezan M, Lau TCL, Mattos CT, da Cunha AC, Nojima LI, Sant'Anna EF, et al. Bone mineral density. Methods of measurement and its influence on primary stability of miniscrews. Angle Orthod 2012;82(1):62-6.

36. Marquezan M, Lima I, Lopes RT, Sant'Anna EF, de Souza MMG. Is trabecular bone related to primary stability of miniscrews? Angle Orthod 2014;84:500-507.

37. Marquezan M, Mattos CT, Sant'Anna EF, de Souza MM, Maia LC. Does cortical thickness influence the primary stability of miniscrews? A systematic review and metaanalysis. Angle Orthod 2014;84(6):1093-103.

38. Marquezan M, de Souza MM, Araújo MT, Nojima LI, Nojima M. Is miniscrew primary stability influenced by bone density? Braz Oral Res 2011;25(5):427-32.

39. Cehreli MC, Karasoy D, Akca K, Eckert SE. Meta-analysis of methods used to assess implant stability. Int J Oral Maxillofac Implants. 2009;24(6):1015-32.

40. Zhang Q, Zhao L, Wu L, Wang $\mathrm{H}$, Zhao Z, Xu Z, et al. The effect of varying healing times on orthodontic mini-implant stability: a microscopic computerized tomographic and biomechanical analysis. Oral Surg Oral Med Oral Pathol Oral Radiol Endod 2011;112(4):423-9.

41. Vande Vannet B, Sabzevar MM, Wehrbein H, Asscherickx K. Osseointegration of 
miniscrews: a histomorphometric evaluation. Eur J Orthod 2007;29(5):437-42.

42. Zhao L, Xu Z, Yang Z, Wei X, Tang T, Zhao Z. Orthodontic mini-implant stability in different healing times before loading: A microscopic computerized tomographic and biomechanical analysis. Oral Surg Oral Med Oral Pathol Oral Radiol Endod 2009;108(2):196-202.

43.Lee YK, Kim JW, Baek SH, Kim TW, Chang YI. Root and bone response to the proximity of a mini-implant under orthodontic loading. Angle Orthod 2010;80(3):452-8.

44. Alves M Jr, Baratieri C, Mattos CT, Araújo MTS, Maia LC. Root repair after contact with mini-implants: systematic review of literature. Eur J Orthod 2013;35(4):491-9.

45. Renjen R, Maganzini AL, Rohrer MD, Prasad HS, Kraut RA. Root and pulp response after intentional injury from miniscrew placement. Am J Orthod Dentofacial Orthop 2009;136(5):708-14.

46.Kuroda S, Yamada K, Deguchi T, Hashimoto T, Kyung HM, Takano-Yamamoto T. Root proximity is a major factor screw failure in orthodontic anchorage. Am J Orthod Dentofacial Orthop 2007;131(4Suppl):S68-73.

47. Janson G, Gigliotti MP, Estelita S, Chiqueto K. Influence of miniscrew dental root proximity on its degree of late stability. Int J Oral Maxillofac Surg 2013;42(4):527-34.

48. Liu H, Lv T, Wang NN, Zhao F, Wang K, Liu D. Drift characteristics of miniscrew and molars for anchorage under orthodontic force: 3-dimensional computed tomography registration evaluation. Am J Orthod Dentofacial Orthop 2011;139(1):e83-9.

49. Frost HM. Bone "Mass" and the "Mechanostat": A proposal. Anat rec 1987;219(1):19.

50. Frost HM. Bone`s mechanostat: a 2003 update. Anat Rec A Discov Mol Cell Evol Biol 2003;275(2):1081-101.

51. Frost HM. Wolff's Law and bone's structural adaptation to mechanical usage: an overview for clinicians. Angle Orthod 1994;64(3):175-88.

52. Frost HM. A 2003 update of bone physiology and Wolff's law for clinicians. Angle Orthod 2004;74(1):3-15.

53. Frost HM. The regional acceleratory phenomenon: a review. Henry Ford Hosp Med J 1983;31(1):3-9.

54. Frost HM. The biology of fracture healing: An overview for clinicians. Part 1. Clin Orthop Relat Res 1989;(248):283-93.

55. Frost HM. The biology of fracture healing: An overview for clinicians. Part II. Clin Orthop Relat Res 1989;(248):294-309.

56. Yaffe A, Fine N, Binderman I. Regional accelerated phenomenon in the mandible 
following mucoperiosteal flap surgery. J Periodontol 1994;65(1):79-83.

57. A Maaitah EF, Safi AAM, Abdelhafez RS. Alveolar bone density changes around miniscrews: A prospective clinical study. Am J Orthod Dentofacial Orthop 2012;142(6):758-67.

58. Enhos S, Veli I, Cakmak O, Ucar FI, Alkan A, Uysal T. OPG and RANKL levels around miniscrew implants during orthodontic tooth movement. Am J Orthod Dentofacial Orthop 2013;144(2):203-9.

59. Chen Y, Kyung HM, Zhao WT, Yu WJ. Critical factors for the success of orthodontic mini-implants: A systematic review. Am J Orthod Dentofacial Orthop 2009;135(3):28491.

60. Oltramari-Navarro PV, Navarro RL, Henriques JF, Cestari TM, Francischone CE, Taga $\mathrm{R}$, et al. The impact of healing time before loading on orthodontic mini-implant stability: A histomorphometric study in mini pigs. Arch Oral Biol 2013;58(7):806-12.

61. Serra G, Morais LS, Elias CN, Meyers MA, Andrade L, Müller CA. Sequential bone healing of immediately loaded mini-implants: histomorphometric and fluorescence analysis. Am J Orthod Dentofacial Orthop 2010;137(1):80-90.

62. Zhang L, Zhao Z, Li Y, Wu J, Zheng L, Tang T. Osseointegration of Orthodontic Micro-screws after Immediate and Early Loading. Angle Orthod 2010;80(2):354-60.

63. Wei X, Zhao L, Xu Z, Tang T, Zhao Z. Effects of cortical bone thickness at different healing times on miniscrew stability. Angle Orthod 2011;81(5):760-6.

64. Nienkemper M, Wilmes B, Pauls A, Drescher D. Impact of mini-implant length on stability at the initial healing period: a controlled clinical study. Head Face Med 2013;9:30.

65. Neinkemper M, Pauls A, Ludwig B, Drescher D. Stability of paramedian inserted palatal mini-implants at the initial healing period: a controlled clinical study. Clin Oral Implants Res 2013;26(8):870-5.

66. Ure DS, Oliver DR, Kim KB, Melo AC, Buschang PH. Stability changes of miniscrew implants over time. A pilot resonance frequency analysis. Angle Orthod 2011;81(6):994-1000.

67. Migliorati M, Drago S, Gallo F, Amorfini L, Dalessandri D, Calzolari C, et al. Immediate versus Delayed loading: comparison of primary stability loss after miniscrew placement in orthodontic patients - a single - centre blinded randomized clinical trial. Eur J orthod 2016;38(6):652-659.

68. Esposito $\mathrm{M}$, Grusovin $\mathrm{MG}$, Maghaireh $\mathrm{H}$, Worthington HV. Interventions for replacing missing teeth: different times for loading dental implants. Cochrane Database Syst Rev 2013;28(3):CD003878.

69. Cuairán C, Campbell P, Kontogiorgos E, Taylor RW, Melo AC, Buschang PH. Local 
application of zoledronate enhances miniscrews implant stability in dogs. Am J Orthod Dentofacial Orthop 2014;145(6):737-49.

70. Miyawaki S, Tomonari H, Yagi T, Kuninori T, Oga Y, Kikuchi M. Development of a novel spike-like auxiliary skeletal anchorage device to enhance miniscrew stability. Am J Orthod Dentofacial Orthop 2015;148(2):338-44.

71.Kim SH, Choi JH, Chung KR, Nelson G. Do sand blasted with large grit and acid etched surface treated mini-implants remain stationary under orthodontic forces? Angle Orthod 2012;82(2):304-12.

72.Miura K, Motoyoshi M, Inaba M, Iwai H, Karasawa Y, Shimizu N. A preliminar study of the effects of low-intensity pulsed ultrasound exposure on the stability of orthodontic miniscrews in growing rats. Eur J Orthod 2014;36(4):419-24.

73.Tabuchi M, Ikeda T, Nakagawa K, Hirota M, Park W, Miyazawa K, et al. Ultraviolet photofunctionalization increases removal torque values and horizontal stability of orthodontic miniscrews. Am J Orthod Dentofacial Orthop 2015;148(2):274-82.

74. Yamazaki M, Yamada M, Ishizaki K, Sakurai K. Ultraviolet-C irradiation to titanium implants increases peri-implant bone formation without impeding mineralization in a rabbit femur model. Acta Odontol Scand 2015;73(4):302-311.

75.Ekizer A, Türker G, Uysal T, Güray E, Tasdemir Z. Light emitting diode mediate photobiomodulation therapy improves orthodontic tooth movement and miniscrew stability: A randomized controlled clinical trial. Lasers in Surgery and Medicine 2016;48(10):936-43.

76. Uysal T, Ekizer A, Akcay H, Etoz O, Guray E. Resonance frequency analysis of orthodontic miniscrews subjected to light-emitting diode photobiomodulation therapy. Eur J Orthod 2012;34(1):44-51.

77.Pinto MR, dos Santos RL, Pithon MM, Araújo MT, Braga JP, Nojima LI. Influence of low-intensity laser therapy on the stability of orthodontic mini-implants: a study in rabbits. Oral Surg Oral Med Oral Pathol Oral Radiol 2013;115(2):e26-e30.

78.Garcez AS, Suzuki SS, Martinez EF, Iemini MG, Suzuki H. Effects of low-intensity laser therapy over mini-implants success rate in pigs. Lasers Med Sci 2015;30(2):727-32.

79.Omasa S, Motoyoshi M, Arai Y, Ejima K, Shimizu N. Low-level laser therapy enhances the stability of orthodontic mini-implants via bone formation related to BMP-2 expression in a rat model. Photomed Laser Surg. 2012;30(5):255-61.

80. Goymen M, Isman E, Taner L, Kurkcu M. Histomorphometric evaluation of the effects of various diode lasers and force levels on orthodontic mini screw stability. Photomed Laser Surg 2015;33(1):29-34.

81. Walsh LJ. The current status of low level laser therapy in dentistry. Part 1. Soft tissue applications. Aust Dent J 1997;42(4):247-54. 
82. Walsh LJ. The current status of low level laser therapy in dentistry. Part 2. Hard tissue applications. Aust Dent J 1997;42(5):302-6.

83.Kasai K, Chou MY, Yamaguchi M. Molecular effects of low-energy laser irradiation during orthodontic tooth movement. Semin Orthod 2015;21(3):203-9.

84.Rodrigo SM, Cunha A, Pozza DH, Blaya DS, Moraes JF, Weber JB, et al. Analysis of the systemic effect of red and infrared laser therapy on wound repair. Photomed Laser Surg 2009;27(6):929-35.

85. Karu T. Photobiology of low-power laser effects. Health Phy 1989;56(5):691-704.

86. Roberts-Harry D. Lasers in orthodontics. Br J Orthod 1994;21(3):308-12.

87. Fornaini C, Merigo E, Vescovi P, Lagori G, Rocca JP. Use of laser in orthodontics: applications and perspectives. Laser Therapy 2013;22(2):115-24.

88. Genovese MD, Olivi G. Use of laser technology in orthodontics: hard and soft tissue laser treatments. Eur J Paediatr Dent 2010;11(1):44-8.

89. Sonesson M, De Geer E, Subraian J, Petrén S. Efficacy of low-level laser therapy in accelerating tooth movement, preventing relapse and managing acute pain during orthodontic treatment in humans: a systematic review. BMC Oral Health. 2016;17(1):11.

90. Xiaoting L, Yin T, Yangxi C. Interventions for pain during fixed orthodontic appliance therapy. A systematic review. Angle Orthod. 2010;80(5):925-32.

91. Shi Q, Yang S, Jia F, Xu J. Does low level laser therapy relieve the pain caused by the placement of the orthodontic separators? - A meta-analysis. Head Face Med 2015;11(1):28.

92. Fujiyama K, Deguchi T, Murakami T, Fujii A, Kushima K, Takano-Yamamoto T. Clinical effect of $\mathrm{CO} 2$ laser in reducing pain in orthodontics. Angle Orthod. 2008;78(2):299-303.

93. Cepera F, Torres FC, Scanavini MA, Paranhos LR, Capelozza Filho L, Cardoso MA, et al. Effect of a low-level laser on bone regeneration after rapid maxillary expansion. Am J Orthod Dentofacial orthop 2012;141(4):444-50.

94. da Silva AP, Petri AD, Crippa GE, Stuani AS, Stuani AS, Rosa AL, et al. Effect of low-level laser therapy after rapid maxillary expansion on proliferation and differentiation of osteoblastic cells. Lasers Med Sci 2012;27(4):777-83.

95. Nascimento LE, Sant'Anna EF, Ruellas AC, Nojima LI, Filho ACG, Freitas AP. Laser versus ultrasound on bone density recuperation after distraction osteogenesis - A cone-beam computed tomograohic analysis. J Oral Maxillofac Surg 2013;71(5):921-8.

96. Kalemaj Z, Debemardl CL, BUti J. Efficacy of surgical and non-surgical interventions on accelerating orthodontic tooth movement: A systematic review. Eur $\mathrm{J}$ Oral Implantol 2015;8(1):9-24. 
97. Gkantidis N, Mistakidis I, Kouskoura T, Pandis N. Effectiveness of non-conventional methods for accelerated orthodontic tooth movement: A systematic review and metaanalysis. J Dent 2014;42(10):1300-19.

98. Long H, Pyakurel U, Wang Y, Liao L, Zhou Y, Lai W. Interventions for accelerating orthodontic tooth movement. A systematic review. Angle Orthod 2013;83(1):164-71.

99. Almeida VL, Gois VL, Andrade RN, Cesar CP, de Albuquerque-Junior RL, Rode S, et al. Efficiency of low-level laser therapy within induced dental movement: A systematic review and meta-analysis. J Photochem Photobiol B 2016;158:258-66.

100. Long H, Zhou Y, Xue J, Liao L, Ye N, Jian F. The effectiveness of low-level laser therapy in accelerating orthodontic tooth movement: a meta-analysis. Lasers Med Sci 2015;30(3):1161-70.

101. Ge MK, He WL, Chen J, Wen C, Yin X, Hu X, et al. Efficacy of low-level laser therapy for accelerating tooth movement during orthodontic treatment: a systematic review and meta-analysis. Lasers Med Sci. 2015;30(5):1609-1618.

102. Carvalho-Lobato P, Garcia VJ, Kasem K, Ustrell-Torrent JM, Tallón-Walton V, Manzanares-Céspedes MC. Tooth movement in orthodontic treatment with low-level laser therapy: A systematic review of Human and Animal Studies. Photomed laser Surg 2014;32(5):302-9.

103. Rossmann JA, Cobb CM. Lasers in periodontal therapy. Periodontol 2000 1995;9:150-64.

104. Amid R, Kadkhodazadeh M, Ahsaie MG, Hakakzadeh A. Effect of low level laser therapy on proliferation and differentiation of cells contributing in bone regeneration. $\mathrm{J}$ Lasers Med Sci 2014;5(4):163-70.

105. Reddy GK. Photobiological basis and clinical role of Low-intensity lasers in Biology and Medicine. J Clin Laser Med Surg 2004;22(2):141-50.

106. Dominguez AC, Castro PZ, Morales MC. Cellular effects related to the clinical uses of laser in orthodontics. The Journal of Oral Laser Applications 2009;9(4):199-203.

107. Dominguez A, Gomez C, Palma JC. Effects of low-level laser therapy on orthodontics: rate of tooth movement, pain and release of RANKL and OPG in GCF. Lasers Med Sci 2015;30(2):915-23.

108. Prados-Frutos JC, Rodriguez-Molinero J, Prados-Privado M, Torres JH, Rojo R. Lack of clinical evidence on low-level laser therapy (LLLT) on dental titanium implant: a systematic review. Lasers Med Sci 2016;31(2):383-92.

109. Osman A, Moneim AA, Harouni NE, Shokry M. Long-term evaluation of the effect of low-level laser therapy on orthodontic miniscrew stability and peri-implant gingival condition: A randomized clinical trial. J World Fed Orthod 2017;6(3):109-14. 
110. Cook TD, Campbell DT, Shadish W. Experimental and quasi-experimental designs for generalized causal inference. Boston: Houghton Mifflin, 2002.

111.Alves M Jr, Baratieri C, Nojima LI: Assessment of mini-implant displacement using cone beam computed tomography. Clin Oral Implants Res 2011;22(10):1151-6.

112. Nienkemper M, Wilmes B, Panayotidis A, Pauls A, Golubovic V, Schwarz F, et al. Measurement of mini-implant stability using resonance frequency analysis. Angle Orthod 2013,83(2):230-8.

113. Meredith N, Alleyne D, Cawley P. Quantitative determination of the stability of the implant-tissue interface using resonance frequency analysis. Clin Oral Implants Res 1996;7(3):261-7.

114. Lee GY, Kim WS. The systemic effect of 830-nm LED phototherapy on the wound healing of burn injuries: A controlled study in mouse and rat models. J Cosmet Laser Ther 2012;14(2):107-10.

115. Coelho RC, Zerbinati LP, de Oliveira MG, Weber JB. Systemic effects of LLLT on bone repair around PLLA-PGA screws in the rabbit tibia. Lasers Med Sci 2014;29(2):703-8.

116. Ono A, Motoyoshi N, Shimizu N. Cortical bone thickness in the buccal posterior region for orthodontic mini-implants. Int J Oral Maxillofac Surg 2008;37(4):334-40.

117. Farnsworth D, Rossouw E, Ceen RF, Buschang PH. Cortical bone thickness at common miniscrew implant placement sites. Am J Orthod Dentofacial Orthop 2011;139(4):495-503.

118. Park HS, Lee SK, Kwon OW. Group distal movement of teeth using microscrew implant anchorage. Angle Orthod 2005;75(4):602-9.

119. Garfinkle JS, Cunningham LL, Beeman CS, Kluemper GT, Hicks EP, Kim MO. Evaluation of orthodontic mini-implant anchorage in premolar extraction therapy in adolescents. Am J Orthod Dentofacial Orthop 2008;133(5):642-53.

120. Motoyoshi M, Matsuoka M, Shimizu N. Application of orthodontic mini-implants in adolescents. Int J Oral Maxillofac Surg 2007;36(8):695-9.

121. Baumgaertel S, Hans MG. Buccal cortical bone thickness for mini-implant placement. Am J Orthod Dentofacial Orthop 2009;136(2):230-5.

122. Motoyoshi M, Uemura M, Ono A, Okazaki K, Shigeeda T, Shimizu N. Factors affecting the long-term stability of orthodontic mini-implants. Am J Orthod Dentofacial Orthop 2010;137(5):588.e1-5; discussion 588-9.

123. Pan C, Chou S, Tseng Y, Yang Y, Wu C, Lan T, et al. Influence of different implant materials on the primary stability of orthodontic mini-implants. Kaohsiung J Med Sci 2012;28(12):673-8. 
124. Woodall N, Tadepalli SC, Qlan F, Grosland NM, Marshall SD, Southard TE. Effect of miniscrew angulation on anchorage resistance. Am J Orthod Dentofacial Orthop 2011;139(2):e147-52.

125. Obradovic RR, Kesic LG, Pesevska S. Influence of low-level laser therapy on biomaterial Osseointegration: a mini-review. Lasers Med Sci. 2009;24(3):447-51.

126. Garcez AS, Ribeiro MS, Núñez SC. Laser de Baixa Potência. Princípios básicos e aplicações clínicas na odontologia. Rio de Janeiro: Elsevier, 2012.

127. Almeida-Lopes L. Laser. J Bras Odontol Clin 1997;1:3-5.

128. Litscher G, Wang L, Schikora D, Rachbauer D, Schwarz G, Ropele S, et al. Biological effects of painless laser needle acupuncture. Medical acupuncture 2004;16(1):24-9.

129. Hayes AM. An experimental study of changes in the mandibular fossa of the rat following unilateral condylectomy. J Can Dent Assoc 1961;27:647-57.

130. Pinheiro AL. Advances and perspectives on tissue repair and healing. Photomed Laser Surg 2009;27(6):833-6.

131. Sakurai Y, Yamaguchi M, Abiko Y. Inhibitory effect of low-level laser irradiation on LPS-stimulated prostraglandin E2 production and cyclooxygenase-2 in human gingival fibroblastos. Eur J Oral Sci 2000;108(1):29-34.

132. Pinheiro AL, Limeira FA, Gerbi ME, Ramalho LM, Marzola C, Ponzi EA, et al. Effect of 830-nm laser light on the repair of bone defects Grafted with inorganic bovine bone and decalcified cortical osseus membrane. J Clin Laser Med Surg. 2003;21(5):3016.

133. Sakin Ç, Ayliker Ö. Techniques to measure miniscrew implant stability. J Orthod Res 2013;1(1):5-10.

134. Motoyoshi M, Hirabayashi M, Uemura M, Shimizu N. Recommended placement torque when tightening an orthodontic mini-implant. Clin Oral Implants Res 2006;17(1):109-14.

135. Lim SA, Cha JY, Hwang CJ. Insertion torque of orthodontic miniscrews according to changes in shape diameter and length. Angle Orthod 2008;78(2):234-40.

136. Reynders R, Ronchi L, Ladu L, Etten-Jamaludin F, Bipat S. Insertion torque and success of orthodontic mini-implants: A systematic review. Am J Orthod Dentofacial Orthop 2012;142(5):596-614.e5.

137. Suzuki EY, Suzuki B. Placement and removal torque values of orthodontic miniscrew implants. Am J Orthod Dentofacial Orthop 2011;139(5):669-78. 
138. Okazaki J, Komasa Y, Sakai D, Kamada A, Ikeo T, Toda I. A torque removal study on the primary stability of orthodontic titanium screw mini-im- plants in the cortical bone of dog femurs. Int J Oral Maxillofac Surg 2008;37(7):647-50.

139. Chen YJ, Chen YH, Lin LD, Yao CC. Removal torque of mini- screws used for orthodontic anchorage. A preliminary report. Int $\mathrm{J}$ Oral Maxillofac Implants 2006;21(2):283-9.

140. Son S, Motoyoshi M, Uchida Y, Shimizu N. Comparative study of the primary stability of self-drilling and self-tapping orthodontic miniscrews. Am J Orthod Dentofacial Orthop 2014;145(4):480-5.

141. Suzuki E, Suzuki B, Harnsiriwattanakit K, Kowanich N. Assessment of Miniscrew Implant Stability by Resonance Frequency Analysis: A Study in Human Cadavers. J Oral Maxillofac Surg 2010;68(11):2682-9.

142. Lachmann S, Laval JY, Jager B, Axmann D, Gomez-Roman G, Groten M, et al. Resonance frequency analysis and damping capacity assessment. Part 2: Peri-implant bone loss follow-up. An in vitro study with the periotest and osstell instruments. Clin Oral Implants Res 2006;17(1):80-4.

143. Zix J, Hug S, Kessler-Liechti G, Mericske-Stern R. Measurement of dental implant stability by resonance frequency analysis and damping capacity asessment: Comparison of both techniques in a clinical trial. Int J Oral Maxillofac Implants 2008;23(3):525-30.

144. Lachmann S, Jäger B, Axmann D, Gomez-Roman G, Groten M, Weber H. Resonance frequency analysis and damping capacity assessment. Part I: an in vitro study on measurement reliability and a method of comparison in the Determination of primary implant stability. Clin Oral Implants Res 2006;17(1):75-9.

145. Manzano-Moreno FJ, Herrera-Briones FJ, Bassam T, Vallecillo-Capilla MF, ReyesBotella C. Factors affecting dental implant stability measured using the ostell mentor device: A systematic review. Implant Dent 2015;24(5):565-77.

146. Atieh MA, Alsabeeha NH, Payne AG. Can resonance frequency analysis predict failure risk of immediately loaded implants? Int J Prosthodont 2012;25(4):326-39.

147. Winter W, Mohrle S, Holst S, Karl M. Parameters of implant stability measurements based on resonance frequency and damping capacity: A comparative finite element analysis. Int J Oral Maxillofac Implants 2010;25(3):532-9.

148. Oh JS, Kim SG, Lim SC, Ong JL. A comparative study of two noninvasive techniques to evaluate implant stability:Periotest and osstell mentor. Oral Surg Oral Med Oral Pathol Oral Radiol Endod 2009;107(4):513-8.

149. Su Y, Wilmes B, Hönscheid R, Drescher D. Application f a Wireless Resonance Frequency transducer to assess primary stability of orthodontic mini-implants: An in vitro study in Pig ilia. Int J Oral Maxillofac Implants 2009;24(4):647-54. 
150. Kim J, Baek S, Kim T, Chang Y. Comparison of stability between cylindrical and conical type mini-implants. Mechanical and histologic properties. Angle Orthod 2008;78(4):692-8.

151. Veltri M, Balleri B, Goracci C, Giorgetti R, Balleri P, Ferrari M. Soft bone primary stability of 3 different miniscrews for orthodontic anchorage: A resonance frequency investigation. Am J Orthod Dentofacial Orthop 2009;135(5):642-8.

152. Song Y, Cha J, Hwang C. Mechanical characteristics of various orthodontic miniscrews in relation to artificial cortical bone thickness. Angle Ortho 2007;77(6):979-85.

153. www.osstell.com O. Clinical Guidelines - Osstell - Implant Stability. [Internet]. Osstell - Implant Stability. 2018 [cited 15 January 2018]. Available from: https://www.osstell.com/clinical-guidelines/

154. Sennerby L. 20 years of experience with the resonance frequency analysis. Implantologie 2013;21(1):21-33.

155. Kokovic V, Jung R, Feloutzis A, Todorovic VS, Jurisic M, Hämmerle CHF. Immediate vs. early loading of SLA implants in the posterior mandible: 5-year results of randomized controlled clinical trial. Clin Oral Implants Res 2014;25(2):e114-9.

156. Bornstein MM, Hart CN, Halbritter SA, Morton D, Buser D. Early loading of nonsubmerged titanium implants with a chemically modified sand-blasted and acidetched surface: 6-month results of a prospective case series study in the posterior mandible focusing on peri-implant crestal bone changes and implant stability quotient (ISQ) values. Clin Implant Dent Relat Res 2009;11(4):338-47.

157. Ostman PO, Hellman M, Sennerby L. Direct implant loading in the edentulous maxilla using a bone density-adapted surgical protocol and primary implant stability criteria for inclusion. Clin Implant Dent Relat Res 2005;7 Suppl 1:S60-9.

158. Rodrigo D, Aracil L, Martin C, Sanz M. Diagnosis of implant stability and its impact on implant survival: a prospective case series study. Clin Oral Implants Res 2010;21(3):255-61.

159. Pagliani L, Sennerby L, Petersson A, Verrocchi D, Volpe S, Andersson P. The relationship between resonance frequency analysis (RFA) and lateral displacement of dental implants: an in vitro study. J Oral Rehabil 2013;40(3):221-7.

160. Trisi P, Carlesi T, Colagiovanni M, Perfetti G. Implant stability quotient (ISQ) vs direct in vitro measurement of primary stabilty (micromotion): effet of bone density and insertion torque. Journal of Osteology and Biomaterials 2010;1(3):141-51.

161. Nienkemper M, Santel N, Hönscheid R, Drescher D. Orthodontic mini-implant stability at different insertion depths. Sensitivity of three stability measurement methods. J Orofac Orthop 2016;77(4):296-303. 
162. Nienkemper M, Pauls A, Ludwig B, Drescher D. Stability of paramedian inserted palatal mini-implants at the initial healing period: a controlled clinical study. Clin Oral Impl Res 2015;26:870-5.

163. Gedrange T, Hietschold V, Mai R, Wolf P, Nicklisch M, Harzer W. An evaluation of resonance frequency analysis for the Determination of the primary stability of orthodontic palatal implants. A study in human cadavers. Clin oral Impl Res 2005;16(4):425-31.

164. Aparicio C, Lang NP, Rangert B. Validity and clinical significance of biomechanical testing of implant/bone interface. Clin Oral Implants Res 2006;17(Suppl. 2):2-7.

165. Yanaguizawa MS, Suzuki SS, Martinez EF, Suzuki H, Pelegrin MC, Garcez AS. Effects of Low-level laser therapy in orthodontic patients on immediate inflammatory response after mini-implants insertion: a preliminary report. Photomed Laser Surg 2017;35(1):57-63.

166. Kinzinger G, Gulden N, Yildizhan F, Hermanns-Sachweh B, Diedrich P. Anchorage efficacy of palatally-inserted miniscrews in molar distalization with a periodontally/miniscrew-anchored distal jet. J Orofac Orthop. 2008;69(2):110-20.

167. Hedayati Z, Hashemi SM, Zamiri B, Fattahi HR. Achorage value of surgical titanium screws in orthodontic tooth movement. Int $J$ Oral Maxillofac Surg. 2007;36(7):588-92.

168. Wehrbein H, Göllner P. Do palatal implants remain positionally stable under orthodontic load? A clinical radiologic study. Am J Orthod Dentofacial Orthop. 2009;136(5):695-9.

169. Lifshitz AB, Munoz M. Evaluation of the stability of self-drilling mini-implants for maxillary Anchorage under immediate loading. World J Orthod. 2010;11(4):352-6.

170. Calderon JH, Valencia RM, Casasa AA, Sánchez MA, Espinosa R, Ceja I. Biomechanical Anchorage evaluation of mini-implants treated with sandblasting and acid etching in Orthodontics. Implant Dent 2011;20(4):273-9.

171. El-Beialy AR, Abou-El-Ezz AM, Attia KH, El-bialy AM, Mostafa YA. Loss of Anchorage of miniscrews: A 3-dimensional assesment. Am J Orthod Dentofacial Orthop. 2009;136(5):700-7.

172. Abbassy MA, Sabban HM, Hassan AH, Zawawi KH. Evaluation of mini-implant sites in the posterior maxilla using traditional radiographs and cone-beam computed tomography. Saudi Med J. 2015;36(11):1336-41.

173. Watanabe $\mathrm{H}$, Deguchi $\mathrm{T}$, Hasegawa $\mathrm{M}$, Ito $\mathrm{M}$, Kim S, Takano-Yamamoto $\mathrm{T}$. Orthodontic miniscrew failure rate and root proximity, insertion angle, bone contact length, and bone density. Orthod Craniofac Res. 2013;16(1):44-55.

174. American Academy of oral and Maxillofacial Radiology. Clinical recommendations regarding use of cone beam computed tomography in orthodontics. Position statement by 
the American Academy of Oral and Maxillofacial Radiology. Oral Surg Oral Med Oral Pathol Oral Radiol 2013;116(2):238-57.

175. Lorenzoni DC, Bolognese AM, Garib DG, Guedes FR, Sant'Anna EF. Cone-beam computed tomography and radiographs in dentistry: Aspects related to radiation dose. Int J Dent 2012;2012:813768.

176. Cevidanes LHC, Heymann G, Cornelis MA, DeClerck HJ, Tulloch JFC. Superimposition of 3-dimensional cone-beam computed tomography models of growing patients. Am J Orthod Dentofacial Orthop 2009;136(1):94-9.

177. Cevidanes LHS, Styner MA, Proffit WR. Image analysis and superimposition of 3dimensional cone-beam computed tomography models. Am J Orthod Dentofacial Orthop 2006;129(5):611-8.

178. Ruellas AC, Yatabe MS, Souki BQ, Benavides E, Nguyen T, Luiz RR, et al. 3D Mandibular superimposition: Comparison of regions of reference for voxel-based registration. PloS one 2016;11(6):e0157625. 
AnExos 

ANEXO A - Parecer do Comitê de Ética em Pesquisa.

\section{FACULDADE DE ODONTOLOGIA DE RIBEIRÃO PRETO/ FORP/ USP}

\section{PARECER CONSUBSTANCIADO DO CEP}

DADOS DO PROJETO DE PESQUISA

Título da Pesquisa: AVALIAÇÃO DA INFLUÊNCIA DO LASER DE BAIXA POTÊNCIA NA ESTABILIDADE E NO DESLOCAMENTO DE MINI-IMPLANTES ORTODÔNTICOS COM APLICAÇÃO DE FORÇA MEDIATA E IMEDIATA

Pesquisador: Fábio Lourenço Romano

Área Temática:

Versão: 2

CAAE: 56108316.0 .0000 .5419

Instituição Proponente: Universidade de Sao Paulo

Patrocinador Principal: Financiamento Próprio

DADOS DO PARECER

Número do Parecer: 1.612 .992

Situação do Parecer:

Aprovado

Necessita Apreciação da CONEP:

Não

RIBEIRAO PRETO, 29 de Junho de 2016

Assinado por:

Simone Cecilio Hallak Regalo

(Coordenador) 
ANEXO B - Registro no site ClinicalTrials.gov

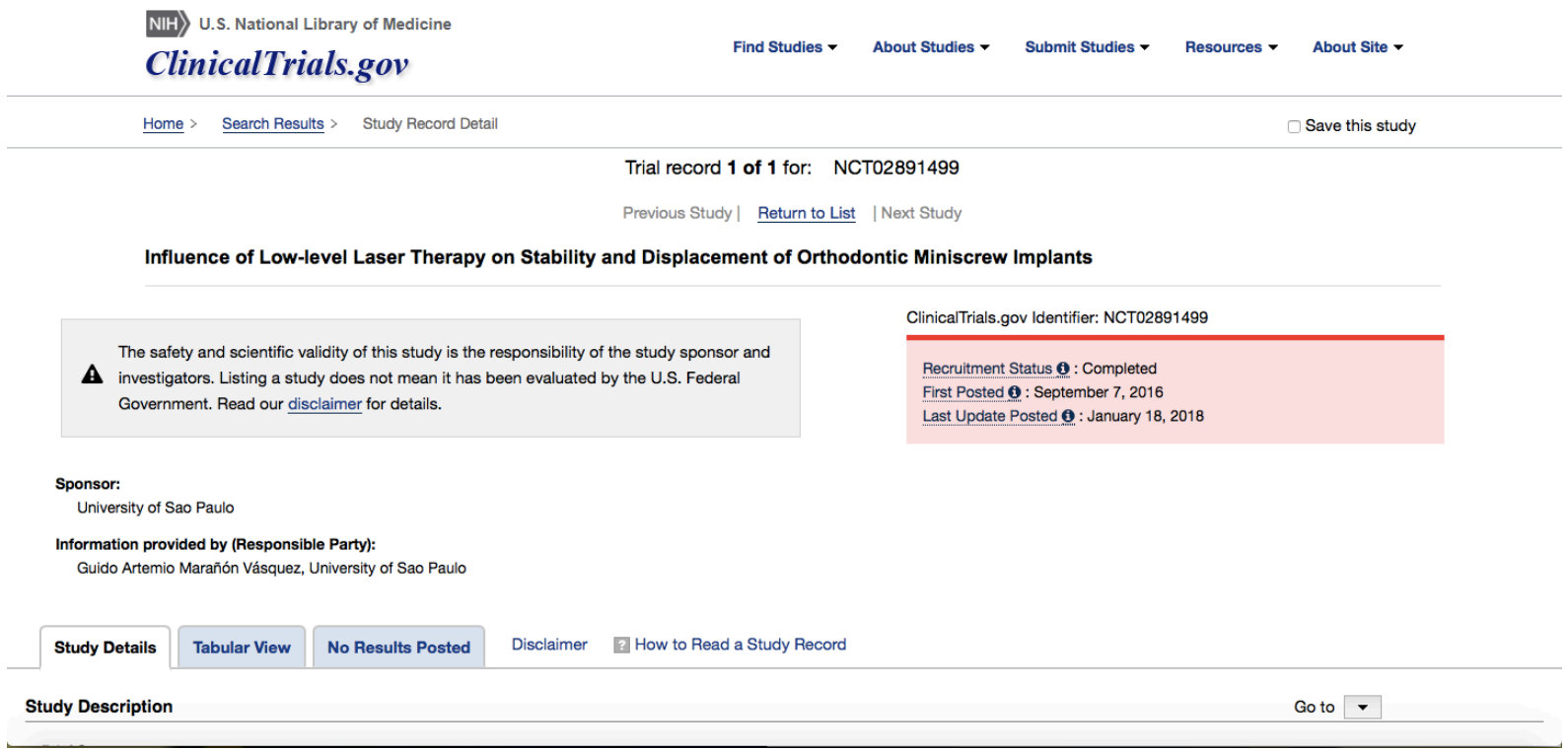


ANEXO C - Protocolo (versão inicial) registrado no site ClinicalTrials.gov

\section{ClinicalTrials. gov PRS}

Protocol Registration and Results System

\section{ClinicalTrials.gov PRS DRAFT Receipt (Working Version)}

Last Update: 08/31/2016 21:38

\section{ClinicalTrials.gov ID: NCT02891499}

\section{Study Identification}

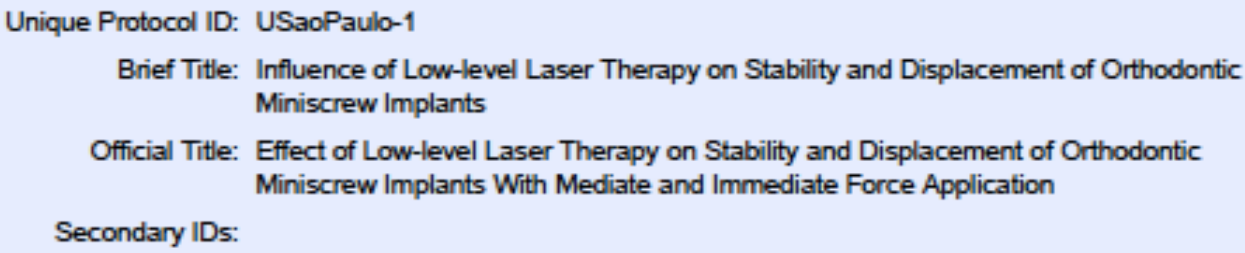

Official Title: Effect of Low-level Laser Therapy on Stability and Displacement of Orthodontic Miniscrew Implants With Mediate and Immediate Force Application

Secondary IDs:

\section{Study Status}

Record Verification: August 2016

Overall Status: Active, not recruiting

Study Start: March 2016

Primary Completion: November 2016 [Anticipated]

Study Completion: November 2016 [Anticipated]

\section{Sponsor/Collaborators}

Sponsor. University of Sao Paulo

Responsible Party: Principal Investigator

Investigator. Guido Artemio Marañón Vásquez [gvasquez]

Official Title: Master of science student

Affiliation: University of Sao Paulo

Collaborators:

\section{Oversight}

FDA Regulated?: No

IND/IDE Protocol?: No

Review Board: Approval Status: Approved

\section{Approval Number: 56108316.0.0000.5419}

Board Name: Ethics Committee of the School of dentistry of Ribeirão Preto

Board Affiliation: Ethics Committee of the School of dentistry of Ribeirão Preto

Phone: (16) 3315-0493

Email: cep@forp.usp.br

Data Monitoring?: No

Plan to Share Data?: 0 -NOTE : Plan to Share Data?: data not entered. 
Oversight Authorities: Brazil: National Committee of Ethics in Research

Brazil: Ethics Committee

\section{Study Description}

Brief Summary: The purpose of this study is to evaluate the effect of Low level laser therapy on stability and displacement of orthodontic miniscrew implants using two different force application protocols.

Detailed Description: The aim of this study is to evaluate the effect of Low level laser therapy (LLLT) on stability and displacement of orthodontic miniscrew implants with mediate and immediate force application. They will be assessed 48 miniscrew implants placed in patients in orthodontic treatment at the postgraduate clinical in Orthodontics, at School of Dentistry of Ribeirão Preto, University of São Paulo. They will be randomly divided into 4 groups: 1- LLLT and immediate force application; 2- LLLT and force application 4 weeks after implantation; 3 -immediate force application without LLLT and 4 - force application 4 weeks after implantation without LLLT. Orthodontic force of $150 \mathrm{gF}$ will be applied for 3 months. A low power laser device Therapy XT with a wavelength of $650 \mathrm{~nm}$ and output of $100 \mathrm{~mW}$ immediately after implantation (energy density. $2 \mathrm{~J} / \mathrm{cm} 2$ ). and $808 \mathrm{~nm}$ with $100 \mathrm{~mW}$ (energy density. $4 \mathrm{~J} / \mathrm{cm} 2$ ), every 48 hours for two weeks in the following applications will be used. The stability will be assessed using Resonance Frequency Analysis (RFA) at three times: the implantation day (T1), one month (T2) and after 3 months of force application (T3). Stability measures will be evaluated in Implant Stability Quotient (ISQ). To assess the amount of miniscrew implant displacement, it will be used Cone Beam Computed Tomography (CBCT) at the beginning (CT1) and final of the application of orthodontic force (CT2). Three-dimensional models will be created in specific programs to compare the distance in millimeters of reference planes in the maxilla and mandible to the mini-implant in CT1 and CT2. The evaluation will be carried out in three points: head of miniscrew implant (point C). thread (point R) and apex of miniscrew implant (point A). The results will be statistically analyzed according to nature of the data and the significance level to be adopted will be $5 \%$.

\section{Conditions}

Conditions: Displacement of Other Bone Devices, Implants and Grafts Mechanical Complication of Other Bone Devices, Implants and Grafts

6. NOTE : Condition Mechanical Complication of Other Bone Devices, Implants and Grafts should have no more than 60 characters.

Keywords: Miniscrews

Mini-implants

Temporal anchorage devices

Bone screws

Stability

Displacement

Low-level laser therapy

Cone-beam computed tomography

Resonance frequency analysis

Orthodontic

Orthodontic miniscrew implant

\section{Study Design}

Study Type: Interventional

Primary Purpose: Supportive Care 
Study Phase: N/A

Intervention Model: Parallel Assignment

Number of Arms: 4

Masking: Single Blind (Outcomes Assessor)

Allocation: Randomized

Endpoint Classification: Efficacy Study

Enrollment: 21 [Anticipated]

\section{Arms and Interventions}

\begin{tabular}{|c|c|}
\hline Arms & Assigned Interventions \\
\hline $\begin{array}{l}\text { Experimental: LLLT + immediate force } \\
\text { Use of Low-level laser therapy and not mediate } \\
\text { orthodontic force application ( } 150 \mathrm{gF} \text { the day of the } \\
\text { implantation). }\end{array}$ & $\begin{array}{l}\text { Procedure/Surgery: Low-level laser therapy } \\
\text { a) Immediate post-operative period (implantation } \\
\text { day) Red emission ( } 650 \mathrm{~nm} \text { ) Energy density: } 2 \mathrm{~J} / \\
\mathrm{cm} 2 \text { Power: } 0.1 \mathrm{~W} \text { Irradiation area: } 0,5 \mathrm{~cm} 2 \text { One } \\
\text { application, } 10 \mathrm{~seconds} \text { of non-contact irradiation } \\
\text { (01 point at the area surrounding the miniscrew) at a } \\
\text { distance of } 15,5 \mathrm{~mm} \text {. b) Mediate post-operative period } \\
\text { (after implantation day) Infrared emission ( } 808 \mathrm{~nm} \text { ) } \\
\text { Energy density: } 4 \mathrm{~J} / \mathrm{cm} 2 \text { Power: } 0.1 \mathrm{~W} \text { Irradiation area: } \\
0,5 \mathrm{~cm} 26 \text { applications every } 48 \text { hours after the day } \\
\text { of implantation, } 20 \text { seconds of non-contact irradiation } \\
\text { (01 point on the area surrounding the miniscrew) at a } \\
\text { distance of } 15,5 \mathrm{~mm} \text {. }\end{array}$ \\
\hline $\begin{array}{l}\text { Experimental: LLLT + mediate force } \\
\text { Use of Low-level laser therapy and mediate } \\
\text { orthodontic force application ( } 150 \mathrm{gF} 4 \text { weeks after the } \\
\text { day of the implantation). }\end{array}$ & $\begin{array}{l}\text { Procedure/Surgery: Low-level laser therapy } \\
\text { a) Immediate post-operative period (implantation } \\
\text { day) Red emission ( } 650 \mathrm{~nm} \text { ) Energy density: } 2 \mathrm{~J} / \\
\mathrm{cm} 2 \text { Power: } 0.1 \mathrm{~W} \text { Irradiation area: } 0,5 \mathrm{~cm} 2 \text { One } \\
\text { application, } 10 \text { seconds of non-contact irradiation } \\
\text { (01 point at the area surrounding the miniscrew) at a } \\
\text { distance of } 15,5 \mathrm{~mm} \text {. b) Mediate post-operative period } \\
\text { (after implantation day) Infrared emission ( } 808 \mathrm{~nm} \text { ) } \\
\text { Energy density: } 4 \mathrm{~J} / \mathrm{cm} 2 \text { Power: } 0.1 \mathrm{~W} \text { Irradiation area: } \\
0,5 \mathrm{~cm} 26 \text { applications every } 48 \text { hours after the day } \\
\text { of implantation, } 20 \text { seconds of non-contact irradiation } \\
\text { (01 point on the area surrounding the miniscrew) at a } \\
\text { distance of } 15,5 \mathrm{~mm} \text {. } \\
\text { Procedure/Surgery: Mediate force application } \\
\text { Mediate force application protocol: orthodontic force } \\
\text { application (150 gF) } 4 \text { weeks after the day of the } \\
\text { implantation. }\end{array}$ \\
\hline \multicolumn{2}{|l|}{$\begin{array}{l}\text { No Intervention: Immediate force application } \\
\text { Not mediate orthodontic force application (150 gF the } \\
\text { day of the implantation). without use of Low-level laser } \\
\text { therapy. }\end{array}$} \\
\hline $\begin{array}{l}\text { Experimental: Mediate force application } \\
\text { Mediate orthodontic force application ( } 150 \mathrm{gF} 4 \text { weeks } \\
\text { after the day of the implantation), without use of Low- } \\
\text { level laser therapy. }\end{array}$ & $\begin{array}{l}\text { Procedure/Surgery: Mediate force application } \\
\text { Mediate force application protocol: orthodontic force } \\
\text { application ( } 150 \mathrm{gF}) 4 \text { weeks after the day of the } \\
\text { implantation. }\end{array}$ \\
\hline
\end{tabular}

\section{Outcome Measures}

Primary Outcome Measure: 
1. Change from baseline miniscrew implant stability at 1 and 3 months of force application.

[Time Frame: T1: Implantation day. T2: after 1 month; and, T3: after 3 months of force application.] [Safety Issue: Yes] It will be used a Resonance frequency analysis (RFA) equipment. Stability measures will be evaluated using a unique unit of measure: Implant stability quotient (ISQ). All groups will be evaluated the day of the implantation (T1) and after 1 month (T2).The last stability measure (T3) will be done 3 months after the implantation day in the groups without mediate force application, and 4 months after the implantation day in the groups with mediate force application.

2. Change from baseline miniscrew implant position at 3 months of force application.

[Time Frame: CT1: Implantation day, and, CT2: 3 months of orthodontic force application.] [Safety Issue: Yes] It will be used Cone Beam Computed tomography (CBCT). Three-dimensional models will be created in specific programs to compare the distance in milimeters between miniscrew implants in CT1 and CT2.

6 NOTE : Normally only one Primary Outcome Measure is specified.

\section{Eligibility}

Minimum Age: 12 Years

Maximum Age:

Gender. Both

Accepts Healthy Volunteers?: Yes

Criteria: Inclusion Criteria:

- Patient with permanent teeth.

- Use of miniscrews in orthodontic planning.

- Miniscrews placed in the labial upper and lower posterior regions.

- Patient who agree to participate (Informed consent)

\section{Exclusion Criteria:}

- Patient with systemic disease.

- Patient with periodontal disease and/or inadequate oral hygiene.

- Use of drugs chronically.

- Patients that consume alcohol or tobacco.

\section{Contacts/Locations}

Study Officials: Guido A Marañón Vásquez, DDS

Study Principal Investigator

University of Sao Paulo

Locations:

\section{References}

\section{Citations:}

Links:

Study Data/Documents:

U.S. National Library of Medicine | U.S. National Institutes of Health | U.S. Department of Health \& Human Services 
ANEXO D - Protocolo (versão final) registrado no site ClinicalTrials.gov

\title{
ClinicalTrials. gov PRS
}

Protocol Registration and Results System

ClinicalTrials.gov Protocol Registration and Results System (PRS) Receipt

Release Date: January 17, 2018

ClinicalTrials.gov ID: NCT02891499

\section{Study Identification}

\author{
Unique Protocol ID: USaoPaulo-1 \\ Brief Title: Influence of Low-level Laser Therapy on Stability and Displacement of \\ Orthodontic Miniscrew Implants \\ Official Title: Effect of Low-level Laser Therapy on Stability|and Displacement of Orthodontic \\ Miniscrew Implants With Mediate and Immediate Force Application \\ Secondary IDs:
}

\section{Study Status}

\author{
Record Verification: January 2018 \\ Overall Status: Completed \\ Study Start: March 2016 [ \\ Primary Completion: February 2017 [Actual] \\ Study Completion: August 2017 [Actual]
}

\section{Sponsor/Collaborators}

Sponsor: University of Sao Paulo

Responsible Party: Principal Investigator

Investigator: Guido Artemio Marañón Vásquez [gvasquez]

Official Title: Master of science student

Affiliation: University of Sao Paulo

Collaborators:

\section{Oversight}

U.S. FDA-regulated Drug:

U.S. FDA-regulated Device:

U.S. FDA INDIDE: No

Human Subjects Review: Board Status: Approved

Approval Number. 56108316.0.0000.5419

Board Name: Ethics Committee of the School of dentistry of Ribeirão Preto

Board Affiliation: Ethics Committee of the School of dentistry of Ribeirão Preto

Phone: (16) 3315-0493

Email: cep@forp.usp.br

Address: 
Data Monitoring: No

FDA Regulated Intervention: No

\section{Study Description}

Brief Summary: The purpose of this study is to evaluate the effect of Low level laser therapy on stability and displacement of orthodontic miniscrew implants using two different force application protocols.

Detailed Description: The aim of this study is to evaluate the effect of Low level laser therapy (LLLT) on stability and displacement of orthodontic miniscrew implants with mediate and immediate force application. They will be assessed 48 miniscrew implants placed in patients in orthodontic treatment at the postgraduate clinical in Orthodontics, at School of Dentistry of Ribeiräo Preto, University of São Paulo. They will be randomly divided into 4 groups: 1- LLLT and immediate force application; 2- LLLT and force application 4 weeks after implantation; 3- immediate force application without LLLT and 4-force application 4 weeks after implantation without LLLT. Orthodontic force of $150 \mathrm{gF}$ will be applied for 3 months. A low power laser device Therapy XT with a wavelength of 650 $\mathrm{nm}$ and output of $100 \mathrm{~mW}$ immediately after implantation (energy density: $4 \mathrm{~J} /$ $\mathrm{cm} 2$ ), and $808 \mathrm{~nm}$ with $100 \mathrm{~mW}$ (energy density. $8 \mathrm{~J} / \mathrm{cm} 2$ ), every 48 hours for two weeks in the following applications will be used. The stability will be assessed using Resonance Frequency Analysis (RFA) at three times: the implantation day (T1), one month (T2) and after 3 months of force application (T3). Stability measures will be evaluated in Implant Stability Quotient (ISQ). To assess the amount of miniscrew implant displacement, it will be used Cone Beam Computed Tomography (CBCT) at the beginning (CT1) and final of the application of orthodontic force (CT2). Three-dimensional models will be created in specific programs and superimpositions of CT1 and CT2 will be used to measure the distance in millimeters between inicial and final position. The evaluation will be carried out in three points: head of miniscrew implant (point C), thread (point R) and apex of miniscrew implant (point A). The results will be statistically analyzed according to nature of the data and the significance level to be adopted will be $5 \%$.

\section{Conditions}

Conditions: Displacement of Other Bone Devices, Implants and Grafts Mechanical Complication of Other Bone Devices, Implants and Grafts

Keywords: Miniscrews

Mini-implants

Temporal anchorage devices

Bone screws

Stability

Displacement

Low-level laser therapy

Cone-beam computed tomography

Resonance frequency analysis

Orthodontic

Orthodontic miniscrew implant 


\title{
Study Design
}

\author{
Study Type: Interventional \\ Primary Purpose: Supportive Care \\ Study Phase: N/A \\ Interventional Study Model: Parallel Assignment \\ Number of Arms: 4 \\ Masking: Single (Outcomes Assessor) \\ Allocation: Randomized \\ Enrollment: 29 [Actual]
}

\section{Arms and Interventions}

\begin{tabular}{|c|c|}
\hline Arms & Assigned Interventions \\
\hline $\begin{array}{l}\text { Experimental: LLLT + immediate force } \\
\text { Use of Low-level laser therapy and not mediate } \\
\text { orthodontic force application ( } 150 \mathrm{gF} \text { the day of the } \\
\text { implantation). }\end{array}$ & $\begin{array}{l}\text { Procedure/Surgery. Low-level laser therapy } \\
\text { a) Immediate post-operative period (implantation } \\
\text { day) Red emission ( } 650 \mathrm{~nm} \text { ) Energy density: } 4 \mathrm{~J} / \\
\mathrm{cm} 2 \text { Power. } 0.1 \mathrm{~W} \text { Irradiation area: } 0.5 \mathrm{~cm} 2 \text { One } \\
\text { application, } 10 \text { seconds of non-contact irradiation } \\
\text { (01 point at the area surrounding the miniscrew) at a } \\
\text { distance of } 15.5 \mathrm{~mm} \text {. b) Mediate post-operative period } \\
\text { (after implantation day) Infrared emission ( } 808 \mathrm{~nm} \text { ) } \\
\text { Energy density: } 8 \mathrm{~J} / \mathrm{cm} 2 \text { Power: } 0.1 \mathrm{~W} \text { Irradiation area: } \\
0,5 \mathrm{~cm} 26 \text { applications every } 48 \text { hours after the day } \\
\text { of implantation, } 20 \text { seconds of non-contact irradiation } \\
\text { (01 point on the area surrounding the miniscrew) at a } \\
\text { distance of } 15.5 \mathrm{~mm} \text {. }\end{array}$ \\
\hline $\begin{array}{l}\text { Experimental: LLLT + mediate force } \\
\text { Use of Low-level laser therapy and mediate } \\
\text { orthodontic force application ( } 150 \mathrm{gF} 4 \text { weeks after the } \\
\text { day of the implantation). }\end{array}$ & $\begin{array}{l}\text { Procedure/Surgery. Low-level laser therapy } \\
\text { a) Immediate post-operative period (implantation } \\
\text { day) Red emission ( } 650 \mathrm{~nm} \text { ) Energy density: } 4 \mathrm{~J} / \\
\mathrm{cm} 2 \text { Power. } 0.1 \mathrm{~W} \text { Irradiation area: } 0,5 \mathrm{~cm} 2 \text { One } \\
\text { application, } 10 \text { seconds of non-contact irradiation } \\
\text { ( } 01 \text { point at the area surrounding the miniscrew) at a } \\
\text { distance of } 15,5 \mathrm{~mm} \text {. b) Mediate post-operative period } \\
\text { (after implantation day) Infrared emission ( } 808 \mathrm{~nm} \text { ) } \\
\text { Energy density: } 8 \mathrm{~J} / \mathrm{cm} 2 \text { Power: } 0.1 W \text { Irradiation area: } \\
0,5 \mathrm{~cm} 26 \text { applications every } 48 \text { hours after the day } \\
\text { of implantation, } 20 \text { seconds of non-contact irradiation } \\
(01 \text { point on the area surrounding the miniscrew) at a } \\
\text { distance of } 15,5 \text { mm. } \\
\text { Procedure/Surgery: Mediate force application } \\
\text { Mediate force application protocol: orthodontic force } \\
\text { application ( } 150 \mathrm{gF}) 4 \text { weeks after the day of the } \\
\text { implantation. }\end{array}$ \\
\hline \multicolumn{2}{|l|}{$\begin{array}{l}\text { No Intervention: Immediate force application } \\
\text { Not mediate orthodontic force application ( } 150 \mathrm{gF} \text { the } \\
\text { day of the implantation). without use of Low-level laser } \\
\text { therapy. }\end{array}$} \\
\hline $\begin{array}{l}\text { Experimental: Mediate force application } \\
\text { Mediate orthodontic force application ( } 150 \mathrm{gF} 4 \text { weeks } \\
\text { after the day of the implantation). without use of Low- } \\
\text { level laser therapy. }\end{array}$ & $\begin{array}{l}\text { Procedure/Surgery: Mediate force application } \\
\text { Mediate force application protocol: orthodontic force } \\
\text { application (150 gF) } 4 \text { weeks after the day of the } \\
\text { implantation. }\end{array}$ \\
\hline
\end{tabular}




\title{
Outcome Measures
}

Primary Outcome Measure:

1. Change from baseline miniscrew implant stability at 1 and 3 months of force application.

It will be used a Resonance frequency analysis (RFA) equipment. Stability measures will be evaluated using a unique unit of measure: Implant stability quotient (ISQ). All groups will be evaluated the day of the implantation (T1) and after 1 month (T2). The last stability measure (T3) will be done 3 months after the implantation day in the groups without mediate force application, and 4 months after the implantation day in the groups with mediate force application.

[Time Frame: T1: Implantation day: T2: after 1 month; and, T3: after 3 months of force application.]

2. Change from baseline miniscrew implant position at 3 months of force application.

It will be used Cone Beam Computed tomography (CBCT). Three-dimensional models will be created in specific programs and superimpositions of $\mathrm{CT} 1$ and $\mathrm{CT} 2$ will be used to measure the distance in millimeters between initial and final position.

[Time Frame: CT1: Implantation day, and, СT2: 3 months of orthodontic force application.]

\section{Eligibility}

\author{
Minimum Age: 11 Years \\ Maximum Age:
}

Sex: All

Gender Based:

Accepts Healthy Volunteers: Yes

Criteria: Inclusion Criteria:

- Patient with permanent teeth.

- Use of miniscrews in orthodontic planning.

- Miniscrews placed in the labial upper and lower posterior regions.

- Patient who agree to participate (Informed consent)

Exclusion Criteria:

- Patient with systemic disease.

- Patient with periodontal disease and/or inadequate oral hygiene.

- Use of drugs chronically.

- Patients that consume alcohol or tobacco.

- Use of fixed palatal or lingual orthodontic devices.

\section{Contacts/Locations}

Central Contact Person: Fábio L Romano, PhD

Telephone: +5516991433116

Email: fabioromano@forp.usp.br

Central Contact Backup: Guido A Marañón Vásquez, DDS

Telephone: +5516988433419

Email: guido_amv@hotmail.com

Study Officials: Guido A Marañón Vásquez, DDS

Study Principal Investigator

University of Sao Paulo

Locations: 
ANEXO E - Termo de consentimento livre e esclarecido.

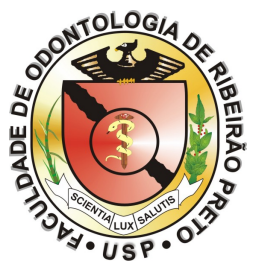

\section{UNIVERSIDADE DE SÃO PAULO \\ FACULDADE DE ODONTOLOGIA DE RIBEIRÃO PRETO}

\section{TERMO DE CONSENTIMENTO LIVRE E ESCLARECIDO}

Este documento é um convite para você

articipar do estudo: Avaliação da Influência do Laser de Baixa Potência na Estabilidade e no Deslocamento de Mini-implantes Ortodônticos com Aplicação de Força Mediata e Imediata. Os responsáveis por esta pesquisa e pela apresentação deste Termo de Consentimento Livre e Esclarecido são: Prof. Dr. Fábio Lourenço Romano (Orientador) e o Pós-graduando (Mestrando em Odontopediatria) Guido Artemio Marañón Vásquez. O objetivo desta pesquisa será avaliar o efeito da terapia com laser de baixa potência (laser para tratamento) na estabilidade e no deslocamento de mini-implantes ortodônticos (micro parafusos colocados na gengiva) que auxiliarão no tratamento ortodôntico de seu caso ou do paciente pelo qual você é responsável. Desta maneira, se vocês concordarem em participar do estudo é importante saber e entender os itens abaixo:

- O exame clínico e a avaliação da documentação ortodôntica identificará se você ou o paciente pelo qual você é responsável estarão aptos a participar do estudo, ou seja, se para auxiliar na correção da maloclusão (corrigir os dentes tortos) será necessária a colocação de mini-implantes ortodônticos (micro parafusos colocados na gengiva).

- Haverão 4 grupos na pesquisa: um grupo com laser e força imediata aplicada no miniimplante; um grupo com laser e força mediata aplicada no mini-implante; um grupo sem aplicação do laser e força imediata aplicada no mini-implante; e um último grupo sem laser e com força mediata aplicada no mini-implante. A força imediata será a força aplicada no momento da colocação do mini-implante e a força mediata será a força aplicada após determinado período de tempo. Cada mini-implante (micro parafuso) colocado em você ou no paciente pelo qual você é responsável poderá participar de um dos grupos citados acima, de acordo com a distribuição (por sorteio) feita pelos pesquisadores e sem conhecimento prévio.

- Todos os materiais e procedimentos relacionados ao estudo serão fornecidos pelos pesquisadores ou pela Faculdade de Odontologia de Ribeirão Preto - USP, entre eles os mini-implantes (micro parafusos), o equipamento de laser, o equipamento de Análise de Freqüência de Ressonância (para ver a movimentação do mini-implante) e as Tomografias computadorizadas do tipo Cone Beam (radiografia digital da região do mini-implante). Desta forma, você ou o participante pelo qual você é responsável não terão nenhum custo financeiro. Poderá haver risco de pequeno desconforto ao paciente no momento da instalação do mini-implante, desconforto este que será minimizado com os procedimentos de anestesia.

- Você ou o participante pelo qual você é responsável deverão executar os procedimentos de higiene bucal sugeridos pelos pesquisadores e seguir firmemente as orientações indicadas em folheto que será entregue a você.

- Os participantes dos grupos que receberão aplicação de laser, deverão comparecer a 7 (sete) consultas, incluindo o dia da colocação do mini-implante. Cada consulta será realizada a cada dois (2) dias durante as duas primeiras semanas após a colocação do mini-implante, nos dias subsequentes $1,3,5,7,9,11$ e 13 para a aplicação do laser. Posteriormente, as consultas serão agendadas a cada duas semanas até completar 3 meses de aplicação de força ao mini-implante. 
- Os participantes dos grupos que não receberão aplicação do laser, deverão comparecer a consultas a cada duas semanas até completar 3 meses de aplicação de força ao miniimplante.

- Você ou o participante pelo qual você é responsável deverão ter disponibilidade para comparecer a estas consultas. $\mathrm{O}$ agendamento para as consultas sempre será realizado com antecedência. Faltas não justificadas poderão exclúi-lo do estudo. Eventuais despesas de transporte e alimentação serão custeadas pelos responsáveis da pesquisa.

- Avaliações da estabilidade e deslocamento (movimentos) dos mini-implantes serão realizadas em todos os grupos. Para isto será utilizado um equipamento de Análise de Freqüência de Ressonância e a Tomografia computadorizada Cone Beam, respectivamente. As avaliações serão realizadas no início e no final do estudo. Estes procedimentos não acarretarão dor ou qualquer outro desconforto.

- Como benefício prestado pelo estudo, você ou o participante pelo qual você é responsável receberão controle de higiene bucal, manutenção e limpeza dos aparelhos ortodônticos a cada duas semanas durante o tempo do estudo. Eventuais problemas decorrentes de má higiene serão avaliados e encaminhados para tratamento.

- Durante todo o período do estudo você ou o participante pelo qual você é responsável poderão solicitar maiores informações ou desistir de participar sem que isto acarrete qualquer penalidade e sem causar prejuízos ao tratamento ortodôntico. Portanto, não haverá interferência no tratamento caso vocês não aceitem participar da pesquisa.

- A utilização da terapia com laser não acarretará nenhum efeito colateral (dor, desconforto) ou dano para a sua saúde ou do paciente pelo qual você é responsável .

- Qualquer desconforto ou problema, causado pelo estudo, será de responsabilidade dos pesquisadores e consequentemente, será resolvido pelos mesmos. Dessa forma, garantese a indenização ou o tratamento dos envolvidos em caso de eventuais danos.

- Todas as informações coletadas serão mantidas sob absoluto sigilo.

- Reclamações e/ou insatisfações poderão ser comunicadas à Secretaria do Comitê de Ética em Pesquisa - CEP/FORP/USP (Secretário: Ricardo Campos Seixas, pelo e-mail cep@,forp.usp.br ou pelo telefone (16) 3315 0493, de segunda à sexta-feira no período das 8 às $12 \mathrm{~h}$. Será necessário que os reclamantes se identifiquem, porém os nomes serão mantidos em anonimato.

- Durante todo o período do estudo, você ou o participante pelo qual você é responsável serão acompanhados pelo Mestrando em Odontopediatria Guido Artemio Marañón Vásquez a quem vocês poderão contatar para conversar sobre assuntos relacionados ao tratamento. O telefone de contato do referido aluno é (16) 988433419 ou você(s) poderão entrar em contato pelo e-mail guido_amv@hotmail.com.

- Este termo foi elaborado em 2 (duas) vias, uma ficará com a equipe de pesquisa e você receberá outra via deste Termo de Consentimento Livre e Esclarecido - TCLE.

Ribeirão Preto - SP, de de 201

Prof. Dr. Fábio Lourenço Romano CPF: 726358436-00
Guido Artemio Marañón Vasquez CPF: 238.091.018-93 
Declaro que li e entendi com clareza os objetivos, os riscos e os benefícios de minha participação na pesquisa e não tenho dúvidas. Após exposto concordo em participar desta pesquisa. 
ANEXO F - Termo de assentimento.

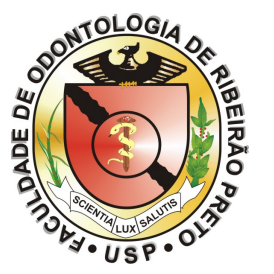

\section{UNIVERSIDADE DE SÃO PAULO \\ FACULDADE DE ODONTOLOGIA DE RIBEIRÃO PRETO}

\section{TERMO DE ASSENTIMENTO}

Este documento é um convite para você

articipar do estudo: Avaliação da Influência do Laser de Baixa Potência na Estabilidade e no Deslocamento de Mini-implantes Ortodônticos com Aplicação de Força Mediata e Imediata. Os responsáveis por esta pesquisa e pela apresentação deste Termo de Assentimento são: Prof. Dr. Fábio Lourenço Romano (Orientador) e o Pós-graduando (Mestrando em Odontopediatria) Guido Artemio Marañón Vásquez. O objetivo desta pesquisa será avaliar o efeito da terapia com laser de baixa potência (laser para tratamento) na estabilidade e no deslocamento de miniimplantes ortodônticos (micro parafusos colocados na gengiva) que auxiliarão no tratamento ortodôntico de seu caso. Desta maneira, se você concordar em participar do estudo é importante saber e entender os itens abaixo:

- O exame clínico e a avaliação da documentação ortodôntica identificará se você está apto a participar do estudo, ou seja, se para auxiliar na correção de sua maloclusão (corrigir os dentes tortos) será necessária a colocação de mini-implantes ortodônticos (micro parafusos colocados na gengiva).

- Haverão 4 grupos na pesquisa que você se concordar, irá participar (um grupo com laser e força imediata aplicada no mini-implante; um grupo com laser e força mediata aplicada no mini-implante; um grupo sem aplicação do laser e força imediata aplicada no miniimplante; e um último grupo sem laser e com força mediata aplicada no mini-implante). A força imediata será a força aplicada no momento da colocação do mini-implante e a força mediata será a força aplicada após determinado período de tempo. Cada miniimplante (micro parafuso) colocado em você poderá participar de um dos grupos citados acima, de acordo com a distribuição (por sorteio) feita pelos pesquisadores e sem conhecimento prévio.

- Todos os materiais e procedimentos relacionados ao estudo serão fornecidos pelos pesquisadores ou pela Faculdade de Odontologia de Ribeirão Preto - USP, entre eles os mini-implantes (micro parafusos), o equipamento de laser, o equipamento de Análise de Freqüência de Ressonância (para ver a movimentação do mini-implante) e as Tomografias computadorizadas do tipo Cone Beam (radiografia digital da região do mini-implante). Desta forma, você não terão nenhum custo financeiro. Poderá haver risco de pequeno desconforto ao paciente no momento da instalação do mini-implante, desconforto este que será minimizado com os procedimentos de anestesia.

- Você deverá executar os procedimentos de higiene bucal sugeridos pelos pesquisadores e seguir firmemente as orientações indicadas em folheto que será entregue a você.

- Os participantes dos grupos que receberão aplicação de laser, deverão comparecer a 7 (sete) consultas, incluindo o dia da colocação do mini-implante. Cada consulta será realizada a cada dois (2) dias durante as duas primeiras semanas após a colocação do mini-implante, nos dias subsequentes $1,3,5,7,9,11$ e 13 para a aplicação do laser. Posteriormente, as consultas serão agendadas a cada duas semanas até completar 3 meses de aplicação de força ao mini-implante.

- Os participantes dos grupos que não receberão aplicação do laser, deverão comparecer a consultas a cada duas semanas até completar 3 meses de aplicação de força ao miniimplante.

- Você deverá ter disponibilidade para comparecer a estas consultas. O agendamento para as consultas sempre será realizado com antecedência. Faltas não justificadas poderão 
excluí-lo do estudo. Eventuais despesas de transporte e alimentação serão custeadas pelos responsáveis da pesquisa.

- Avaliações da estabilidade e deslocamento (movimentos) dos mini-implantes serão realizadas em todos os grupos. Para isto será utilizado um equipamento de Análise de Freqüência de Ressonância e a Tomografia computadorizada Cone Beam, respectivamente. As avaliações serão realizadas no início e no final do estudo. Estes procedimentos não acarretarão dor ou qualquer outro desconforto a você.

- Como benefício prestado pelo estudo, você receberá controle de higiene bucal, manutenção e limpeza dos aparelhos ortodônticos a cada duas semanas durante o tempo do estudo. Eventuais problemas decorrentes de má higiene serão avaliados e encaminhados para tratamento.

- Durante todo o período do estudo você poderá solicitar maiores informações ou desistir de participar sem que isto acarrete qualquer penalidade e sem causar prejuízos ao tratamento ortodôntico. Portanto, não haverá interferência no tratamento caso você não aceite participar da pesquisa.

- A utilização da terapia com laser não acarretará nenhum efeito colateral (dor, desconforto) ou dano para a sua saúde.

- Qualquer desconforto ou problema, causado pelo estudo, será de responsabilidade dos pesquisadores e consequentemente, será resolvido pelos mesmos. Dessa forma, garantese a indenização ou o tratamento dos envolvidos em caso de eventuais danos.

- Todas as informações coletadas serão mantidas sob absoluto sigilo.

- Reclamações e/ou insatisfações poderão ser comunicadas à Secretaria do Comitê de Ética em Pesquisa - CEP/FORP/USP (Secretário: Ricardo Campos Seixas, pelo e-mail cep@,forp.usp.br ou pelo telefone (16) 3315 0493, de segunda à sexta-feira no período das 8 às $12 \mathrm{~h}$. Será necessário que você se identifique, porém seu nome será mantido em anonimato.

- Durante todo o período do estudo, você será acompanhado pelo Mestrando em Odontopediatria Guido Artemio Marañón Vásquez a quem você poderá contatar para conversar sobre assuntos relacionados ao tratamento. O telefone de contato do referido aluno é (16) 988433419 ou você(s) poderão entrar em contato pelo e-mail guido_amv@hotmail.com.

- Este termo foi elaborado em 2 (duas) vias, uma ficará com a equipe de pesquisa e você receberá outra via deste Termo de Assentimento.

Ribeirão Preto - SP, de de 201

Prof. Dr. Fábio Lourenço Romano CPF: 726358436-00
Guido Artemio Marañón Vasquez CPF: 238.091.018-93 
Declaro que li e entendi com clareza os objetivos, os riscos e os benefícios de minha participação na pesquisa e não tenho dúvidas. Após exposto concordo em participar desta pesquisa. 
ANEXO G - Ficha de coleta de dados.

FICHA DE COLETA DE DADOS

NOME:

PACIENTE $N^{0}$ :

DATA DE NACIMENTO:

SEXO: IDADE:

ENDEREÇO: TELEFONE:

PROFESSOR SOLICITANTE:

OPERADOR:

\section{GRUPO DO ESTUDO:}

DATA DA IMPLANTAÇÃO:

$N^{\circ}$ DE MINI-IMPLAMTES: LOCALIZAÇÃO:

ESTABILIDADE PRIMÁRIA:

MECÂNICA UTILIZADA:

ANÁLISE DE FREQÜÊNCIA DE RESSONÂNCIA

T1:

$\mathrm{T} 2:$

T3:

TOMOGRAFIA COMPUTADORIZADA CONE BEAM

DISTANCIA T1 - T2

PONTO C:

PONTO R: PONTO A: 
ANEXO H - Controles de acompanhamento (Grupo 1).

GRUPO 1 (Força imediata + TLBP)

\begin{tabular}{|c|c|c|c|c|c|c|c|c|c|}
\hline \multirow[b]{2}{*}{ № VISITA } & \multirow[b]{2}{*}{ DATA } & \multirow[b]{2}{*}{ PROCEDIMENTO } & \multirow[b]{2}{*}{ AFR } & \multirow[b]{2}{*}{ TCCB } & \multirow[b]{2}{*}{ TLBP } & \multicolumn{3}{|c|}{ AVALIAÇÃO } & \multirow[b]{2}{*}{ OBSERVAÇÕES } \\
\hline & & & & & & $\begin{array}{c}\text { MAGNITUDE DA } \\
\text { FORÇA }\end{array}$ & HIGIENE BUCAL & $\begin{array}{l}\text { ESTABILIDADE DO } \\
\text { MINI-IMPLANTEE }\end{array}$ & \\
\hline 1 & & Implantação & SIM & SIM & SIM & & & & \\
\hline 2 & & TLBP & & & $\operatorname{SIM}$ & & & & \\
\hline 3 & & TLBP & & & SIM & & & & \\
\hline 4 & & TLBP & & & SIM & & & & \\
\hline 5 & & TLBP & & & SIM & & & & \\
\hline 6 & & TLBP & & & SIM & & & & \\
\hline 7 & & TLBP & & & SIM & & & & \\
\hline 8 & & Controle & & & & & & & \\
\hline 9 & & Controle & & & & & & & \\
\hline 10 & & Controle & & & & & & & \\
\hline 11 & & Controle & & & & & & & \\
\hline 12 & & Controle & & & & & & & \\
\hline 13 & & Controle & & & & & & & \\
\hline 14 & & Controle & & & & & & & \\
\hline 15 & & Controle & & & & & & & \\
\hline 16 & & Controle & & & & & & & \\
\hline 17 & & Controle & & & & & & & \\
\hline 18 & & Controle & SIM & SIM & & & & & \\
\hline
\end{tabular}


ANEXO I - Controles de acompanhamento (Grupo 2).

\section{GRUPO 2 (Força mediata + TLBP)}

\begin{tabular}{|c|c|c|c|c|c|c|c|c|c|}
\hline \multirow[b]{2}{*}{ № VISITA } & \multirow[b]{2}{*}{ DATA } & \multirow[b]{2}{*}{ PROCEDIMENTO } & \multirow[b]{2}{*}{ AFR } & \multirow[b]{2}{*}{ TCCB } & \multirow[b]{2}{*}{ TLBP } & \multicolumn{3}{|c|}{ AVALIAÇÃO } & \multirow[b]{2}{*}{ OBSERVAÇÕES } \\
\hline & & & & & & $\begin{array}{l}\text { MAGNITUDE DA } \\
\text { FORÇA }\end{array}$ & HIGIENE BUCAL & $\begin{array}{l}\text { ESTABILIDADE DO } \\
\text { MINI-IMPLANTE }\end{array}$ & \\
\hline 1 & & Implantação & SIM & SIM & SIM & & & & \\
\hline 2 & & TLBP & & & SIM & & & & \\
\hline 3 & & TLBP & & & SIM & & & & \\
\hline 4 & & TLBP & & & SIM & & & & \\
\hline 5 & & TLBP & & & SIM & & & & \\
\hline 6 & & TLBP & & & SIM & & & & \\
\hline 7 & & TLBP & & & SIM & & & & \\
\hline 8 & & Controle & $\mathrm{SIM}$ & & & & & & \\
\hline 9 & & Controle & & & & & & & \\
\hline 10 & & Controle & & & & & & & \\
\hline 11 & & Controle & & & & & & & \\
\hline 12 & & Controle & & & & & & & \\
\hline 13 & & Controle & & & & & & & \\
\hline 14 & & Controle & & & & & & & \\
\hline 15 & & Controle & & & & & & & \\
\hline 16 & & Controle & & & & & & & \\
\hline 17 & & Controle & & & & & & & \\
\hline 18 & & Controle & & & & & & & \\
\hline 19 & & Controle & & & & & & & \\
\hline 20 & & Controle & $\mathrm{SIM}$ & $\mathrm{SIM}$ & & & & & \\
\hline
\end{tabular}


ANEXO J - Controles de acompanhamento (Grupo 3).

GRUPO 3 (Força imediata sem TLBP)

\begin{tabular}{|c|c|c|c|c|c|c|c|c|c|}
\hline \multirow[b]{2}{*}{ № VISITA } & \multirow[b]{2}{*}{ DATA } & \multirow[b]{2}{*}{ PROCEDIMENTO } & \multirow[b]{2}{*}{ AFR } & \multirow[b]{2}{*}{ TCCB } & \multirow[b]{2}{*}{ TLBP } & \multicolumn{3}{|c|}{ AVALIAÇÃO } & \multirow[b]{2}{*}{ OBSERVAÇÕES } \\
\hline & & & & & & $\begin{array}{l}\text { MAGNITUDE DA } \\
\text { FORÇA }\end{array}$ & HIGIENE BUCAL & $\begin{array}{l}\text { ESTABILIDADE DO } \\
\text { MINI-IMPLANTE }\end{array}$ & \\
\hline 1 & & Implantação & SIM & SIM & & & & & \\
\hline 2 & & Controle & & & & & & & \\
\hline 3 & & Controle & & & & & & & \\
\hline 4 & & Controle & & & & & & & \\
\hline 5 & & Controle & & & & & & & \\
\hline 6 & & Controle & & & & & & & \\
\hline 7 & & Controle & & & & & & & \\
\hline 8 & & Controle & & & & & & & \\
\hline 9 & & Controle & & & & & & & \\
\hline 10 & & Controle & & & & & & & \\
\hline 11 & & Controle & & & & & & & \\
\hline 12 & & Controle & & & & & & & \\
\hline 13 & & Controle & SIM & SIM & & & & & \\
\hline
\end{tabular}


ANEXO K - Controles de acompanhamento (Grupo 4).

GRUPO 4 (Força mediata sem TLBP)

\begin{tabular}{|c|c|c|c|c|c|c|c|c|c|}
\hline \multirow[b]{2}{*}{ № VISITA } & \multirow[b]{2}{*}{ DATA } & \multirow[b]{2}{*}{ PROCEDIMENTO } & \multirow[b]{2}{*}{ AFR } & \multirow[b]{2}{*}{ TCCB } & \multirow[b]{2}{*}{ TLBP } & \multicolumn{3}{|c|}{ AVALIAÇÃo } & \multirow[b]{2}{*}{ OBSERVAÇÕES } \\
\hline & & & & & & $\begin{array}{l}\text { MAGNITUDE DA } \\
\text { FORCCA }\end{array}$ & HIGIENE BUCAL & $\begin{array}{c}\text { ESTABILIDADE DO } \\
\text { MINI-IMPLANTE }\end{array}$ & \\
\hline 1 & & Implantação & SIM & SIM & & & & & \\
\hline 2 & & Controle & & & & & & & \\
\hline 3 & & Controle & SIM & & & & & & \\
\hline 4 & & Controle & & & & & & & \\
\hline 5 & & Controle & & & & & & & \\
\hline 6 & & Controle & & & & & & & \\
\hline 7 & & Controle & & & & & & & \\
\hline 8 & & Controle & & & & & & & \\
\hline 9 & & Controle & & & & & & & \\
\hline 10 & & Controle & & & & & & & \\
\hline 11 & & Controle & & & & & & & \\
\hline 12 & & Controle & & & & & & & \\
\hline 13 & & Controle & & & & & & & \\
\hline 14 & & Controle & & & & & & & \\
\hline 15 & & Controle & $\mathrm{SIM}$ & SIM & & & & & \\
\hline
\end{tabular}

